\title{
AN EXAMINATION OF THE RELATIONSHIP BETWEEN ETHICAL WORK CLIMATE AND MORAL AWARENESS
}

\author{
Craig V. VanSandt \\ Dissertation submitted to the Faculty of the \\ Virginia Polytechnic Institute and State University \\ in partial fulfillment of the requirements for the degree of
}

Doctor of Philosophy

in

Management

Jon M. Shepard, Chair

Richard E. Wokutch

Carroll U. Stephens

Eloïse Coupey

Bart Victor

John P. Christman

August 20, 2001

Blacksburg, Virginia

Keywords: Ethical Work Climate, Moral Awareness, Organizational Climate

Copyright 2001, Craig V. VanSandt 


\author{
ABSTRACT \\ An Examination of the Relationship \\ Between Ethical Work Climate and \\ Moral Awareness \\ by \\ Craig V. VanSandt \\ Jon M. Shepard, Chair
}

\begin{abstract}
This dissertation draws from the fields of history, sociology, psychology, moral philosophy, and organizational theory to establish a theoretical connection between a social/organizational influence (Ethical Work Climate) and an individual cognitive element of moral behavior (moral awareness). The research was designed to help fill a gap in the existing literature by providing empirical evidence of the connection between organizational influences and individual ethical choices, which has heretofore largely been merely assumed. Additional aspects of moral behavior beyond moral judgment, as suggested by the Four Component Model (Rest, 1994) were investigated. Extensively relying on the work of Victor and Cullen (1987, 1988), Rest (1979, 1986, 1994), and Blum (1991, 1994), seven hypotheses were formulated and tested to determine the nature of the direct relationship between the organizational level Ethical Work Climate and individual level moral awareness, and that relationship as moderated by four demographic and individual variables. Seven of the climate types identified by Cullen, Victor, and Bronson (1993) were replicated in the present study. All three of the hypotheses pertaining to the direct relationship between Ethical Work Climate and moral awareness were supported, as were three of the four hypotheses related to the moderating variables. These results provide evidence that Ethical Work Climate is a primary predictor of individual moral awareness, and that social influence often overrides the effects of individual differences is a work group setting. Implications for future research are provided.
\end{abstract}




\section{ACKNOWLEDGEMENTS}

Having worked in the South for nearly twenty years, I became an aficionado and collector of down-home, pithy sayings that captured an essential truth about the world. One of my favorites is "Even a blind hog finds an acorn once in a while." Finding Virginia Tech's Ph.D. program in Management was, for me, akin to the blind hog's good fortune. It was only through a chance meeting with Rich Wokutch at our sons' youth soccer tournament that I found out that Virginia Tech had a program in business ethics, and the rest, as they say, is history.

I feel almost an embarrassment of riches when I compare my Ph.D. experiences to those of my contemporaries at other schools. The support and encouragement that I have received from everyone affiliated with the program has been nothing short of phenomenal. If I hadn't experienced it myself, I'm not sure I would believe it.

Much of the credit for the climate within the management department at Virginia Tech must go to the chair of the department, and chair of my committee, Jon Shepard. Jon showed a genuine interest in my ideas and me from the very first day I visited the campus. That relationship has continued and grown throughout the five years I have known him. Looking back on that period I find it incredible the amount of time and effort Jon put into making my experience both meaningful and enjoyable. There aren't many Ph.D. candidates, I'm sure, who can say that their committee chairs spent time with them every day, reading drafts, making comments, and discussing the ideas entailed in the project. I could go on and on about Jon, but I think I can sum up my feelings by simply saying that, during a time that is usually one of the most stressful and potentially antagonistic, I have instead discovered a true friend and colleague. Jon, another one of those Southern sayings is about "a gentleman and a scholar." No words could better describe you, and I am immensely fortunate to know you.

Rich Wokutch has also been a significant influence and benefactor during my time at Virginia Tech. He continues to have the best interests of his students as his first priority. From the time and interest he initially showed when I first expressed an interest in studying business ethics, to basically dragging me to my first academic conferences, to making co-authorship opportunities available, Rich has helped me tremendously. However, like any good mentor, Rich knew when to draw the line-conference presentations in Berkeley, Paris, and Amsterdam somehow weren't included in the student benefit package!

Carroll Stephens has been a wonderful source of knowledge, wisdom, and support. It was Carroll who, on my initial campus visit to find out what academia was all about, explained what being a college professor could mean, in terms of being able to satisfy my intellectual curiosity. That was, in many ways, the deciding factor in entering Tech's Ph.D. program. Once there, I quickly learned what a valuable resource she is, both because of her knowledge of the literature and her extensive network of colleagues. To top it off, she too showed incredible interest in my academic career and provided invaluable support. 
The other three members of my committee-Eloïse Coupey, John Christman, and Bart Victor-were also very supportive and great resources. None of them had any real incentive for serving on my committee other than a willingness to help and an interest in the topic. Eloïse was especially brave to take on this responsibility, not having tenure at the time (although that accomplishment was never in doubt), and being forewarned that methods and statistical analysis were not my favorite part of the research process. She guided me through those minefields with a steady hand, good humor, and a heavy dose of practicality. I was fortunate to have John Christman for a philosophy class while he was still teaching at Virginia Tech. From that class, I learned just how much I had to learn about making logically sound arguments. John could spot holes in my papers quicker than I could have imagined-but he added to that with gentle, yet sure, guidance on how to plug the gaps. If I have one regret about my dissertation process, it is that I did not utilize Bart Victor's profound knowledge and experience more than I did. Bart agreed to serve on my committee in the midst of moving back to the United States from Europe, and starting a new position at Vanderbilt. This would have been a lot to ask of anyone, but he was very generous with his time and expertise every time I asked for help. And it is obvious that his shoulders are some that I trod on most heavily in my work.

Two other colleagues at Virginia Tech deserve a special note of appreciation. Wanda Smith went out of her way innumerable times to make sure that I was "making it." She had no reason to do so, other than what one of my ethics professors said about virtue ethics, "That's just what friends do." Finally, I couldn't have asked for a better classmate than Jamie Hendry. We met on the first day of orientation and quickly found that we shared many of the same obsessivecompulsive traits. We were able to put those traits to good use though, by leaning heavily on each other throughout our time at Virginia Tech. Jamie, I can't imagine getting through this without your friendship.

Finally, my family played a huge role in this undertaking. My mother and father contributed their financial, emotional, and genetic support. Unfortunately, my father did not live to see me follow in his footsteps as "Doc Van," but my mother was the first person I called with the news that I am now officially a "doctor." My children - Courtney, Matthew, and Reed-had no real say in the path I chose. My time at Virginia Tech represents well over one-fourth of their lives, during some of the most difficult times in adolescents' development. They have all dealt with the hardships and vagaries with aplomb, and have turned out to be really neat persons, whom I am infinitely proud to know and be related to.

Patti, as you well know, these have been the toughest years we have ever experienced. You recognized my affinity and potential for an academic career long before I did, and were unwavering in your support and encouragement. My repayment of that debt was more often than not to escape into my world of books and ideas, and to ask you to fend for yourself. For that I am truly sorry, and I hope that our next fifty years together can make up for these past five. 


\section{TABLE OF CONTENTS}

CHAPTER 1 - INTRODUCTION.............................................................................................. 1

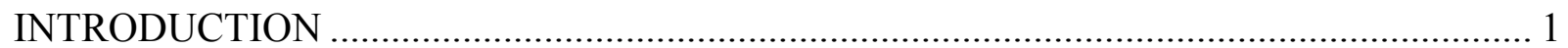

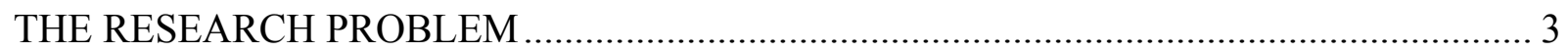

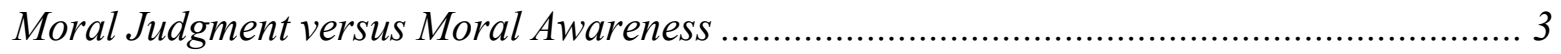

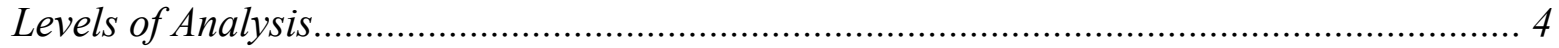

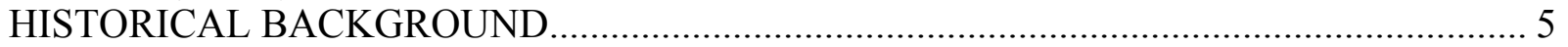

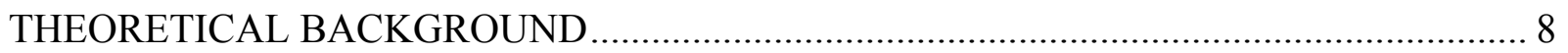

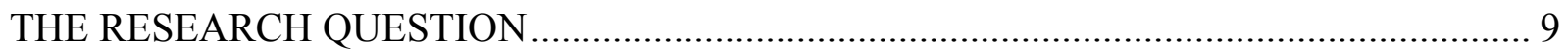

INDEPENDENT VARIABLE: ETHICAL WORK CLIMATE …………………………...... 10

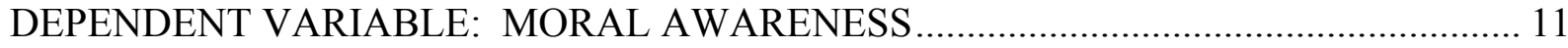

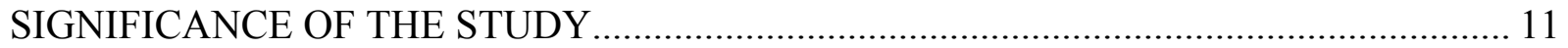

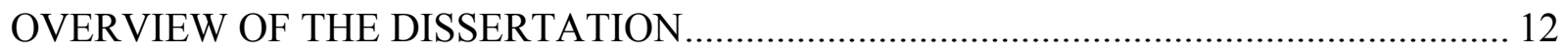

CHAPTER 2 - REVIEW OF LITERATURE ….............................................................. 13

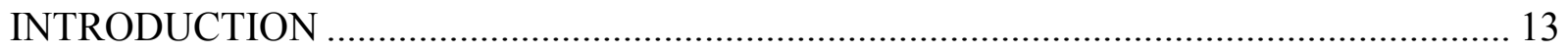

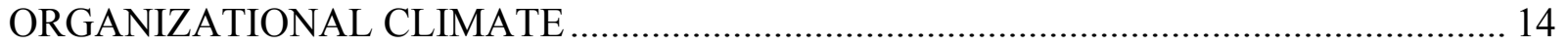

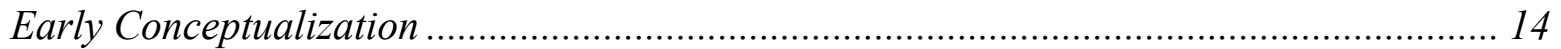

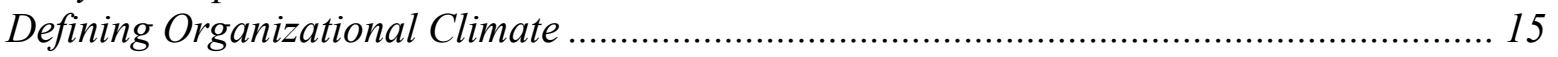

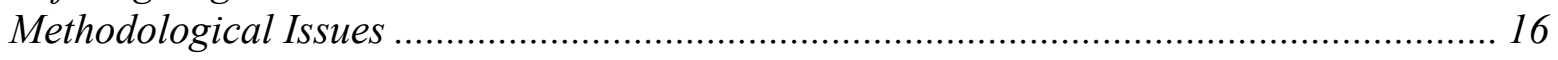

The State of the Organizational Climate Literature Today ............................................. 17

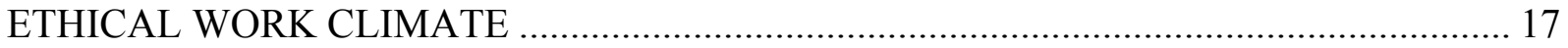

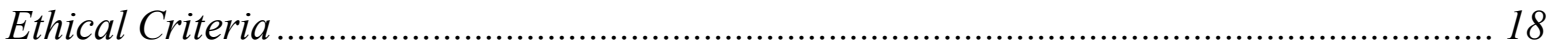

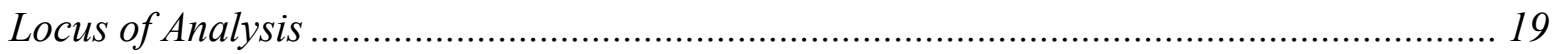

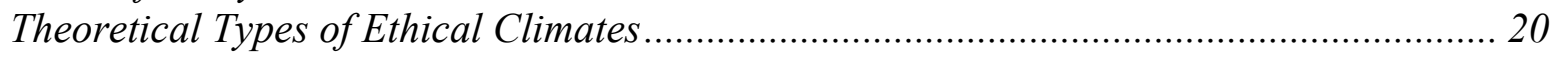

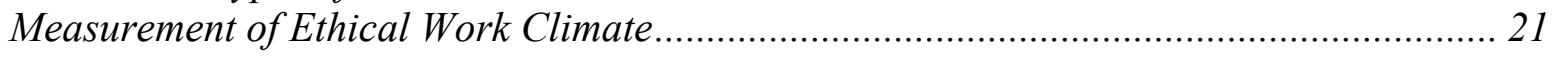

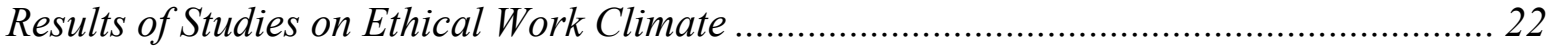

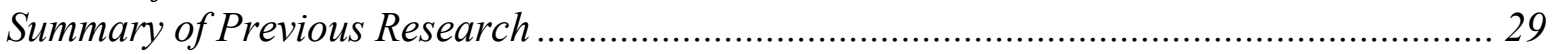

The Relation of Ethical Work Climate to Moral Awareness............................................. 31

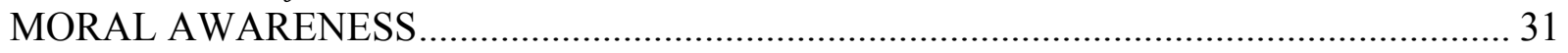

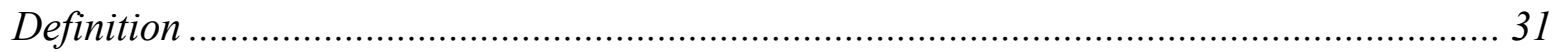

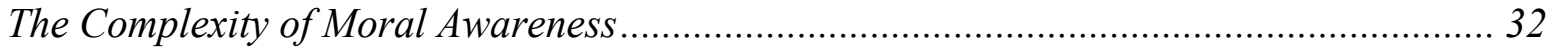

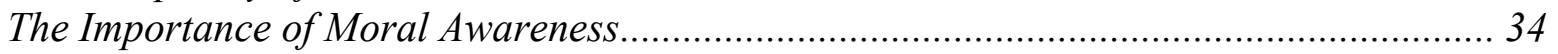

The Promotion of Individual Moral Awareness in Organizations ..................................... 35

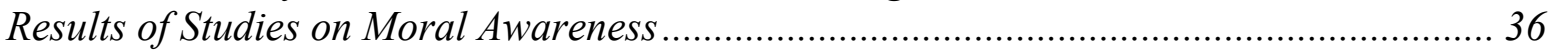

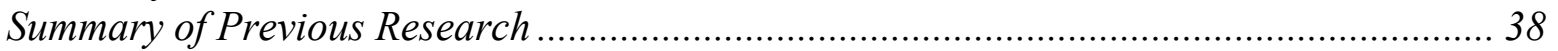

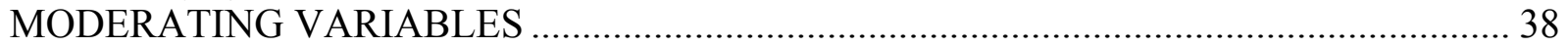

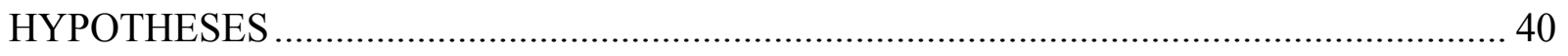

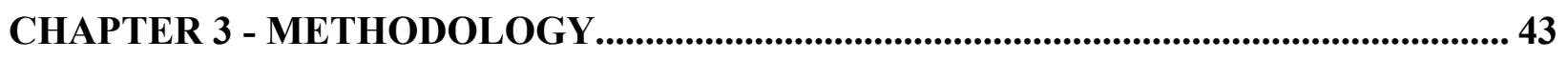

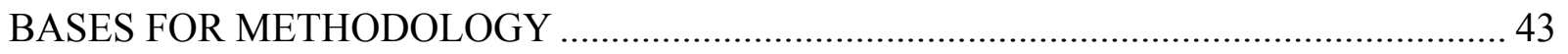




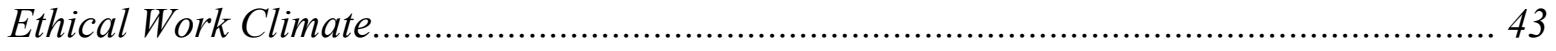

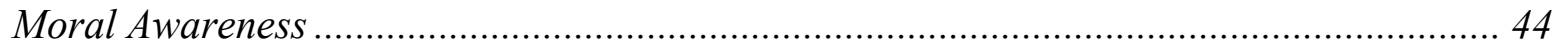

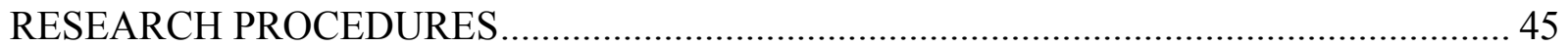

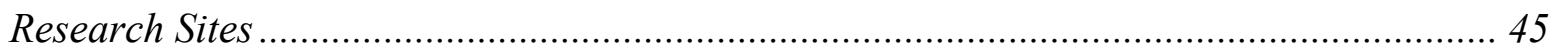

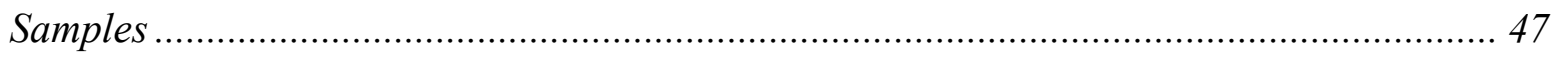

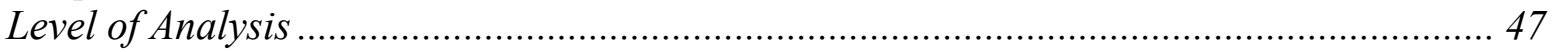

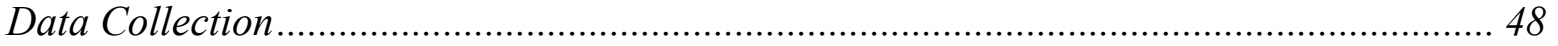

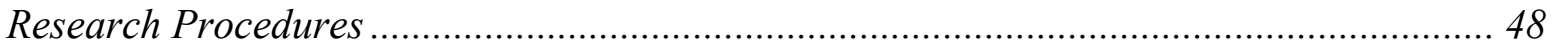

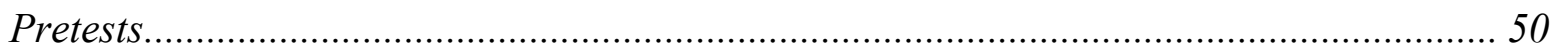

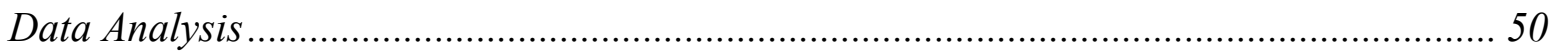

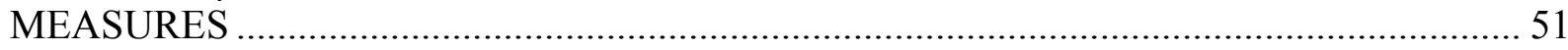

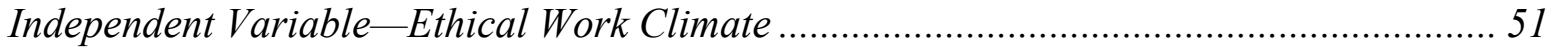

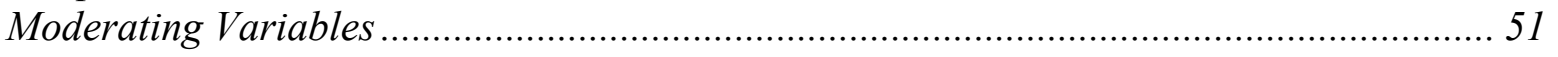

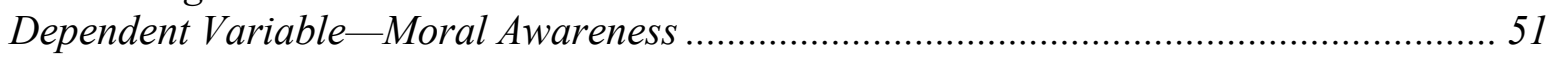

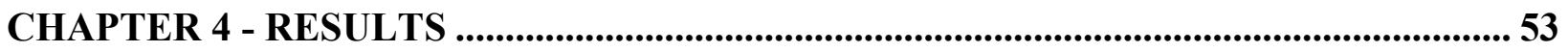

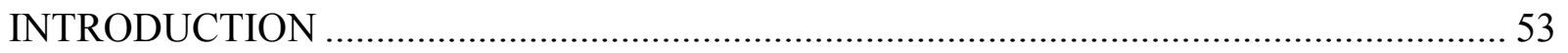

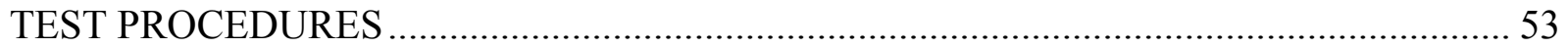

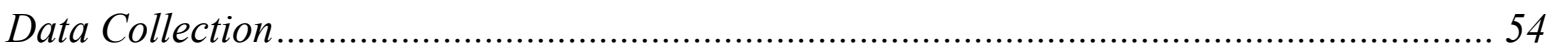

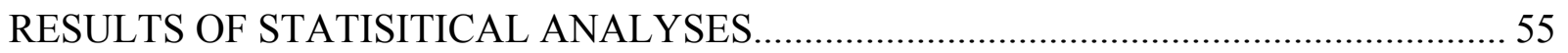

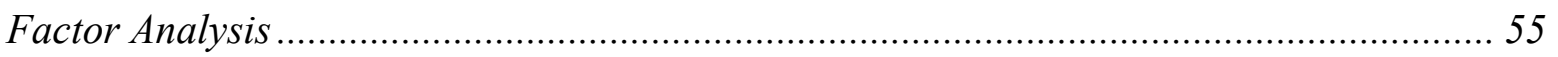

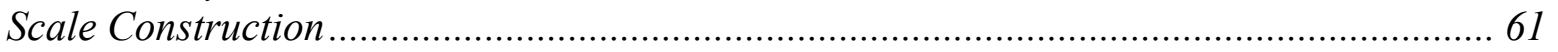

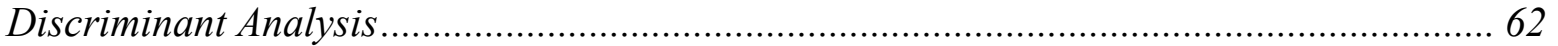

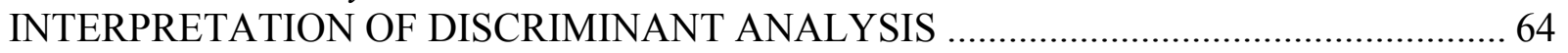

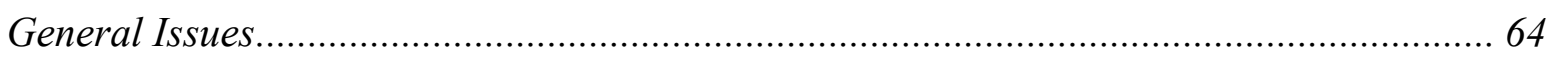

Interpretation of Organizations' Ethical Work Climates ...................................................... 66

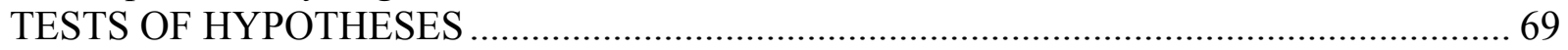

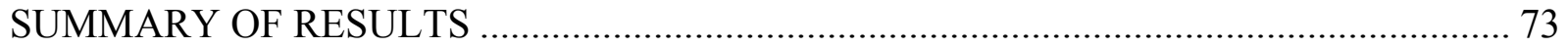

CHAPTER 5 - DISCUSSION AND SUMMARY.................................................................... 75

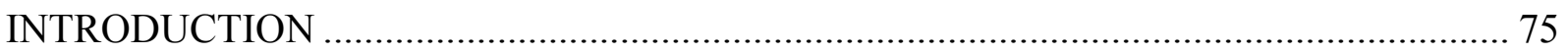

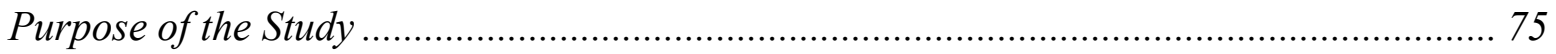

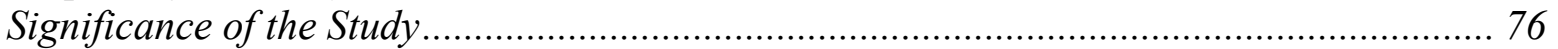

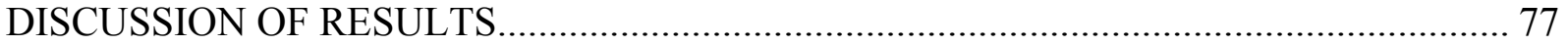

Validation of the Ethical Work Climate Construct …………............................................. 77

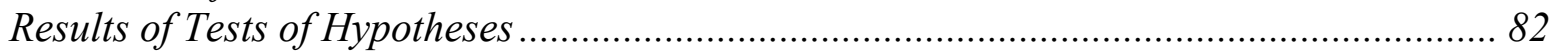

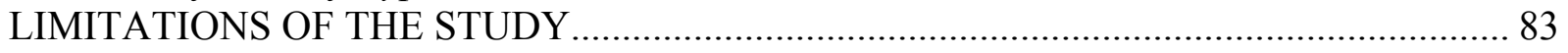

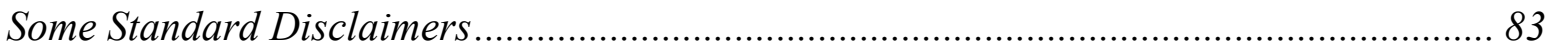

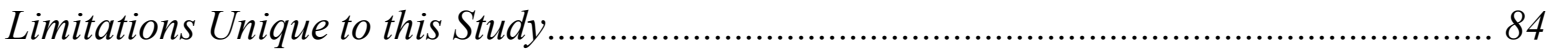

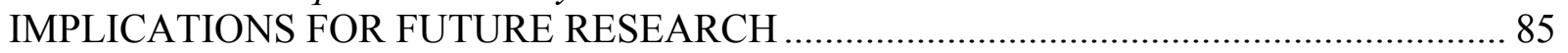

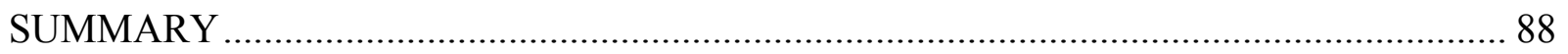

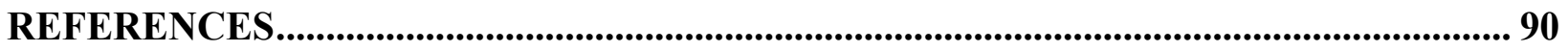

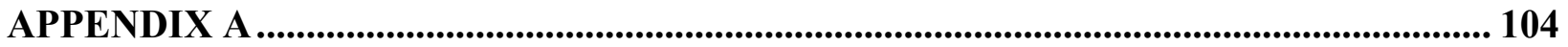

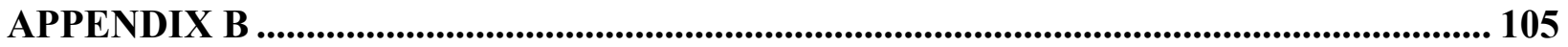


APPENDIX C ........................................................................................................................................... 107

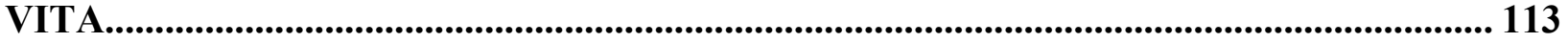




\section{CHAPTER 1 - INTRODUCTION}

\section{INTRODUCTION}

Ford Motor Company sells a car that its executives realize has a high probability of exploding into flames if rear ended. B. F. Goodrich executives provide the military with falsified engineering tests in their attempt to fulfill the company's contract for jet-aircraft brakes, knowing that the failure of the brakes could mean death for the pilot. Lincoln Savings executives deliberately invest depositors' money in high-risk ventures that could cause depositors to lose their lives' savings. Michael Milken and Ivan Boesky are convicted of a variety of federal securities laws, fined and sentenced to time in jail. Kidder, Peabody \& Company fires its chief government bond trader after discovering his fraudulent trades that were intended to inflate the firm's profits and the trader's bonus. More recently, Xerox announces that its CEO tripled his annual compensation, within weeks of announcing that the company has laid off nearly a third of its workforce. These are just a few of the high-profile cases of business-ethics breaches during the last twenty-five years. Many more such cases may go undetected or unreported. As Frederick (1995: 277) notes:

The normative bill of particulars brought against American corporate business is lengthy, shocking, and saddening. From many quarters and over long stretches of time, a clamorous chorus has sounded out a damning indictment of specific business practices and, in some cases, a condemnation of the institution itself. Greed, selfishness, ego-centeredness, disregard of the needs and well-being of others, a narrow or nonexistent social vision, an ethnocentric managerial creed imposed on nonindustrial cultures, a reckless use of dangerous technologies, an undermining of countervailing institutions such as trade unions, a virtual political takeover of some pluralist government agencies, and a system of self-reward that few either inside or outside business have cared to defend as fair or moral —all of these attributes have been credited to the business account.

The underlying assumption in this dissertation is that reducing unethical business practices is a desirable goal. In order to bring about lasting changes, people interested in reducing unethical business practices must seek first to understand the causes behind these behaviors. In activities as complex as business practices, the causes are numerous, complicated, interdependent, and often enigmatic, making the business reformer's job exceedingly difficult. Not only is an individual's overt behavior a culmination of a series of cognitive and physical processes, but a plethora of factors in the social environment also influences the individual. This dissertation will examine the relationship between one of those environmental factors - the work group's ethical work climate (EWC) - and one of the cognitive processes - moral awareness. ${ }^{1}$

\footnotetext{
${ }^{1}$ In this dissertation the term "moral awareness" will be used synonymously with moral "recognition," "perception," "cognition," and "sensitivity."
} 
Specifically, hypotheses that certain types of EWC enhance moral awareness, while other climate types retard moral awareness, will be tested.

Recent work in business ethics has produced a seeming conundrum. On the one hand, there has been a significant increase in research in business ethics and corporate social responsibility in academic circles, and calls for higher ethical standards from external stakeholders and industry/trade groups. What Mathews (1988) refers to as a "revival of interest in ethics" is captured in Lewin and Stephens's (1993: 401) observation that "the public is increasingly demanding that business organizations take extraeconomic values into account when establishing both goals and means." There has been a spate of literature produced by academicians researching corporate social responsibility (Frederick, 1995); increased attention also has been given to the impacts of business activity on the natural environment (e.g. Stead \& Stead, 1992); and the use of social-responsibility criteria in financial investing, such as the Kinder, Lydenberg and Domini corporate social performance database, and the Council on Economic Priorities' The Corporate Report Card, has gained popularity (Gerde, 1998). More than \$2 trillion had been invested in this way by 1999 (Social Investment Forum, 1999). Business membership organizations such as The Conference Board and The Business Roundtable have published literature focussing on enhancing business's contributions to society. On the other hand, in spite of this increased attention, we regularly hear about all manner of unethical behavior carried out in the names of business entities and for personal gain on the part of corporate employees. Frederick's observations about the ethical lapses in American corporations noted earlier portray this phenomenon, as do numerous other researchers. "Recent years have witnessed both a substantial proliferation of revealed ethical violations involving important social institutions and their leaders, and a strong response from organizations to perceived low levels of moral character among their members" (Jones \& Ryan, 1997: 663). Why, with all of the attention that business ethics has been given over the past several decades, do we still see so many prominent cases of unethical business practices?

There are many possible reasons for sustained unethical business practices, despite the growing attention paid to ethics. Many writers have focussed on individual moral failure in their explanations of unethical business practices (Waters, 1978). Another equally important explanation can be drawn from cognitive failures. "Perhaps unethical choices in organizations are often made not because of human evil or unethicality, but because ethical decision making is cognitively complex and strongly affected by organization design" (Stephens \& Lewin, 1992: 3). The inherent complexity of business situations makes recognition of a moral component difficult, and business decisions involving a moral component are arguably even more complex than the average (Stephens \& Lewin, 1992; Jones \& Ryan, 1997).

The inherent complexity of business situations is not the only cognitive factor that perpetuates unethical business practices. Individuals bring with them varying capacities to recognize the moral component of a business situation. It is the degree of ability to recognize the moral content of a situation — known as moral awareness (Blasi, 1980; Blum, 1991; Jones, 1991; Jones \& Ryan, 1997) — that I focus on in this dissertation.

I have three reasons for investigating the role of moral awareness in business decision making. First, any problem-solving technique begins with identification of the problem (Blasi, 
1980; Abelson \& Levi, 1985; Robbins \& Coulter, 1999; Dessler, 1998; Robbins \& De Cenzo, 1998). Without recognition of a moral component to the problem, there cannot be any consideration or weight given to that component during the deliberation, solution, and action phases of decision making. Secondly, moral awareness is one facet of moral behavior that researchers have largely overlooked. In fact, few of the existing moral-behavior models explicitly acknowledge this step in the process, and business ethicists and philosophers only rarely speak of the key role that perception of the moral element plays in moral judgment and behavior (Blasi, 1980; Blum, 1991; Jones, 1991). Third, none of the sparse research on moral awareness has linked it to EWC. More generally, a connection between organizational influences and individual ethical choices has long been assumed, but there has been little empirical evidence collected to test the validity of this assumption (Jones \& Ryan, 1998). "Most of the models that purport to explain moral decision making in organizations...contain an element that refers to organizational or environmental influences on the moral agent, but few provide much in the way of detail regarding how these influences work....[T]heory linking organizational/environmental factors and individual ethical decision making is in short supply" (Jones \& Ryan, 1997). The theoretical basis for this connection, based upon sociological and social-psychological evidence that macrosocial and group contexts, respectively, influence moral perception, will be developed later in this chapter.

Some scholars do, however, recognize the importance of moral awareness, although few have researched it. Werhane (1998) refers to the ability to conceive of the possibilities of various actions as "moral imagination." She blames much of the unethical behavior in business on a narrow perspective of the situation and the inability to imagine a wide range of possible issues (Werhane, 1998). Werhane is not alone in her views. She is preceded by several others, including Blasi (1980), Blum (1991), Jones (1991), and Jones \& Ryan (1997). David Hume and Adam Smith were two of the first scholars to discuss enhancing the perception of moral issues. A central tendency of human nature that Smith hypothesized was sympathy, which allows a person to see and understand a particular situation through another person's eyes (Smith, 1759/1986). Although sympathy and moral imagination are not exactly congruent concepts, both point to the importance of identifying moral issues in problem situations. Other prominent philosophers, such as Iris Murdoch (1970), Martha Nussbaum (1985, 1986), Barbara Herman (1985), Nancy Sherman (1989), and Lawrence Blum (1991) also note the role that awareness plays in moral behavior.

\section{THE RESEARCH PROBLEM}

\section{Moral Judgment versus Moral Awareness}

The concept of moral development was first researched by Jean Piaget in the 1930s, although it did not become widely recognized until Lawrence Kohlberg's work in the 1950s and 1960s. Both Kohlberg (1973, 1981, 1984) and James Rest $(1979,1986,1994)$ have explored cognitive moral development (CMD) in great depth. Although CMD is a widely accepted construct, and literally hundreds of studies have investigated it using both Kohlberg's interview techniques and Rest's Defining Issues Test, the focus has been almost exclusively on moral

judgment, which is distinct from, but related to, moral awareness. Being aware of a moral 
component involves the recognition that an ethical issue is at stake in a given situation. Awareness necessarily precedes judgment, which is a process of seeking the most morally justifiable course of action from the alternatives (Blum, 1991; Rest, 1994).

Both Kohlberg and Rest acknowledge the vital role of moral awareness in moral development. As Rest notes, "[T] here is more to moral development than moral judgment development, and there is more to moral judgment than the six stages [of Kohlberg's model of moral development]. Many people may be surprised to hear that Kohlberg agreed. He also saw moral judgment as only part of the psychology of morality" (Rest, 1994: 22). Rest explicitly includes moral awareness in his Four Component Model of moral behavior, calling it "moral sensitivity" (Rest, 1994: 23).

Blum also highlights the importance of moral perception. He notes that a moral agent may have all of the requisite judgment skills, but still fail to act morally because of a lack of moral awareness: "Yet unless she perceives moral situations as moral situations, and unless she perceives their moral character accurately, her moral principles and skill at deliberation will be for nought and may even lead her astray. In fact one of the most important moral differences between people is between those who miss and those who see various moral features of situations confronting them" (Blum, 1991: 701). Blum says that moral perception cannot be identified with moral judgment-perception must occur prior to judgment, and perception involves moral capacities not encompassed by judgment.

As discussed above, the topic of moral awareness is of critical importance in the study of moral behavior, and thus in business ethics. Despite its crucial nature in CMD, moral awareness has not, unfortunately, been extensively researched (Blasi, 1980; Jones, 1991). Rest (1986, 1994) made note of the paucity of research on this component, citing the lack of accepted methods or validated measures. Blum (1991) has also lamented the scarcity of attention this topic has attracted. Nor has there been much attention given to moral awareness in studies on ethical decision making in business (Butterfield, Treviño, \& Weaver, 1996, 1997). My review of the literature in Chapter 2 will cover the scant work that has been done in this area to date.

\section{Levels of Analysis}

As one would expect from the psychological perspective taken by most researchers in CMD, almost all of the independent variables examined to date have dealt exclusively with the individual. It was, after all, Kohlberg, the founding father of CMD theory, who said that it is the individual who makes determinations of right and wrong-even though the individual's judgments may be socially determined (Rest, et. al., 1999); indeed, in Kohlberg's schema, the extent to which a given individual's moral judgment is or is not socially derived is a key determinant of the individual's level of CMD. Kohlberg's perspective, originally developed in the 1950s, was in direct opposition to behaviorism, the dominant school of thought in psychology at the time. Behaviorists believed that human behavior was little more than a stimulus/response relationship. Once the appropriate conduct had been learned, the person's behavior was an automatic response to the given situation or stimulus, with virtually no judgment involved. According to this thinking, moral development was a matter of learning and internalizing one's cultural norms, and behaving in accordance with them (Rest, 1994). 
Kohlberg acknowledged the ongoing influence of the social environment on the individual's moral cognition, even though he continued to emphasize the individual's role in moral development: He deemed people at the post-conventional levels of CMD able to cast off local social conventions and rules to make moral judgments in an abstract, principled manner. Even Blum (1991), who approaches the question of moral sensitivity from the philosophical perspective, believes that most of the differences in persons' abilities to perceive moral components are based on individual differences.

In contrast to the psychological perspective, the sociological perspective (which will be used in this dissertation) attributes much of the reason for variances in how individuals think, act, and feel to the groups and society in which they are embedded (e.g. Wilson, 1983; Smelser \& Swedberg, 1994; Shepard, 1999). Granovetter clearly expressed this view in his work on embeddedness in economic activities. He argues that most behavior is embedded in networks of ongoing interpersonal relationships, an outlook that avoids the extremes of what he terms the "undersocialized" and "oversocialized" views of human action (Granovetter, 1985). The perspective that will be employed in this dissertation corresponds with Granovetter's ideas on embeddedness, "that culture is not a once-for-all influence but an ongoing process, continuously constructed and reconstructed during interaction. . . . I believe this to be so for all behavior" (Granovetter, 1985: 486, 504, emphasis added).

This social embeddedness, which entails the influence of small groups on individuals, has roots in a rich sociological tradition (Smelser \& Swedberg, 1994). Emile Durkheim's $(1937 / 1996)$ work is particularly relevant to the current question because of his foci on social influences on individuals, the economy's place in society, and social upheavals resulting from cataclysmic changes in the social order. To fully understand the theoretical linkage between EWC and individual moral awareness, it will be helpful to review the historical events that led to the social milieux Durkheim observed, which is, in certain important ways, analogous to current social and economic conditions.

\section{HISTORICAL BACKGROUND}

Because the amoral theory of business (Shepard et. al., 1995) is currently the dominant paradigm in our society, it is reasonable to expect that the social influences on moral awareness in business settings will be different than they are in other social institutions. Therefore, the overarching framework for the following discussion is the shift from a unified system of moral constraints over all social institutions to one in which the economic institution is viewed as somewhat separate from the other institutions and immune to some moral regulations (the "amoral theory of business"). It will be argued that modern Western societies have moved from a communitarian ideology, wherein all social institutions were dominated by the church, to a more individualistic ideology. This, in turn, facilitated the separation of social institutions, and the rise to prominence of the economic institution.

To fully understand the preceding paragraph and the theoretical framework for this dissertation, it is necessary to quickly review some facets of Western history. Of particular

concern is the shift, beginning in the seventeenth century, from the "moral-unity" theory of 
business to the "amoral theory of business" (Shepard et. al., 1995). The moral-unity theory of business postulates that the economic institution is viewed as an integral part of the overall society, and that it is subject to all of the same norms and moral regulations as all of the other social institutions. In contrast, the amoral theory of business sees the economic institution as separate from other social institutions, largely insulated from all of the moral norms followed in the rest of society. In this shift, then, the economic institution has been separated morally in certain significant ways from other social institutions such as the church, the state, the community, and the family. As a result, the economic institution has come to be exempt from some generally accepted norms. Or, as some have stated, the economic norms have become the only ones that matter.

You may prefer to think it's just a leftist structural theory that labor and export market stability are often the underlying reasons for various U. S. sanctions, military actions, and other foreign policies. Or you can just read Investor's Daily Business and the like, when such things are often spelled out explicitly by the players themselves, with remarkably little concept that any other paradigm for human behavior might exist" (Harris, 1999: 122-123).

Shepard et. al. (1995) point to several factors in this shift from the moral-unity to the amoral theory of business. From the earliest Western civilizations, the dominant ideology was uniformly communitarian. In ancient Greece, the prevailing view was that individuals existed only within the context of the overall society, and that economic activity was a necessary evil, useful only to provide the necessities of life. Early Christians held views similar to the Greeks on the relation between the individual and economic activities. With the birth of Jesus and the establishment of the Christian church (then the Catholic Church), most Western societies were unified under the domination of the church, clearly representing the moral-unity theory. A significant turning point came with the Protestant Reformation, and its notion that individuals could have a direct relation with their God, without the intervention of the church. This novel idea laid the groundwork for the first true recognition of the individual as an entity separate and apart from society. Calvinism and its revolutionary idea of predestination inadvertently provided further impetus for the acceptance of economic activity, and for the first time, approved the accumulation of individual wealth - albeit towards the end of communitarian purposes.

Although neither Luther nor Calvin intended to do so, both of their doctrines promoted the acceptability of a more individualistic ideology. This in turn provided fertile ground in which the spirit of capitalism could grow, as documented by Weber (1904-05/1958). Weber viewed the development of rationalism as an integral component of the development of the spirit of capitalism. Along with the Enlightenment's conviction that humans could, through reason alone, solve the puzzles of the universe, it was a short road to the belief that man was his own master (a notion completely foreign to Luther and Calvin). This notion reduced the influence of the church, and gradually, economic activity was placed in a special domain somewhat removed from moral rules associated with other social institutions; this separation constitutes the amoral theory of business.

Two major themes arise from this intellectual history. The first is the rise of the individual as an entity separate from the society in which she is situated. Robert Nisbet (1993) 
refers to this as the process of individualization, or the separation of individuals from communal social structures. The new societies heralded the rise of moral egoism and social atomization. Even though this process emphasized the role of the individual in society, the sociological perspective easily co-exists with individualization (Miller, 1996; Shain, 1994). The second theme is the separation of the economy from other social institutions. Beginning with the ancient Greeks, Western civilization had viewed society as composed of unified institutions, including the family, the state, the church, and the economy. However, because of the forces just outlined, people came to see the economy as separate in some ways from other institutions. Both of the processes described by these themes have been instrumental in the rise of the amoral theory of business. In turn, this paradigm is quite possibly a major contributor to a general breakdown in moral awareness and behavior in business settings.

Emile Durkheim, like other early sociologists, had seen the effects of the profound disruption of society engendered by the shift just outlined, including the growing separation of the economy from the rest of society: "For two centuries economic life has taken on an expansion it never knew before. From being a secondary function, despised and left to inferior classes, it passed on to one of first rank" (Durkheim, 1937/1996: 11). In Professional Ethics and Civic Morals, Durkheim explored the problems of an advanced, complex society in which the economy had become so detached from other social institutions that it became an end in itself. He wrote that in Western societies neither government nor society held moral sway over the economic institution; a state of anarchy within the economic sphere was therefore inevitable. He made several references to "the anarchy of the economy" in this work (a concept virtually identical to the amoral theory of business.) According to Durkheim, "We can give some idea of the present situation by saying that the greater part of the social functions (and this greater part means to-day the economic - so wide is their range) are almost devoid of any moral influence..." (Durkheim, 1937/1996: 29).

As Victor and Stephens (1994) note, for all intents and purposes, everything and nothing has changed since Durkheim, over one hundred years ago, gave the lectures that now comprise Professional Ethics and Civic Morals. In some ways the milieux are eerily similar. Instead of the Industrial Revolution, we are now undergoing the Information Revolution, and instead of shifting from an agrarian society to an industrial one, we are in the midst of the transition from industrial society to a post-industrial society. Durkheim saw the effects of the transition from an agriculturally based economy to an industrial one, and we are seeing the shift to a service and information-based economy. Finally, we, like Durkheim, are still looking for an institution that can instill morals into the economic institutions; Durkheim was correct when he observed that the market in a capitalistic economy has difficulty imposing a set of moral rules on the participants in that market. As Turner notes, "The problem facing modern Europe [and the United States] is the separation of the economy from society and the absence of any effective regulation of the market place" (Turner, 1996: xxxi). Society today is undergoing many of the same types of social upheavals, with the same types of effects that Durkheim witnessed a century ago. Francis Fukuyama has termed this the "Great Disruption" in the social values that had prevailed in the industrial-age society of the mid-twentieth century.

This period, roughly the mid-1960s to the early 1990s, was also marked by seriously deteriorating social conditions in most of the industrialized world. 
Crime and social disorder began to rise, making inner-city areas of the wealthiest societies on earth almost uninhabitable. The decline of kinship as a social institution, which has been going on for more than 200 years, accelerated sharply in the second half of the twentieth century. Marriages and births declined and divorce soared; and one out of every three children in the United States and more than half of all children in Scandinavia were born out of wedlock. Finally, trust and confidence in institutions went into a forty-year decline (Fukuyama, 1999:5556).

Durkheim's concern over the social chaos in his time is clearly still relevant today. Within the economic sphere, one of the common indicators of this condition is the continued prevalence of unethical business practices. Lack of moral awareness may be a contributing factor to this state.

In essence, Durkheim anticipated my research question over one hundred years ago. His concern about the effects of the removal of moral constraints on economic behavior mirrors mine. To the extent that general moral constraints are not considered pertinent to economic activities (as is the case under the amoral theory of business), moral awareness in the economic domain will be retarded. If moral awareness does not develop, major ethical breaches in business are to be expected.

Many contemporary economic organizations are concerned about ethical violations. Consequently, some organizations, more than others, attempt to bridge the perceived gap between economics and ethics through the promotion of positive ethical norms. Although it is not a measure of the morality of the organization, nor a prescription of what the norms ought to be, the EWC construct does measure the shared perception of what the ethical norms are in a work group. Furthermore, I will argue the theoretical possibility that particular EWCs are more consonant with moral awareness than others, thus introducing a prescriptive component into the heretofore descriptive EWC research.

\section{THEORETICAL BACKGROUND}

The sociological perspective that I will use in this dissertation rests on several basic assumptions, two of which are particularly relevant here. The first is the existence of what Durkheim called "social facts," or social phenomena that are external to an individual. These social facts include such things as legal and economic institutions, religious beliefs, and social movements (Durkheim, 1895/1962). The second assumption is the primacy of society over the individual. Durkheim was especially noted for his emphasis on these assumptions. He argued that the individual is what she is only in the context of society (Davy, 1996). He went so far as to argue that our knowledge of the world is not grounded in a priori categories of the individual

mind, but rather comes from collective categories of thought modeled on the structure of society itself (Turner, 1996). For Durkheim, society is ontologically prior to the individual, and the ideas, morality, language, and relationships of the individual "are but reflections of the anterior reality of society" (Nisbet, 1965: 25). Thus, social facts exercise social and moral constraint over individual behavior. 
Durkheim explicitly included moral activity in his theories of social relations (Wallwork, 1972; Bellah, 1973; Miller, 1996). He proposed that individuals' moral judgment and actions stem directly from their group experience. His contention was that the moral rules and norms that bind individuals do so because they are socially shared and embody the authority of the group. $\mathrm{He}$ also realized that group cohesion, along with a set of formal rules that comprised group authority, was necessary to build morality in individuals within the group. Kohlberg (who was one of the first to break from behaviorism) also noted that the "socio-moral" atmosphere of an organization was a significant factor in the ethical decision making of individuals within it (Wyld \& Jones, 1997). In an earlier speech Kohlberg stated, "[I]ndividual moral action usually takes place in a social or group context and that ... context usually has a profound influence on the moral decision making of individuals" (Kohlberg, 1981: 37-38).

This discussion of Durkheim and Kohlberg has focussed exclusively on moral judgment and action, not moral awareness (the topic of this dissertation). Actually, both men's views at least imply the component of moral awareness. It is entirely reasonable to believe that Durkheim would strongly agree that the group influences the individual's moral awareness as well as judgment and actions: "Now this adherence to some thing that goes beyond the individual, and to the interests of the group he belongs to, is the very source of all moral activity" (Durkheim, 1937/1996: 24, emphasis added). The fact that Kohlberg's position leaves room for the importance of other aspects of moral development beyond judgment is reflected in Rest's observation that Kohlberg saw moral judgment as only one component of the psychology of morality (Rest, 1994). Combining that observation with Kohlberg's acknowledgement of the group's influence on individual moral action, one can infer that he would agree with Durkheim that the group context influences individual moral perception.

\section{THE RESEARCH QUESTION}

The preceding discussion has established the historical and theoretical backgrounds for the potential relationship between EWC and moral awareness. It is important to note that the current literature in business ethics also recognizes the potential for influence that the organization has on individual moral behavior. This relationship has been conceived in several different ways, but perhaps the most relevant is the continuing debate over moral agency within organizations, which closely mirrors the debate on psychological and sociological perspectives (McDonald \& Victor, 1988). The most generally accepted concept today seems to be that the individual within the organization is the moral agent, but that the firm exerts "significant influence" on the ethical behavior within its boundaries (Sims, 1992). "The issue of business morality is, and cannot avoid being, both a personal and an institutional matter for every corporate executive and for every employee who does not mean to surrender his individual integrity, his honor, his very soul to an organization" (Silk \& Vogel, 1976: 231).

In this dissertation, I intend to examine moral awareness from a sociological (or perhaps more specifically, a social-psychological) perspective. In particular, the sociological factor I will focus on is ethical work climate. The foregoing discussion of society's influence on the individual and the central role that perception of moral issues plays in ethical behavior leads to 
the research question this dissertation will seek to elucidate, "How does ethical work climate within an organization relate to individuals' moral awareness?"

\section{INDEPENDENT VARIABLE: ETHICAL WORK CLIMATE}

It is important to distinguish between organizational climate and ethical work climate. According to Tagiuri, organizational climate is "a relatively enduring quality of the internal environment of an organization that (a) is experienced by its members, (b) influences their behavior, and (c) can be described in terms of the values of a particular set of characteristics (or attributes) of the organization" (Tagiuri, 1968: 27). Victor \& Cullen (1987) construe ethical climate as one dimension of organizational work climate.

The ethical work climate construct was first introduced in the late 1980s by Bart Victor and John Cullen. They define EWC as "the shared perceptions of what is ethically correct behavior and how ethical issues should be handled" (Victor \& Cullen, 1987: 51-52). Victor and Cullen's framework $(1987,1988)$ proposed to identify various ethical climate types, based on two dimensions: a) ethical criteria (egoism, benevolence, or principle) used to make decisions, and b) the "locus of analysis" (individual, local, or cosmopolitan). It was not their purpose to develop a measure of the morality of the organization prescriptively, but rather to describe the different types of ethical climates that could appear. After empirical research, the nine theoretically possible ethical climates in Victor and Cullen's three-by-three matrix were reduced to five that actually occurred-instrumental, caring, independence, rules, and laws/code. These climates can be briefly characterized by the following descriptors:

Instrumental- "In this company, people are mostly out for themselves." Caring - "In this company, people look out for each other's good."

Independence_- "In this company, people are expected to follow their own personal moral and ethical beliefs."

Rules - "It is very important to follow strictly the company's procedures here."

Laws/code - "In this company, the first consideration is whether a decision violates any law" (Victor \& Cullen, 1988).

This construct will be further explicated in Chapter 2.

The construct of ethical work climate is a manifestation of the two assumptions previously identified as bases of sociology. It is certainly a social fact as defined by Durkheim, since it is external to the individual. The hypothesized influence of EWC on individual moral awareness also implicitly recognizes Durkheim's second major assumption - the exercise of social and moral constraint on individuals that operates because of the primacy of society. Although Durkheim's work was primarily focussed on the macro level of analysis, he also explicitly acknowledged the influence of smaller organizations, such as the professional groups he recommended in Professional Ethics and Civic Morals. "There should be rules telling each of the workers his rights and his duties, not vaguely in general terms but in precise detail, having in view the most ordinary day-to-day occurrences....It is the task of the very group to which they are to apply" (Durkheim, 1937/1996: 13). 


\section{DEPENDENT VARIABLE: MORAL AWARENESS}

Moral awareness, as used in this dissertation, is defined as the degree to which an individual recognizes the aspects of a situation that carry a reasonable likelihood of moral wrong or harm to individuals, classes of people, or other entities (e.g. spotted owls, wetlands, corporate competitors, etc.). Harm is used as a criterion on the assumptions: a.) that if a given action brings universal benefit there is no moral dilemma, and b.) that most people view morality in terms of harm to self or others. ${ }^{2}$ This definition, although more specific, is similar to Rest's: "Moral sensitivity is the awareness of how our actions affect other people. It involves being aware of different possible lines of action and how each line of action could affect the parties concerned. It involves imaginatively constructing possible scenarios, and knowing causeconsequence chains of events in the real world; it involves empathy and role-taking skills" (Rest, 1994: 23).

\section{SIGNIFICANCE OF THE STUDY}

In this research, I expect to find lower levels of moral awareness in ethical work climates that employ the egoistic ethical criterion than in EWCs that utilize the benevolence or principle criteria. I also anticipate that moral awareness will tend to be higher in EWCs with broader loci of analysis; i.e., for a given ethical criterion, moral awareness will be higher at the local locus of analysis than at the individual locus, and higher still at the cosmopolitan locus. By the very definition of moral awareness ("the degree to which an individual recognizes the aspects of a situation that carry a reasonable likelihood of moral wrong or harm"), a cosmopolitan locus of analysis should lead to heightened moral awareness, if only because the moral agent will be "aware" of a wider population that may be affected in a given situation. Similarly, ethical criteria of benevolence or principle should provide the agent with a broader view than will the egoistic criterion.

If the expected results are obtained, this research will provide new support for the influence of a group's ethical climate. Furthermore, such results will lay groundwork for further research that may affect management practices in today's business world. If business leaders are concerned with continued breaches of morals and are looking for ways to reduce their occurrence, this research can provide insight on one possible way to influence workers' abilities to perceive the moral components in business situations. Climate researchers have shown that climate can be manipulated by organizational elites, although specific means to change ethical climates are still unclear. These points will be amplified in the final chapter.

\footnotetext{
${ }^{2}$ There is some debate among moral philosophers whether all immoral acts involve specific harms other than the moral harm involved in performing the act. This issue is a central component of the debate between proponents of deontological and teleological moral philosophies. Although it may be fair to say that a moral issue involves a question of harm, it is not accurate to say that the existence of harm defines the moral issue. Thus, "harm" may be a sufficient, but perhaps not necessary condition for a moral issue. I will not attempt to make this distinction in the current research project, instead relying on the possibility of a specific harm to operationalize the concept of a moral component in a situation.
} 


\section{OVERVIEW OF THE DISSERTATION}

This dissertation contains four additional chapters. Chapter 2 reviews the current literature on ethical work climate and moral awareness. These streams of research are then integrated to show how they inform my research question. Predicted relationships between the independent and dependent variables are described and presented as testable hypotheses. Chapter 3 outlines the research methodology employed. Chapter 4 reports the results of the field work and data analyses. Finally, Chapter 5 states conclusions based on the field work, explores implications of the results, and offers suggestions for further research topics related to the current project. 


\section{CHAPTER 2 - REVIEW OF LITERATURE}

\section{INTRODUCTION}

Chapter 1 established the historical and theoretical background for a potential relationship between an organization's ethical work climate and the moral awareness of the organization's members. Primary reliance was placed on sociological and social-psychological theory for this relationship. In this chapter, I will further explicate the role of climate in its influence over organizational members' moral awareness. But the question must be asked, "Why climate?" Any number of constructs could have been chosen to investigate. Motivation theories, emphasizing either need or instrumentality, are used by researchers in organizational behavior to explain almost everything that people do at work (Schneider \& Reichers, 1983). Leadership theories focus on the organizational elites' roles in eliciting certain behaviors or responses from workers (Vroom \& Jago, 1988). Script theory suggests that people employ cognitive frameworks to impose structure on complex situations to facilitate understanding and decision-making (Taylor \& Crocker, 1981). However, none of these alternatives is broad enough in scope to capture the full extent of the organization's influence on employees' moral awareness. Nor do they capture the sociological perspective that I take.

For example, in the description of his involvement in the Ford Pinto fires, Dennis Gioia (Ford's Field Recall Coordinator at the time) blames his failure to recognize the moral implications of the case on his reliance on Ford's scripted decision process (Gioia, 1992). In this context a script is a specialized type of cognitive framework that people use to impose structure on information, situations, and expectations to facilitate understanding (Gioia \& Poole, 1984). The script allows individuals to process information and situations efficiently by sorting and categorizing them based on certain relevant factors. By retaining knowledge of appropriate behaviors for specific contexts, the worker is able to process the information and act upon it without active thought or analysis (Abelson, 1976, 1981; Gioia, 1992). Because scripts are constructed from "normal" situations, they hardly ever provide the necessary cues to recognize abnormal or unusual elements, which almost always entail the moral elements of a situation. Gioia disputes the assumption in most models of moral decision making that people recognize a moral dilemma when confronted with one, because their scripts do not provide the necessary elements to allow such recognition (Gioia, 1992).

The need to rely on scripts implicitly recognizes the constraints of "bounded rationality" (March \& Simon, 1958). The cognitive overload encountered by decision makers in deliberating about "normal" situations is mirrored, or even exaggerated, in situations involving moral components. Stephens and Lewin (1992) term this notion "bounded morality."

Gioia personally experienced the effects of bounded morality. Because he identifies organizational scripts' inability to recognize a moral dilemma or provide direction when one is evident, he provides suggestions to enhance moral behavior in organizations. In his prescription 
for including ethical considerations in organizational scripts and thus improving moral behavior, Gioia relies on recommendations that invoke the very idea of organizational ethical climatetraining that concentrates on exposure to ethical considerations, and the inclusion of ethical components in job descriptions, management development, mentoring, and other similar processes (Gioia, 1992). Script theory, then, is too narrow in its scope to encompass significant influence over individual moral awareness. As I will describe later in this chapter, ethical work climate is a broader construct than that of scripts, motivation, or leadership theories, and is therefore more likely to capture the influence on individual's moral awareness.

Because ethical work climate is one dimension of organizational climate and shares many of the same assumptions, measurement issues, and conceptual methodological difficulties, I will first review the literature on organizational climate before turning specifically to ethical work climate.

\section{ORGANIZATIONAL CLIMATE}

\section{Early Conceptualization}

The concept of organizational climate has been a popular research topic since the mid1960s (Field \& Abelson, 1982; Schneider, 1983; Schneider \& Reichers, 1983). ${ }^{3}$ Nearly twenty reviews of climate literature have been published since that time (Forehand \& Gilmer, 1964; Litwin \& Stringer, 1968; Tagiuri \& Litwin, 1968; Campbell, et al., 1970; Hellriegel \& Slocum, 1974; James \& Jones, 1974; Schneider, 1975, 1983; Pugh, 1976; Powell \& Butterfield, 1978; Woodman \& King, 1978; Jones \& James, 1979; Joyce \& Slocum, 1979, 1984; Naylor, Pritchard, \& Ilgen, 1980; Field \& Abelson, 1982; Payne \& Schneider \& Reichers, 1983; Denison, 1996; Verbeke, Volgering, \& Hessels, 1998). This stream of research originates from studies in industrial and organizational psychology, and is an outgrowth of attempts to identify environmental influences on individual motivations and behaviors (Reichers \& Schneider, 1990). Early in its existence, the organizational climate construct was hailed in some quarters as "one of the most important to enter the thinking of industrial-organizational psychologists in many years" (Guion, 1973: 120). Many researchers in this field view organizational climate as a key link between the organization or sub-group and the individual (Field \& Abelson, 1982). Such support was far from universal, however, and many of the early reviews of the literature were quite critical of the conceptualization and measurement of the construct (Schneider \& Reichers, 1983; Hofstede, 1998). These critiques revolved primarily around questions of the inability to separate measures of climate from attitudinal measures. One of the earliest concerns with climate research was the alleged conflation of organizational climate and job satisfaction.

\footnotetext{
${ }^{3}$ There is significant debate among social scientists regarding the definitions and relative merits of the climate and culture constructs. Although there is a general consensus that the two constructs are closely related, agreement seems to end there. Differences arise from the academic disciplines and traditions from which they originated, the research methods commonly employed, and the level of abstraction at which they are presumed to operate, among others. For further information on this debate, I refer the reader to Benjamin Schneider (ed.), Organizational Climate and Culture (San Francisco: Jossey-Bass Publishers, 1990) and Daniel R. Denison, "What Is the Difference between Organizational Culture and Organizational Climate? A Native's Point of View on a Decade of Paradigm Wars" in Academy of Management Review, 21, 1996, 619-654. Because organizational climate is a widely accepted construct (as I will show in this chapter), I will not delve further into this discussion here.
} 
Indeed, some early research found that there was no difference between climate and job satisfaction (Guion, 1973; Johanneson, 1973). Woodman and King were perhaps the most vocal of the critics, stating, "until these issues of validity can be resolved, much speculation about organizational climate is likely to elude science and remain in the realm of organizational folklore" (1978: 824).

However, when climate is conceptualized descriptively, as individuals' beliefs about "the way things are around here," researchers have demonstrated repeatedly that climate and job satisfaction are different concepts (Schneider \& Reichers, 1983; Reichers \& Schneider, 1990; Hofstede, 1998). For example, when specifying this approach to survey respondents, Schneider and Snyder (1975) found an intercorrelation between the two measures of only 0.19 . Other studies have confirmed this finding (Lafollette \& Sims, 1975; Newman, 1977; Joyce \& Slocum, 1979).

\section{Defining Organizational Climate}

Partly because of improvements in conceptualization, the definition of organizational climate has evolved during its four decades. Forehand and Gilmer (1964:362) were among the first to offer a concise description, which referred:

...to the set of characteristics that describe an organization and that (a) distinguish the organization from other organizations, (b) are relatively enduring over time, and (c) influence the behavior of people in the organization.

Tagiuri (1968: 27) expanded the definition, by citing organizational climate as:

...a relatively enduring quality of the internal environment of an organization that (a) is experienced by its members, (b) influences their behavior, and (c) can be described in terms of the values of a particular set of characteristics (or attributes) of the organization.

Hellriegel and Slocum (1974: 256) added the idea of "subsystems" to their definition:

Organizational climate refers to a set of attributes which can be perceived about a particular organization and/or its subsystems, and that may be induced from the way that organization and/or its subsystems deal with their members and environment.

The common components of these definitions include the enduring quality of climate, and the facts that it can be measured and that it influences the behavior of individuals in the organization.

Several other issues regarding the definition of organizational climate are relevant. First, researchers now recognize that climate can be specific to subsystems within a given organization, thus allowing for multiple facets of the same elements of climate within one organization (Field \& Abelson, 1982). Second, individual perceptions of climate versus group or organizational climate remains a research question. According to Schneider (1973) and James 
and Jones (1974), there are different levels of analysis inherent in the organizational climate research. These researchers suggest that the individual level be referred to as "psychological climate," while the term organizational climate should be reserved for reference to organizationwide or group parameters.

As the preceding paragraphs show, defining organizational climate is more difficult than it may first appear. The difficulty in trying to separate conceptual and methodological issues contributes to this difficulty. As Schneider and Reichers (1983: 21) note, "In a sense, it is artificial to separate conceptual from methodological issues, since a lack of conceptual clarity frequently leads to inadequate or inappropriate measurement techniques." The following discussion of methodological issues closely maps on these conceptual issues.

\section{Methodological Issues}

Early criticisms of climate research also cited questions of level of analysis and the validity of aggregating individual perceptions to represent organizational realities. Recognition of the multiplicity of climates within one organization has led to (or been the result of, depending on one's view) two methodological issues plaguing climate research. The first of these is what Schneider and Reichers (1983) refer to as the multi-dimensional issue. This is the failure to recognize that there is no such thing as a single type of work climate. "The climate construct is so intuitively appealing to uninitiated researchers that they seem to want $a$ measure of 'it.' As noted above, climate is not an 'it,' but a set of 'its,' each with a particular referent.... [W]ork settings have numerous climates and...these climate are for something...To speak of organizational climate per se, without attaching a referent is meaningless" (Schneider \& Reichers, 1983: 21-22).

The second methodological issue is the aggregation problem (Schneider \& Reichers, 1983; Denison, 1996). This refers to the distinction between psychological and organizational climates discussed in the definition section. The issue is neatly encapsulated in the question, "How can we meaningfully aggregate individuals' descriptions of their work environment so as to represent larger social units?" (Joyce \& Slocum, 1979: 32). Joyce and Slocum provide a widely accepted solution to the query by proposing three criteria for evidence of an organizational climate:

1. Differences in the mean perceptions between organizations,

2. Internal consistency in perceptions within organizations, and

3. Predictable relationships between mean perceptions and organizational characteristics (Joyce \& Slocum, 1979, 1984).

Many researchers in this field have adopted this approach, and concur with the operationalization of the shared aspect of individuals' perceptions (Reichers \& Schneider, 1990).

It has been noted previously that the organizational climate construct rose out of industrial and organizational psychology (Reichers \& Schneider, 1990). This, in itself, does not affect the applicability of the sociological approach that will be employed in this dissertation. Sociologists routinely perform their research by collecting individual-level data and deriving 
meaning for the larger group from such data. Such "methodological individualism" is not inconsistent with a sociological perspective (Weber, 1910/1978; Shain, 1994; Swedberg, 1999).

Both of these methodological issues will be addressed in Chapter 3, which describes the research design for this dissertation.

\section{The State of the Organizational Climate Literature Today}

Organizational climate is a construct that has been extensively conceptualized, researched, and debated. Continued research, improvements in the conceptualization of the construct, and progress in methodologies have combined to make organizational climate a much more widely accepted concept at the current time (Field \& Abelson, 1982; Schneider \& Reichers, 1983; Denison, 1996; Hofstede, 1998). In fact, some researchers have even expressed concern that interest in climate research has waned because of its acceptance (Schneider, 1985; Denison, 1996). It is fair to now characterize the concept of organizational climate as having construct validity, but nonetheless being continually plagued by issues of measurement validity. As with any topic involving human perceptions, accurate and valid measurement is a continuing challenge. These topics will be given careful consideration in the design of this research project, and limitations will be reported in the final chapter.

This review of the organizational climate literature sets the stage for the ensuing review of the literature on the more-delimited concept of ethical work climate, and has also introduced topics that will be further explored in Chapter 3.

\section{ETHICAL WORK CLIMATE}

Victor and Cullen first introduced the ethical work climate construct in 1987. They noted that it is one dimension of work climate, and defined it as "the shared perceptions of what is ethically correct behavior and how ethical issues should be handled" within an organization (Victor \& Cullen, 1987: 51-52). It should be noted at the outset that EWC was not conceived as a normative construct for measuring how ethical a given organization was; rather it was developed as a descriptive indicator of the prevailing mode of ethical thought within an organization.

Consideration of ethical situations, broadly conceived, generally entails two dimensions. The first is the criteria that are used to reason about the situation-which might include the outcomes, the principles involved, or other rules for decision making. These are the very topics that moral philosophers have been debating for millennia. The second dimension (termed locus of analysis) encompasses who or what is considered as being affected by an event or situation in an ethically relevant way. This could include the self only, the focal organization, all of creation, or even present and future generations (Rachels, 1989, 1999; Solomon, 1992).

Victor and Cullen $(1987,1988)$ employed these two dimensions in their conceptualization of the EWC construct. To capture the ethical criteria dimension the authors used theories from moral philosophy (Williams, 1985) and moral psychology (Kohlberg, 1981). 
Kohlberg's work, along with theories of organizational roles and reference groups (Merton, 1957; Gouldner, 1957), were used to capture the idea of who or what would be considered. The use of these theories in the EWC construct will be examined below.

\section{Ethical Criteria}

Moral Philosophy. In very general terms moral philosophy can be categorized into two major classes: teleological and deontological. Teleological moral philosophies are primarily concerned with the outcomes or consequences of an ethical situation (Rachels, 1989, 1999; Brandt, 1995), while deontological philosophies do not focus solely on consequences but rather on the principles and/or duties involved in the situation (Kant, 1785/1959; Korsgaard, 1996). The teleological moral philosophies can be subdivided into two classes - those that give the moral agent primary consideration (egoistic) and those that hold that all actors involved should be given equal weight (utilitarian or benevolent). Victor and Cullen $(1987,1988)$ utilized these three classifications of moral philosophy to designate the criteria dimension of the EWC construct. Very brief (and therefore, very imprecise) descriptions of the criteria labels are:

Egoism - maximization of self interest

Benevolence - maximization of joint interests

Principle - adherence to duties, rules, laws, or standards (Victor \& Cullen, 1988; J. Weber, 1995).

Moral Psychology. In his work on cognitive moral development, Kohlberg (1981) differentiated moral reasoning (how moral dilemmas ought to be resolved) from cognitive reasoning (how people actually reason about the facts of the situation or how the dilemma will be resolved). He postulated that individuals develop moral reasoning skills and use different types of criteria in an invariant sequence with hierarchical transformations. The individual is further predicted to reason at the highest achieved stage of development regardless of the moral issue involved, without regression to lower stages, which have been superseded. The categories consist of three levels, each containing two stages (Kohlberg, 1973, 1981; Logsdon \& Yuthas, 1997):

Pre-conventional Level - Behavioral norms are viewed as being external to the individual.

Stage 1 - Punishment-obedience orientation

Stage 2 - Instrumental hedonism and concrete reciprocity

Conventional Level - Externally validated norms are internalized by the individual.

Stage 3 - Orientation to interpersonal relations of mutuality

Stage 4 - Maintenance of social order; fixed rules and authority

Post-conventional Level - Individual recognition that external norms may not fully encompass ethical behavior.

Stage 5 - Social contract, with conscience orientation

Stage 6 - Universal ethical principle orientation 
Inherent in the progression specified by Kohlberg are three primary types of ethical standards: self-interest, caring, and principle (Victor \& Cullen, 1987). Not coincidentally, these ethical standards correspond directly to the three classifications of moral philosophy noted above.

Kohlberg's theory of cognitive moral development shares another feature with moral philosophy. Researchers have shown that the levels and stages of moral reasoning in Kohlberg's model are distinct and relatively incompatible (Kohlberg, 1981; Gilligan, 1982; Haan, Aerts, \& Cooper, 1985). The continuing debate over the merits of various moral philosophies is indicative of their distinctiveness and incompatibility as well. This feature is important in the current context because it implies that organizations, like individuals, can be classified along these criteria, as postulated by the EWC construct.

\section{Locus of Analysis}

The second dimension of moral reasoning is the consideration of whom or what is included in the analysis. This level of consideration can range from solely the focal individual, the focal organization, to all of mankind, animals, the ecosystem, and all future generations.

Kohlberg's stages of moral development encompass this concept (Haan, Aerts, \& Cooper, 1985). In the first two stages, the locus of concern is the individual; in the third and fourth stages the individual's referent group becomes a larger social system; and in the highest stages consideration is given to humanity and other considerations as a whole.

Sociological theories of organizations also point to this differentiation in locus of analysis. Merton's (1957) work on organizational roles and reference groups identified different reference groups that influence individuals' behaviors and attitudes within the organization. He employed this information to distinguish between a local and a cosmopolitan role. In the local role, reference groups are contained within the organization, while cosmopolitan roles are defined outside the organization. Gouldner $(1957,1958)$ also used the concepts of local and cosmopolitan roles to distinguish the professional from the "organization man." In addition to the local and cosmopolitan loci of analysis, Victor and Cullen (1988) also specify the individual level. In this level, the ethical climate of the organization would support a referent for moral reasoning within the individual.

Although Victor and Cullen $(1987,1988)$ did not rely on moral philosophy as a basis for the locus of analysis dimension, philosophers have also discussed the question of who warrants moral consideration (Moberg \& Seabright, 2000). One of the first to discuss this concept was Deutsch $(1974,1985)$. He used the term "scope of justice," saying,

Justice is not involved in relations with others-such as heathens, 'inferior races,' heretics, 'perverts'-who are perceived to be outside one's potential moral community or opposed to it. An implication of this line of reasoning is that the narrower one's conception of one's community, the narrower will be the scope of situations in which one's actions will be governed by considerations of justice (Deutsch, 1985: 36-37). 
Staub (1989) and Opotow (1990) have approached the idea from the opposite perspective, by examining "moral exclusion." Moral exclusion takes place "when individuals or groups are perceived as outside the boundary in which moral values, rules, and considerations of fairness apply (Opotow, 1990: 1). Both of these concepts, scope of justice and moral exclusion, capture almost perfectly the essence of Victor and Cullen's $(1987,1988)$ locus of analysis.

Moral exclusion (and thus, also, its complement, locus of analysis) are best viewed as continua rather than as dichotomous variables. Moral exclusion implies partiality in moral deliberations and awareness, so that parties vary in their centrality to the agent's consideration. Parties central to the agent's moral community would be given full consideration, while those on the periphery or fully excluded could be merely overlooked or completely disregarded (Opotow, 1990; Moberg \& Seabright, 2000). This implies that the locus of analysis axis of Victor and Cullen's EWC construct $(1987,1988)$ should be viewed as a continuum, with gradations of those considered, rather than three distinct loci.

Similar to the distinctions between ethical theories, Merton (1957) and Gouldner (1957, 1958) also saw incompatibilities between the local and cosmopolitan roles. Victor and Cullen (1987, 1988) assumed that this incompatibility would also extend to the individual locus of analysis. Thus the EWC construct envisions distinct and relatively incompatible methods of moral reasoning, depending on the moral agent's locus of analysis. This allows the researcher to locate an ethical work climate within a specific intersection of ethical criterion and locus of analysis, without excessive concern over construct redundancy.

The idea of locus of analysis must be further clarified at this point. Although the loci of analysis identify the reference groups and limits of consideration in moral reasoning, it is important to note that the precise context will differ, depending on the ethical criterion employed. Thus, for the egoistic ethical criterion, an individual level of analysis would encompass solely the self; at the local level the referent group would be the organization (however that is defined for the particular study); and the cosmopolitan locus would embody the larger social or economic system. With the benevolence criterion, the loci of analysis set boundaries for "who belongs and who doesn't." Using the benevolence criterion at the individual level involves consideration of entities other than (and including) the agent, without reference to organizational membership; for the local level, the referent group is the organization as a whole; at the cosmopolitan locus, consideration is given to external stakeholders. The loci of analysis in the principle ethical criterion refer to the sources of ethical principles to be used. At the individual level of analysis, it is the agent's personal moral principles that guide the decision; at the local level, the organization's rules, standards, and procedures are the referent source; and at the cosmopolitan locus of analysis, external rules such as laws or professional codes govern the moral reasoning process (Victor \& Cullen, 1988).

\section{Theoretical Types of Ethical Climates}

Victor and Cullen $(1987,1988)$ combined the two dimensions of moral reasoning (ethical criteria and locus of analysis) to form a typology of theoretically possible ethical climate types. This is represented graphically in Table 2.1 . 
Table 2.1: Theoretical Ethical Climate Types

\begin{tabular}{|l|c|c|c|}
\hline LOCUS & INDIVIDUAL & LOCAL & COSMOPOLITAN \\
\hline EGOISM & Self-Interest & Company Interest & Efficiency \\
\hline BENEVOLENCE & Friendship & Team Play & $\begin{array}{c}\text { Social } \\
\text { Responsibility }\end{array}$ \\
\hline PRINCIPLE & Personal Morality & $\begin{array}{c}\text { Rules } \\
\text { The Law or } \\
\text { Professional Code }\end{array}$ \\
\hline
\end{tabular}

(Victor \& Cullen, 1987: 56)

In addition to providing the conceptual bases for ethical work climate, Victor and Cullen also devised a method for testing the construct. The result of this phase of the research is known as the Ethical Climate Questionnaire. Its theoretical bases, development, and current form are described in the following section.

\section{Measurement of Ethical Work Climate}

Victor and Cullen $(1987,1988)$ devised the Ethical Climate Questionnaire (ECQ) in keeping with the "climate approach" advocated by Schneider (1983). The instrument was "developed to tap respondents' perceptions of how the members of their respective organizations typically make decisions concerning various 'events, practices, and procedures' requiring ethical criteria" (Victor \& Cullen, 1988: 109).

So conceived, the questionnaire was originally written with thirty-six climate descriptors, four for each of the nine theoretically possible climate types. Each descriptor was to be rated by the respondent (based on how he or she perceived it really was in his or her organization, not how he or she preferred it to be) on a six-point Likert-type scale, ranging from "completely false" to "completely true." The questionnaire was then administered to thirty-five university faculty members. They were asked to complete the questionnaire and note any ambiguities or other problems in the instrument. Based on the feedback received from this pilot study, the questionnaire was revised before being used in further research projects. The originators have reported results of three separate tests using the ECQ (Victor \& Cullen, 1987, 1988; Cullen, Victor, \& Bronson, 1993). Twenty-five descriptors were used in the first of these, twenty-six in the second, and thirty-six in the third. Several other researchers have used the ECQ in other studies. Some have used all thirty-six descriptors from the 1993 study, and others have used twenty-six from the earlier studies, or just selected descriptors from verified climate types. One of these studies (J. Weber, 1995) asked the respondents to rank the seven descriptors that best described the values embodied in their group's decision processes. This was done to avoid the 
social desirability bias often encountered when using Likert scales in business ethics survey research (Ravlin \& Meglino, 1987; Randall \& Gibson, 1990).

It is important to note that the ECQ was specifically designed to measure respondents' perceptions of the form of ethical reasoning rather than the content (Victor \& Cullen, 1988). Kohlberg (1984) too differentiates between the content - the possible outcomes of the decisionmaking process - and the form - the structure of the decision-making process itself. This distinction was made by Victor and Cullen in order to address the question of work climate conceptualization, that of differentiating between descriptions of climate and worker attitudes (Schneider \& Reichers, 1983; Reichers \& Schneider, 1990, Hofstede, 1998).

More than twenty separate research projects have employed the EWC construct and ECQ. The next section will summarize the results of those studies.

\section{Results of Studies on Ethical Work Climate}

Victor \& Cullen, 1987. The ECQ with twenty-five descriptors was administered to four distinct employed groups: a general managerial sample of employed students in a Masters of Business Administration program $(\mathrm{n}=75)$; twenty-five faculty members at a midwestern university; twenty-nine military personnel; and seventeen managers from a trucking firm. A factor analysis of the results of the survey was performed, verifying six of the theoretical climate types. The climates identified in this study are shown in Table 2.2.

Table 2.2: Identified Ethical Climate Types

\begin{tabular}{|c|c|c|c|}
\hline CRITERION & INDIVIDUAL & LOCAL & COSMOPOLITAN \\
\hline EGOISM & \multicolumn{2}{|c|}{ Instrumental } & Efficiency \\
\hline BENEVOLENCE & \multicolumn{2}{|c|}{ Caring } & \\
\hline PRINCIPLE & Independence & Rules & \\
\hline
\end{tabular}

(Victor \& Cullen, 1987)

Because climate is a "shared perception" and the purpose of this study was primarily instrument development, Victor and Cullen purposely chose a group that should have had a lower degree of internal consistency. The MBA students who comprised one of the groups were employed by a wide variety of firms. The results of discriminant analysis and analyses of variance performed on the four groups confirmed the authors' proposition. The internal consistency for the MBA students was lower than for any of the groups comprised from a single 
organization, thus confirming Joyce and Slocum's $(1979,1984)$ second requirement to establish the existence of an organizational climate. In addition, Victor and Cullen's finding indicates that surveying individuals employed by a number of different companies is not a valid measurement technique for ethical climate research.

Based on the criteria for evidence of an organizational climate proposed by Joyce and Slocum $(1979,1984)$, the results of statistical analysis on these data indicate that ethical work climate does exist. Victor and Cullen found both differences in the mean perceptions between organizations and internal consistency in perceptions within single organizations (see the discussion of the MBA group in the preceding paragraph). Furthermore, there were predictable relationships between mean perceptions and organizational characteristics. For example, the military climate had the highest rules factor and the academic climate indicated a higher emphasis on independence. While Victor and Cullen called for further instrument development, they concluded that ethical work climate is a valid construct, and that further research was warranted.

Victor \& Cullen, 1988. In this study, four firms of varying size and industry were selected to survey. These included a printing company with thirty-three employees, a savings and loan with 450 employees, a manufacturing plant $(n=200$ managers $)$, and a local telephone company ( $\mathrm{n}=500$ non-union employees). A response rate of seventy-four percent was achieved, providing 872 usable surveys. The version of the ECQ used in this study was the same as in the 1987 study, with one additional descriptor included. A factor analysis of the data revealed the existence of five distinct ethical climates, as shown in Table 2.3.

Table 2.3: Identified Ethical Climate Types

\begin{tabular}{|c|c|c|c|}
\hline$\overbrace{\text { CRITERION }}^{\text {LOCUS }}$ & INDIVIDUAL & LOCAL & COSMOPOLITAN \\
\hline EGOISM & \multicolumn{2}{|c|}{ Instrumental } & \multirow{2}{*}{ Caring * } \\
\hline BENEVOLENCE & \multicolumn{2}{|c|}{ Caring } & \\
\hline PRINCIPLE & Independence & Rules & Law and Code $* *$ \\
\hline
\end{tabular}

* Changed from Victor \& Cullen, 1987

** This climate remained the same as Victor \& Cullen, 1987, but was renamed

(Victor \& Cullen, 1988) 
As noted in Table 2.3, two of the climate types differed from those found in the 1987 study. The egoism criterion/cosmopolitan locus was found to be a "caring" climate instead of the earlier finding of an "efficiency" climate, and the benevolence criterion/cosmopolitan locus was also found to be a "caring" climate instead of the earlier "professional" climate. Victor and Cullen believed that the instability of the egoism/cosmopolitan items could be traced to the particular meanings they conveyed within the contexts of each organization (e.g., efficiency being more embedded in the manufacturing plant than in other sites). Also note that the principle criterion/cosmopolitan locus was simply renamed "law and code" although it exhibited the same factor loadings as the 1987 study.

Based on the results of this study, Victor and Cullen provide additional evidence of the existence of ethical work climate.

Cullen, Victor, \& Bronson, 1993. This study employed a revised ECQ that encompassed the twenty-six descriptors in the 1988 survey and added ten more. Thus, the 1993 ECQ returned to four descriptors for each of the nine potential climate types. Four accounting firms were surveyed for the 1993 report, including 149 respondents. This study verified seven distinct climate types, as shown in Table 2.4 .

Table 2.4: Identified Ethical Climate Types

\begin{tabular}{|l|c|c|c|}
\hline LOCUS & INDIVIDUAL & LOCAL & COSMOPOLITAN \\
\hline EGOISM & Instrumental * & Efficiency \\
\hline BENEVOLENCE & \multicolumn{2}{|c|}{ Caring * } & $\begin{array}{c}\text { Social } * * \\
\text { Responsibility }\end{array}$ \\
\hline PRINCIPLE & Independence $*$ & Rules $*$ & Law and Code $*$ \\
\hline
\end{tabular}

* Identified in all three studies in which Victor and Cullen participated

** Newly identified climate type, based on descriptors added for this study

(Cullen, Victor, \& Bronson, 1993)

Six of the nine theoretically possible ethical climate types were confirmed for the third time in this study, as noted in Table 2.4. The "social responsibility" climate found in the benevolence criterion/cosmopolitan locus is new in this study, and loaded on factors new to this version of the ECQ. The blank found in the egoistic criterion/local locus is because of the fact that the descriptors for this climate type either did not load on meaningful factors or did not contribute to the reliability of the factor. 
The authors conclude that they have produced reliable evidence that ethical climates are perceived at the psychological level. However, because of the small number of organizations sampled (they claim twelve, but one of the groups in the 1987 study was actually a collection of MBA students employed by different organizations, thus reducing the number to eleven) and lack of industrial diversity among the organizations sampled (four of the eleven were accounting firms), the authors are loath to confirm the existence of ethical climates at the group level.

J. Weber, 1995. This was the first study published that attempted to link EWC to another level of analysis, in this case, the types of departments within a given organization (Thompson, 1967). James Weber surveyed 167 employees of a large, midwestern financial institution, representing technical core, buffer, and boundary spanning departments. The 1988 version of the ECQ was employed, with the same twenty-six descriptors used by Victor and Cullen.

Although Weber did not specifically report a factor analysis of the ECQ results, the majority of his hypotheses linking types of departments with EWC were supported, thus lending indirect support for the five climate types found in Victor and Cullen's 1988 study. This study was the first to specifically target ethical subclimates, and find empirical evidence to support the concept of differences between and consistency within work groups (Joyce \& Slocum, 1979, 1984).

Weber did report a tendency of the subjects in a pre-test phase to rate the descriptors at the high end or the low end of the Likert scale that he was using at the time. To avoid the possibility of a social desirability bias often noted in business ethics surveys (Randall \& Gibson, 1990), Weber switched to a ranking procedure during the actual survey. Respondents were asked to rank the seven descriptors that best described the values embodied in their group's decision processes. The use of ranking has been found to be very reliable (Ravlin \& Meglino, 1987). Weber suggests that future research utilizing the ECQ be performed in a similar manner.

Wimbush, Shepard, \& Markham, 1997a. The purpose of this study was to determine whether the ethical climate types identified by Victor and Cullen $(1987,1988)$ could be verified in a multi-unit organization. This research also implicitly built on Weber's work with ethical subclimates. This study surveyed 639 employees of a national retail chain. Fifty of the respondents worked in the credit department, sixty-four were in the central office, and 525 were commissioned salespeople in the retail stores. The 1993 version of the ECQ with thirty-six descriptors was used. The authors found the existence of four distinct climate types, as shown in Table 2.5.

One of the climate types, labeled "service," was not previously identified by other researchers, and the "caring" climate previously noted by Victor and Cullen was mixed in this study. Some the factors that loaded on the "caring" climate in the 1997a study also loaded on "caring" for Victor and Cullen, but some had previously loaded on "instrumental."

This study, because it surveyed three distinctly different types of work groups, could be useful in validating the existence of ethical climates at the work group level of analysis. However, because there were no statistically significant differences between the three work 
groups with respect to the instrumental ethical climate, and there were mixed results with the other climates, only partial support can be claimed for Victor and Cullen's hypotheses.

Table 2.5: Identified Ethical Climate Types

\begin{tabular}{|l|c|c|c|}
\hline CRITERION & INDIVIDUAL & LOCAL & COSMOPOLITAN \\
\hline EGOISM & Instrumental & & \\
\hline BENEVOLENCE & $*$ & & Service $* *$ \\
\hline PRINCIPLE & Independence & $* * *$ & Law and Code \\
\hline
\end{tabular}

* $\quad$ Factor analysis was mixed

** $\quad$ Climate type not previously identified

*** No distinction found between Law and Code climate type

(Wimbush, Shepard, \& Markham, 1997a)

Wimbush, Shepard, \& Markham, 1997b. This research utilized the same data pool as the authors' 1997a study. This was the first study published whose purpose was to determine if there is a relationship between EWC and ethical behavior-an important point, because it introduced an explicitly normative component into the purportedly descriptive EWC literature. Because of the focused purpose of the research, analysis was performed only on the 525 commissioned sales people who worked in the retail chain's stores. The 1993 version of the ECQ with thirty-six descriptors was used. The authors found the existence of five distinct climate types, as shown in Table 2.6.

As in their 1997a study, the authors found a "service" climate that Victor and Cullen had not previously verified. However, unlike the 1997a report, this study did verify a "caring" climate, as had Victor and Cullen.

Because of its focus on just one work group, and the insignificance of findings at the district level of aggregation, this study will add little support for my dissertation. 
Table 2.6: Identified Ethical Climate Types

\begin{tabular}{|l|c|c|c|}
\hline CRITERION & INDIVIDUAL & LOCAL & COSMOPOLITAN \\
\hline EGOISM & Instrumental & & \\
\hline BENEVOLENCE & Caring & & Service \\
\hline PRINCIPLE & Independence & $*$ & Law and Code \\
\hline
\end{tabular}

- No distinction found between Law and Code climate type

(Wimbush, Shepard, \& Markham, 1997b)

Agarwal \& Malloy, 1999. The authors applied the EWC construct for the first time to the not-for-profit sector. The subjects for the study were 148 members of a Canadian provincial sport federation. The ECQ used in this study was the 1993, thirty-six descriptor version, with slight modifications made to conform to the non-profit context.

Five climate types were verified, but were somewhat different than previous types identified by Victor and Cullen. The climates identified by Agarwal and Malloy are shown in Table 2.7.

The authors identified two distinct "caring" climates, one at the individual locus of analysis, the other at the cosmopolitan level. They also noted the lack of any verifiable climates at the local level of analysis. Agarwal and Malloy (1999) contend that this is because organizational rules and procedures are not the typical subclimates in non-profits, as they are in the for-profit sector. Instead, the climates are polarized between the individual and cosmopolitan levels.

Even though this study focuses on sub-units within one organization, it is clearly distinct from other types of organizations surveyed to date. The fact that no local level climate types were identified lends credence to the existence of organizational ethical climates, at least on Joyce and Slocum's $(1979,1984)$ "difference between" criterion. 
Table 2.7: Identified Ethical Climate Types

\begin{tabular}{|l|c|c|c|}
\hline CRITERION & INDIVIDUAL & LOCAL & COSMOPOLITAN \\
\hline EGOISM & Machiavellianism * & & \\
\hline BENEVOLENCE & Individual Caring ** & & Social Caring ** \\
\hline PRINCIPLE & Independence & & Law and Code \\
\hline
\end{tabular}

* This climate type replicated previously identified types, but was renamed

** Previous studies had identified "caring" climate types, but this study found distinctions between these two types

(Agarwal \& Malloy, 1999)

Treviño, Butterfield, \& McCabe, 1998. Treviño first introduced the idea of an ethical culture several years ago (Treviño, 1990). In this study the authors used two separate questionnaires to measure the independent variables of ethical work climate and ethical work culture. The thirty-six item ECQ used in Cullen, Victor, and Bronson's 1993 study was used to capture the climate variable, while a new questionnaire was developed by the authors to measure culture. These independent variables were tested for correlations with dependent variables of organizational commitment and observed unethical behavior. Survey respondents were alumni from two private colleges in the northeastern United States $(n=318)$.

A factor analysis of the survey results identified ten separate ethical context factors. Each of the factors was derived either from climate measures or culture measures - none of the factors had combined items from climate and culture. According to the authors this provided empirical evidence of distinction between the climate and culture constructs. The authors contend that this study generally replicated previous factor analyses of climate types, implying that future research can continue to use the ethical work climate construct. However the authors also point to the usefulness of the culture construct, particularly in predicting ethical conduct in organizations with a code of ethics. Inclusion of cultural factors, particularly leadership and reward systems, is thought to provide a more comprehensive picture of the influences on moral behavior.

The authors conclude that there is a large degree of overlap between the two constructs, reflecting a broader, long-standing debate over the meaning and importance of organizational climate/culture (see footnote 3). Many researchers are now using the terms interchangeably, and the primary differences between the two may not indicate an actual distinction in the constructs, 
but may be a difference in the research perspectives taken on the concepts (Pettigrew, 1990; Denison, 1996).

This study provides evidence of an organizational culture factor that influences employee behavior, in addition to verifying previously identified ethical climate factors. However, my dissertation will not include the culture factor for several reasons. First, as noted in footnote 3, this debate is not specifically pertinent to my research question. Second, the culture factor found in the Treviño, Butterfield, and McCabe (1998) study has not been validated by other researchers. In fact, Key (1999) questions whether the culture questionnaire measures shared beliefs about an organization's culture at all. Results of Key's study suggest that what is being measured is individual perceptions regarding organizational ethics. ${ }^{4}$ Key's results bring up the third reason for my not using the culture factor in my dissertation. In the Treviño, Butterfield, and McCabe (1998) study, the individuals surveyed presumably did not all work for the same organization, or even a small number of organizations. The survey pool was a group of alumni from two colleges, but the survey items asked about their work environments, not a shared environment. Thus, there could be no valid aggregation of "shared perceptions."

Other Studies. Several studies have attempted to correlate aspects of EWC with other organizational variables. These include linking ethical climate with ethical behavior and success (Deshpande, 1996a); ethical climate types and facets of job satisfaction (Deshpande, 1996b); ethical climate and conflict with stress in the sales force (Schwepker, Ferrell, \& Ingram, 1997); ethical climate and sales managers' intentions to reward or punish sales force behaviors (DeConinck \& Lewis, 1997); ethical climate and person-organization fit (Sims \& Keon, 1997); ethical climate and moral reasoning (Brower \& Shrader, 2000); and ethical climates and the ethical dimension of decision making (Fritzsche, 2000). In addition, other researchers have attempted to develop different constructs describing ethical climate/culture (Treviño, 1990; Cohen, 1995; Treviño, Butterfield, \& McCabe, 1998; Babin, Boles, \& Robin, 2000). Primarily because of methodological deficiencies, the studies employing the EWC construct provide only limited empirical support for the theoretical construct, but they and the other proposed constructs do indicate the widening interest in and acceptance of ethical climates.

\section{Summary of Previous Research}

Based on the results of the studies reviewed in the previous section, several conclusions can be reached. First, four of the predicted climate types (Instrumental, Caring, Independence, and Laws and Code) have been verified in all of the studies done to date, thus providing strong evidence of their existence. Second, the climate types within the local locus of analysis have been particularly unstable. This could indicate a problem with the ECQ, or more likely, could indicate a lack of identification at the organizational level (VanSandt \& Neck, forthcoming). As one author notes:

Our findings about the central role of practices in organizational culture contrast with the common belief in the management literature (e.g. Peters and Waterman 1982) that shared values are the core of an organization's culture. The

\footnotetext{
${ }^{4}$ Key refers to a Treviño, Butterfield, and McCabe paper presented at the 1995 Academy of Management meeting instead of the 1998 paper reviewed here. The 1995 paper is subsumed in the 1998 article (Treviño, 1999).
} 
disagreement can be understood from the fact that the management literature nearly always draws its information about company values from managers, even top managers. We surveyed samples of the total populations, as we believe that an organization's culture is located in the mental programmes of all members of the organization. There is little doubt that practices are designed according to the values of the founders and, in later phases, of significant top managers of the organization in question, but this does not mean that all members of the organization share these values. A work organization is not a total institution. Members have to follow the practices if they want to remain members, but they do not have to confess to the values. Leaders' values become followers' practices (Hofstede, 1998:482-483, author's emphasis).

If Hofstede's observations are accurate, the lack of worker "buy-in" could conceivably affect respondents' answers to the ECQ at the local level. Given the recent decline in job security in the United States (The New York Times, 1996), it would not be surprising to find that workers (including middle and upper level managers) discount the organizational level values inherent in the local locus of analysis.

The third conclusion that comes out of the studies is that, for the most part, the conceptual and measurement issues inherent in climate research have been adequately answered in the EWC studies. The primary conceptual issue of whether climate is descriptive (what does happen) or normative (what the respondent would like to happen) in content has been resolved by careful wording of the questionnaire items and instructions to "emphasize the description of, rather than feelings about, the work setting" (Victor \& Cullen, 1987: 58). The "multidimensional issue" in climate measurement (Schneider \& Reichers, 1983) is obviated by the focus on the ethical work climate. The aggregation problem in measuring climate-making sure that what is being measured is organizational reality, not merely individuals' perceptions - is, as Schneider and Reichers (1983) noted, the remaining sticky issue. Several of the studies reviewed did survey multiple respondents within a single organization, and some also surveyed multiple organizations within the same study. This type of research design allowed those studies to answer Joyce and Slocum's (1979: 32) question, "How can we meaningfully aggregate individual's descriptions of their work environment so as to represent larger social units?" However, some of the studies did not survey individuals from the same organizations. Consequently the results of those surveys are not able to answer the aggregation problem. The research design for this dissertation (see Chapter 3 ) will fully consider this issue.

The final conclusion to be drawn from these studies is that since the basic construct and measure are valid, further research in this area may be conducted, answering specific questions unaddressed by the earlier studies. My dissertation will contribute to the field by:

- Providing further validation of the EWC construct

- Examining the relation between aggregate-level EWC and individual-level moral awareness

- Emphasizing the tacit prescriptive component of ethical work climate research. 


\section{The Relation of Ethical Work Climate to Moral Awareness}

Chapter 1 established the historical and theoretical background for a potential relationship between an organization's ethical work climate and moral awareness. In this section I will review the current literature for further support of this link.

Wimbush and Shepard (1994) state that studies they reviewed provide substantial evidence that there is a direct relationship between organizational climate and behavior. Some of the studies reviewed herein postulate a relationship between EWC and ethical behavior. As I described in Chapter 1 and will explicate further in the next section, moral awareness is a necessary and integral part of moral behavior (Blum, 1991; Rest, 1994). Some of the researchers come even closer to specifically recognizing the moral awareness concept. For example, Victor and Cullen (1987: 55) note that "the dominant type of ethical climate in an organization may influence the types of ethical conflicts considered," a short leap to "recognition." Cullen, Victor, and Stephens (1989: 51) state, "The company's ethical climate helps to determine... which issues organization members consider to be ethically pertinent..." Wyld and Jones (1997) propose that ethical climate does not affect just the final decision, but the entire decision-making process, from issue recognition (or non-recognition) to conclusion. Finally, in her 1995 paper, Cohen states that the moral climates of organizations (a construct that she equates with ethical work climate) are used to address issues with a moral component. "These issues include identifying moral problems..." (Cohen, 1995: 318, emphasis added).

Thus, several researchers have acknowledged the possible connection between ethical work climate and various constructs resembling moral awareness. With that, I will turn to an examination of the literature related to moral awareness.

\section{MORAL AWARENESS}

\section{Definition}

I define moral awareness as the degree to which an individual recognizes the aspects of a situation that carry a reasonable likelihood of moral wrong or harm to individuals, classes of people, or other entities--human or non-human, living or reifications. Harm is used as a criterion on the assumptions that if a given action brings universal benefit there is no moral dilemma, and that most people view morality in terms of harm to self or others.

This definition is similar to others used in the literature. Butterfield, Treviño, and Weaver (1997: 3) believe that "Moral awareness occurs when a person realizes that his/her response to a given issue could affect the interests, welfare, or expectations of the self or others in a fashion which may conflict with one or more ethical standards or norms." Rest (1994: 23) states, "Moral sensitivity is the awareness of how our actions affect other people. It involves being aware of different possible lines of action and how each line of action could affect the parties concerned. It involves imaginatively constructing possible scenarios, and knowing causeconsequence chains of events in the real world; it involves empathy and role-taking skills." 
One significant difference between my definition and some of the others is the notion of “degree." Butterfield, Treviño, and Weaver and Rest see moral awareness as an either/or state. Either the moral agent is aware of the moral components of a situation or she is not. But as Blum $(1991,1994)$ emphasizes, moral awareness is a more complex state than these other definitions imply.

Blum is the only person who has written about the process and state of moral perception to any significant extent. His primary purposes in doing so were to distinguish perception from judgment in moral reflection and to emphasize the importance of awareness in the process (Blum, 1991, 1994). He includes in perception "anything contributing to or encompassed within the agent's take on the situation - his salience-perception - prior to his deliberating about what to do" (Blum, 1991: 707). This includes not only the way in which people perceive particular situations, but also their ability to recognize the morally significant components as moral situations.

\section{The Complexity of Moral Awareness}

To further explicate this idea, Blum discusses three aspects of complete moral awareness. The first of these is an initial recognition of the moral component of a situation. Blum (1991) uses an example to make his point: A woman carrying two heavy shopping bags gets onto a crowded subway train. One of the passengers (John) already seated on the train is cognizant of her presence, but is not particularly paying attention to her. Another passenger, Joan, not only is aware of her presence, but also perceives her discomfort. Blum uses these "different levels" of awareness to clarify the difference between John's "perception" of the particular situation and Joan's recognition of the moral component as a moral situation. The woman's discomfort was a salient feature of the situation for Joan (who was morally aware) but was not for John (who was morally unaware).

The second aspect involves fully grasping what the moral component of a situation means to the party(ies) affected. Blum (1991: 705) notes, "[A]dequate moral perception is not only a matter of making 'moral discriminations'-noting morally distinct elements in the situation. It is also a matter of the moral aspect of the situation...weighing adequately within one's...view of the situation....[There is] the necessarily affective dimension to the empathic understanding which is often...required for fully adequate moral perception."

This notion evokes David Hume's and Adam Smith's emphasis on the role of sympathy in overcoming exclusive self-interest (Hume, 1751; Smith, 1759/1986).

Sympathy, in Smith's technical use of the term, is not empathy, but rather, an agreement or understanding of sentiments. When I sympathize I place myself in another's situation, not because of how that situation might affect me, but rather as if I were that person in that situation. I truly project myself into another's experience, according to Smith, in order to understand, although not experience, what another person is feeling rather than merely relate that situation to my own. Sympathy, then, is the comprehension of what another feels or might feels (sic) in 
a situation, but it is not an experiential or sentimental identification with that feeling (Werhane, 1998: 81).

The third aspect of full moral perception involves the agent's ability to construe situations in ways that elicit their moral components, and to infer motives that may have moral significance. (Although Blum did not delineate construal and inference as separate conditions of moral awareness, the two concepts are sufficiently distinct that he could have specified a fourth aspect. For moral awareness in business situations, it seems that construal-being able to see a situation in a certain way or from a certain viewpoint - is more critical than is inference of motives.) Blum (1991: 706) again uses an example to vivify his idea: "Tim, a white male, is waiting for a taxi at a train station. Waiting near him are a black woman and her daughter. A cab comes by, past the woman and her daughter, and stops in front of him. Tim, with relief, gets in the cab." According to Blum, in order for Tim to see the moral significance in this circumstance he must be able to construe the situation as the cab passing up the woman and her child, rather than just as his good fortune in hailing a cab. In addition, Tim would have to be able to infer the driver's motive in passing by the black woman and her daughter. Blum notes that both construal and inference require some degree of moral imagination, a concept also invoked by Werhane (1998). Blum further points out that these abilities depend on the agent already having certain moral categories - if, for example, Tim had never heard of racism or sexism, he would have no frame of reference within which he could construe the situation as morally significant.

This third aspect (but perhaps not the "fourth" of inference of motives) has profound implications for the research question in this dissertation. Organizational climate wields significant influence over individuals' perceptions and behaviors, as previously discussed. If the climate in an organization discourages the members from making construals, the members' abilities to perceive moral components will most likely be inhibited. Gioia (1992) has shown the constraints that organizational scripts place on individuals' cognitive processes. In a similar vein, framing or problem setting plays a critical role in problem solving (Stephens \& Lewin, 1992; Baucus \& Rechner, 1995, 1996; Rechner \& Baucus, 1997). "As Bolman and Deal...note: 'Frames are both windows on the world and lenses that bring the world in to focus. Frames filter some things while allowing others to pass through easily. Frames help us to order experiences and decide what action to take.' Frames also determine what information-or ethical dimensions of a situation or issue - we attend to and what we omit or ignore" (Rechner \& Baucus, 1997: 246). Ethical work climate is a broader construct than either scripts or frames, and as such, should wield even more influence over a group member's ability to recognize moral elements in a situation.

Two final points should be made regarding the complexity of moral awareness. First, as Blum (1991: 715-716) notes, "[S]ituational perception is not a unified capacity. Different parts of one's moral makeup are brought to bear in 'seeing' (and not seeing) different features of situations, of moral reality. Different aspects of moral reality can draw on different sorts of sensitivities or forms of awareness....Some people are better at perceiving some sorts of particulars than other sorts." In addition, some people are more sensitive to the plights of different classes of humans (e.g. children, the poor, or the aged) or other affected parties such as animals or the physical environment. 
The second point is that moral awareness, once achieved, is not a static state. In the description of his Four Component Model of moral behavior, Rest (1994) notes that there are complex interactions among all four stages. Although he notes that moral cognition must precede moral judgment, Rest is very clear that his model does not represent a sequential ordermoral judgment (the second component), moral motivation (the third component), and moral character (the fourth component) can and do influence the first stage, moral sensitivity. Blum also acknowledges the interaction of moral perception and judgment: "Once an agent begins deliberating in a situation, the process of deliberation can further affect her perception of the situation" (Blum, 1991: 707).

Blum has pointed out several aspects of moral awareness. Measurement of moral awareness in this dissertation, as described in Chapter 3, will indicate the existence of salience, sympathy, and construal, as described by Blum. However, inference of motives will not necessarily be a factor in respondents' recognition and identification of moral issues. I will say more about this topic in Chapter 3.

Having defined and described moral awareness, the question arises, "Why is it important?" This question will be examined in the next section.

\section{The Importance of Moral Awareness}

Blum, a philosopher, argues that moral perception is a good in its own right. He claims, "We praise, admire, and encourage correct perception and moral insight prior to and partly independent of its issuing in right action" (Blum, 1991: 713). Although I do not dispute Blum's argument, in this dissertation I take a more pragmatic view of the value of moral awareness, in its role as a necessary precursor to moral behavior.

In general terms, perception or identification of the problem is the first step in the problem-solving process, without which no further reflection or action can take place (Kuhn, 1963, 1974). As a determinant of moral behavior, Rest $(1986,1994)$ states that moral cognition must occur before moral judgment can begin (this is the one exception he makes to his admonition that all four components interact with each other). A corollary to this idea is that moral action can occur without prior moral awareness of a situation (i.e. one can do something that affects others in a morally significant way without having been aware beforehand of the moral implications of the action); however, doing so precludes any possibility of moral deliberation about the action. This type of scenario is precisely what most business people attempt to avoid - acting without knowing the ramifications of the action.

Jones and Ryan (1997: 431) point out that "The moral agent must first recognize the moral issue. An agent who does not recognize the moral aspects of an issue will certainly rely on 'non-moral' criteria in making a decision." Ramifications for businesses acting without moral awareness can be disastrous (Butterfield, Treviño, \& Weaver, 1997).

In short, "perception is the setting for action" (Blum, 1991: 703). Blasi (1980: 8) notes, "Almost any action can be relevant to morality if it is perceived as relevant by the agent, whereas no action is appropriate if the agent does not see its moral import." 
If, as others and I have argued, moral awareness is both complex and important, it would appear that researchers would want to know how this capacity is developed in humans. The next sections will address these issues.

\section{The Promotion of Individual Moral Awareness in Organizations}

The central idea of this section is addressed in the question, "Do people differ in their readiness to interpret the world in moral terms?" (Blasi, 1980: 40). To this Blum answers an emphatic "yes." He states, "[T]he way people perceive particular situations, and their ability to discern the morally significant character of particular situations, is not mysterious and ineffable but is bound up with general features of people's character and their moral makeup. This is partly because...the perception of particularities is often a sensitivity to particular sorts of moral features-injustice, racism, physical pain, discomfort-and general things can be said about what promotes those sensitivities, about the obstacles to such sensitivities, and about how such sensitivities develop (Blum, 1991: 715). Some of the contributing factors may be imagination, attention, empathy, critical reason, habit, and exposure to new moral categories (Blum, 1991). Recent research has also shown the effects of certain demographic factors on ethical attitudes (which can be considered analogous to moral awareness), such as gender, age, career stage, education level, and ethics education (Luthar, DiBattista, \& Gautschi, 1997). In their Model of Moral Perception in Organizations, Butterfield, Treviño, and Weaver (1996) postulate that individual characteristics are one of three general categories of influence on moral awareness in organizational settings. The only specific individual characteristic they offer for examination is locus of control, which, in their empirical findings, received only mixed support as an influence.

Of more interest in this dissertation are potential organizational or societal progenitors of moral awareness. Chapter 1 examined these in some detail. Durkheim's work on social facts and the primacy of society over the individual and Kohlberg's theory of cognitive moral development both expressed the strong influence of the group on individuals' perceptions.

I have argued that a specific social influence, the amoral theory of business (the view that the economic institution is somewhat separate from other institutions and immune to some moral regulations), is quite possibly a major factor in the breakdown of moral awareness and behavior in business settings. If the amoral theory of business is indeed the dominant paradigm, the overarching social milieux in business would tend to make moral awareness less important to the organization, thus leading to its diminution. Therefore, if specific organizations seek to mitigate the effects of the amoral theory of business, it is incumbent upon those organizations to provide countervailing milieux within their boundaries. The question is how this can be done.

Although most researchers seem to agree that social and organizational factors have a strong impact on moral behavior (including moral awareness), very few have specified or tested those influences (Butterfield, Treviño, \& Weaver, 1996, 1997; Jones \& Ryan, 1998 are exceptions). Jones and Ryan (1997: 665) note, "Most of the models that purport to explain moral decision making [which encompasses moral awareness] in organizations...contain an element that refers to organizational or environmental influences on the moral agent, but few provide much in the way of detail regarding how these influences work." Butterfield, Treviño, and Weaver's $(1996,1997)$ Model of Moral Perception in Organizations argues that organizational 
socialization, in the form of norms and framing, influence moral awareness. This dissertation, which examines the effects that EWC has on individual moral awareness, also addresses the question of how these influences work. The few existing studies on moral awareness will be reviewed in the following section.

\section{Results of Studies on Moral Awareness}

The role of moral awareness in decision making and behavior has received scant attention in theoretical models and even less empirical investigation (Blum, 1991; Jones, 1991; Butterfield, Treviño, \& Weaver, 1996, 1997; Jones \& Ryan, 1997, 1998). The following summaries review the only empirical studies involving moral awareness in business settings done to date.

Butterfield, Treviño, \& Weaver, 1996. In this study the authors introduce their Model of Moral Perception in Organizations that postulates three primary influences on moral awareness - organizational socialization (including norms and framing), moral intensity of the issue, and individual characteristics. Subjects included 138 MBA students, most of whom were formerly employed full-time in business organizations. The study sought to relate four independent variables - organizational norms, framing, moral intensity, and individual locus of control - to the dependent variable, moral awareness. The authors hypothesized direct relationships between each of the independent variables and moral awareness. Partial support was found for all four hypotheses.

Because measurement of moral awareness is particularly problematic, it is instructive to review the techniques employed in this study. Each respondent was asked to read four scenarios (two versions each of two different scenarios) and respond to an eleven-item questionnaire for each version. Results were then analyzed using multiple regression techniques. Separate regressions were run, one employing relatively objective scenario manipulations (measured by zero or one, depending on the moral intensity, framing, and norms variables), and the other based on perceptual measures of these variables.

This was the first study done in the business ethics field that attempted to measure antecedents of moral awareness empirically. It presented a basis from which measurement scales can be further developed and refined, and provided preliminary evidence of the validity of these measures.

Treviño \& Weaver, 1996. The purpose of this qualitative study was to build an empirically-grounded theory of the antecedents of moral awareness. The authors interviewed twenty-five practitioners in the competitive intelligence (CI) field, using open-ended questions designed to elicit comments regarding ethical dilemmas in their profession. Interview notes or tapes were transcribed and analyzed using a three-phase content analysis procedure (Glaser \& Strauss, 1967; Miles \& Huberman, 1984). This involved a "unitizing" phase in which the transcripts were broken down into "thought units;" a "categorizing" phase in which patterns in the thought units were identified; and an identification of gaps and failures to perceive potential ethical issues involved in the CI field. 
Because of the research design in this study, it is not directly applicable to my study of EWC as an antecedent of moral awareness. Many of the interviewees were CI consultants who work on their own or corporate CI practitioners who received little guidance from their organizations regarding ethical issues. As a result the researchers found out more about individual standards for moral perception than they did organizational influences. However, as the researchers note, "In the absence of organizational norms and structures, individuals' ethical sensitivities and what they recognize (and do not recognize) as ethical issues are influenced by the broader social context that includes the law, the media, previous work settings, and the family" (Treviño \& Weaver, 1996: 29). Their conclusion provides additional support for the approach taken in this dissertation: "In fact, these influences are 'individual' only to the extent that they differ from person to person. One person may rely on reference to his or her mother's standards, another a grandmother, another the Wall Street Journal. To that extent, it is impossible to predict the standards being used. But, these findings also support views of morality as primarily social in nature [as Durkheim discussed] and suggest that, in the absence of organizational support and guidance, individuals look to other social sources of guidance about what they should attend to" (Treviño \& Weaver, 1996: 30-31).

Butterfield, Treviño, \& Weaver, 1997, 2000. In a follow-up to their 1996 study, the authors surveyed 291 members of the Society for Competitive Intelligence Professionals. The focus in this study was limited to societal and organizational norms and framing (the individual locus of control variable from the 1996 research was not considered). Respondents were asked to answer questions assessing the norms in their organizations, and the other two independent variables were manipulated in the scenarios that were used to measure moral awareness.

Moral awareness was measured using a qualitative approach that asked the respondents to: 1) list and rank the relative importance of issues they felt were important in the scenarios (no cues were provided by the researchers as to what issues could or should be considered), and 2) answer open-ended questions designed to allow spontaneous discussions of the issues that seemed important. All of the qualitative measures were considered by the authors, but only the issue identification and ranking was used to create the dependent variable measure. A post hoc content analysis of the data was conducted to provide additional insight into the nature of moral awareness in organizations.

Support was found for three of the four hypotheses in the study. These three were that a.) company/industry norms supporting ethics, b.) framing that utilizes moral language, and c.) the magnitude of consequences (operationalized as harm to a competitor) are positively correlated with moral awareness. The fourth hypothesis, that company norms encouraging harming a competitor would decrease moral awareness, was not supported.

This study is of particular significance to my dissertation because of the method used to measure moral awareness. As fully described in Chapter 3, the methods I use to gauge moral awareness in my study closely resemble the methods used by Butterfield, Treviño, and Weaver (1997), a prior version of the authors' paper published in 2000. In the 1997 paper, the authors included the respondents' ratings of the importance of the ethical issue in their measure of moral awareness, but the 2000 paper employed a dichotomous variable ( 1 or 0 ) to indicate whether an 
ethical issue had been identified or not. Similar techniques have also been used in other research (e.g., Bebeau \& Brabeck, 1989; Shaub, Finn, \& Munter, 1993).

\section{Summary of Previous Research}

Several conclusions can be drawn from these studies. First, from these few studies, a link between organizational influences and moral awareness has been empirically established. This link has been assumed for some time (Jones \& Ryan, 1998), but the Butterfield, Treviño, and Weaver papers present solid evidence that the relationship does exist.

Second, the studies provide evidence of how organizational influence occurs within work groups. Butterfield, Treviño, and Weaver $(1996,1997,2000)$ examine specific processes by which moral awareness is affected.

Third, we see that moral awareness can be measured. Rest $(1986,1994)$ lays partial blame for the lack of research into moral awareness on the lack of accepted methods or validated measures. Bebeau and Brabeck, 1989 and Shaub, Finn, and Munter, 1993 laid the groundwork for this methodology, and Butterfield, Treviño, and Weaver $(1997,2000)$ demonstrate a method by which the construct can be measured in a business setting. Only further testing can validate it. This dissertation will begin that process.

Finally, it is clear that much more research is needed in the study of moral awareness. My dissertation will be one step in that direction. It will move knowledge forward by:

- Providing a direct link to Blum's conceptualization of moral awareness

- Conducting a study of moral awareness at the organization level

- Validating prior measures of moral awareness

- Refining techniques for the measurement of moral awareness.

The remainder of this chapter will focus on the hypothesized relationships between ethical work climate and moral awareness. But before examining those connections in detail and stating my hypotheses, I will examine some other variables that have been shown in previous studies to affect moral judgment and behavior. These "person variables" (Baron \& Kenny, 1986) have previously been tested as independent predictors of moral judgment and behavior. However, in the present study, I am interested in how these variables affect the direction or strength of the relationship between EWC and moral awareness as moderating variables. By extending the work of Durkheim (1937/1996), Kohlberg (1981), and Rest (1994), as discussed in Chapter 1, and relying on the similarities between moral awareness, judgment, and behavior, I can hypothesize the moderating effects of these variables on the relationship between ethical work climate and moral awareness.

\section{MODERATING VARIABLES}

Baron and Kenny (1986: 1174) define a moderating variable as "a qualitative (e.g., sex, race, class) or quantitative (e.g., level of reward) variable that affects the direction and/or 
strength of the relation between an independent or predictor variable and a dependent or criterion variable." Moderators are typically third variables that partition a focal independent variable into subgroups of varying effectiveness in its relation to the dependent variable. A moderating effect is represented by an interaction between the independent variable and the moderator that specifies the appropriate conditions for the independent variable's operation. As noted by the authors, moderating variables are distinct from mediating variables (i.e., active organisms that intervene between stimulus and response by various transformation processes internal to the organism) in both the ways that they affect the relationship between independent and dependent variables, and in the appropriate statistical tests for their existence and operation (Baron \& Kenny, 1986). In the current study, the variables chosen for investigation are categorical variables related to individual characteristics of the respondents (specifically sex, age, level of education, and exposure to ethics training) that correspond to Baron and Kenny's definition of moderators.

Consistent with the sociological perspective I have taken in this study, the primary focus is on the relationship between ethical work climate and individual moral awareness. However, it is also widely recognized in the literature that many other factors influence ethical attitudes. These other factors include individual characteristics, or "person variables," such as age and gender; others reflect broader social influences, or "situational variables" (Baron \& Kenny, 1986). Because this study focuses on the influence of groups on individuals, it will be most instructive to employ person variables as moderators. In this manner, the relative strength of the group influence (EWC) and person variables can be assessed. If these person variables do moderate the relationship between ethical work climate and moral awareness, then it will be clear that individual characteristics retain some influence in group settings. However, if there is no significant moderating effect, the primacy of the group over the individual will be demonstrated empirically.

Four moderating variables have been chosen for inclusion in this study, based on several factors. First, the variables have been shown to have some degree of effect on ethical attitudes, judgment, and/or behavior in previous studies. Second, none has been shown to be consistently correlated with moral characteristics, so further validation and refinement of previous studies can be accomplished by including them here. Third, inclusion of these factors will allow significant refinements in the measurement of moral awareness, as described in Chapter 3.

Gender has been a matter of continuing debate in determining causes of differences in ethical perceptions and attitudes toward social issues (Luthar, DiBattista, \& Gautschi, 1997). Gilligan (1982) has been a vocal critic of Kohlberg's methods of measuring moral development, arguing that females have a distinct way of approaching moral issues, placing emphasis on care, empathy, and compassion. In contrast, she says, men appear to see moral issues as matters of rights, justice, and fairness. Although Gilligan's work has been criticized for methodological and other reasons, some of her basic ideas of gender differences in moral development have been supported by other researchers (Langdale, 1983; Lyons, 1983). Other studies have found that females take more highly ethical positions, however measured, than do their male counterparts (Rest, 1986; Arlow, 1991; Ruegger \& King, 1992). On the other hand, several studies have found no differences between males' and females' ethical attitudes or moral reasoning (McNichols \& Zimmerer, 1985; Fritzsche, 1988; Derry, 1989). 
Age has been shown to be a factor in determining values in business settings by a number of researchers. England (1978) and Johnson, Neelankavil, and Jadhav (1986) have shown that younger managers tend to place more emphasis on money and advancement opportunities, and less emphasis on trust and honor than do their older counterparts. Barnett and Karson (1989) discovered that younger (as measured by career stage) respondents acted less ethically than people who were in later career stages.

Kohlberg (1984) and Rest $(1986,1994)$ have found that the single most important factor in the development of moral judgment is length of formal education. Rest speculates that it is not specific experiences that foster development of moral judgment, but rather becoming more aware of the social world in general and one's place in it. Implicit in Rest's views on this subject is the idea that formal education tends to promote exactly this type of awareness of the social world and the student's place in it. In addition to the exposure to new ideas and a broader view of the student's place in the world, the structured environment of a school setting may also contribute to moral development by exposing the student to well-defined social statuses and by raising the general level of intellectual sophistication.

Some studies of the results of training in ethical perception and reasoning have found little evidence of significant effects (Arlow, 1991; Stevens, 1984; Mayer, 1988). Arlow (1991) suggests that students are more influenced by exposure to socio-cultural norms than by ethics training. However, other research has shown that ethics training does sensitize students to moral issues (Bok, 1976; Gautschi \& Jones, 1998), and does marginally affect behavior (Salmans, 1987).

Specific hypotheses encompassing the moderating and independent variables will be discussed in the following section.

\section{HYPOTHESES}

The definition of moral awareness used in this dissertation is "the degree to which an individual recognizes the aspects of a situation that carry a reasonable likelihood of moral wrong or harm to individuals, classes of people, or other entities." Thus the key element in the moral awareness construct is consideration of possible harm to others. As a general rule, one would expect that an individual's moral awareness would increase in proportion to the breadth of that person's locus of analysis and with the degree of concern her ethical criteria holds for other parties. The development of the EWC construct, with its ideas of "who" and "what" are considered in moral deliberations, supports this generalization (Victor \& Cullen, 1987, 1988).

The other major component of the definition of moral awareness is situational- the ability to see elements of a situation as morally significant. Because these elements may be very different from situation to situation, it would be difficult, if not impossible, to make any meaningful generalizations about this aspect of the definition. As Blum (1991: 716) said, "In a way it is misleading to speak of someone as 'sensitive to particulars' (or 'good at perceiving the moral character of particulars') tout court. Some people are better at perceiving some sorts of particulars than other sorts." Therefore, in formulating hypotheses regarding the relationships 
between ethical work climate and moral awareness, I will be focussing on the first component of the definition discussed above, namely consideration of possible harm to others.

One of the distinguishing features of moral philosophy is the need for the moral agent to consider the welfare of others than himself or herself. Rachels (1999) sees this element, which he terms impartiality, as one of the most basic criteria for a minimum conception of morality. ${ }^{5}$ Because an egoistic ethical criterion, by definition, does not consider others beyond the agent's self or group, it is logical that a utilitarian (benevolence) or deontological (principle) ethical criterion should engender a higher level of moral awareness. Benevolence and principle incorporate Rachels's concept of impartiality, which requires the moral agent to consider the impact on others as equally important as the effect on the agent. By requiring that others be considered, moral awareness should be heightened. It is impossible to say definitively which of those two ethical criteria is "better" at considering others' welfare (centuries of debate among moral philosophers have failed to resolve that question), so my first hypothesis is:

$\mathbf{H}_{1}$ : Organizations with ethical work climates that utilize benevolence or principle ethical criteria at all loci of analysis will be associated with higher levels of moral awareness among their members than will organizations with ethical work climates using the egoistic ethical criterion.

The first hypothesis addresses the ethical criterion axis of the EWC construct; the other axis is locus of analysis. By specifying a dominant locus of analysis, the organization is influencing a priori who or what groups will be considered as potentially being harmed when a member of the organization scans the environment or reflects on the organization's actions. Anything less than consideration of all possible affected parties artificially truncates moral awareness. Thus, the second hypothesis is:

$\mathbf{H}_{2}$ : Within a specific ethical criterion, organizations with ethical work climates employing broader loci of analysis will be associated with higher levels of moral awareness among their members than will organizations with ethical work climates utilizing narrower loci of analysis.

Because both the ethical criterion used and the locus of analysis are hypothesized to affect moral awareness, their interaction makes it impossible to predict the degree of moral awareness within each of the nine theoretically possible ethical work climates. But, at the limits, when the hypothesized effects of both ethical criteria and locus of analysis are combined, it seems that the polar extremes of moral awareness should be at the intersections of egoistic ethical criterion/individual locus of analysis and principle ethical criterion/cosmopolitan locus of analysis. However, because the construct is not hierarchical (i.e., even though Kohlberg argues that it is in his model, the EWC does not consider the principle ethical criterion to be a "higher" level of moral reasoning), it is impossible to say whether benevolence or principle ethical

\footnotetext{
${ }^{5}$ The reader may note at this point that in the ethical work climate construct, the intersection of the egoistic ethical criterion and individual locus of analysis (or potentially the entire egoistic ethical criterion) seems to violate Rachels's impartiality criterion. This would appear to be a valid subject for further discussion, but is a topic I choose to bracket at this point. The EWC construct is a descriptive measure of the form of moral reasoning in an organization. That egoistic reasoning is widely used in many business settings, and that the amoral theory of business implicitly assumes egoistic reasoning, would be difficult to dispute. These two factors provide sufficient reason to proceed with the EWC construct as is.
} 
criterion should be associated with a higher level of moral awareness (Victor \& Cullen, 1988). Thus, it is not clear how to hypothesize which ethical climate type is associated with the highest level of moral awareness. However, the association between the lowest level of moral awareness and ethical climate can be predicted. Therefore, the third hypothesis is:

$\mathbf{H}_{3}$ : An organization with an ethical work climate associated with the egoistic ethical criterion and individual locus of analysis will be associated with the lowest degree of moral awareness among its members.

The remaining hypotheses specify the moderating variables' expected effects on the relationship between the independent and dependent variables. The previous section of this chapter presented evidence of significant differences of effect on moral judgment and behavior within each of the variables presented: sex, age, education level, and ethics training. However, in the studies reviewed, these variables were utilized as independent variables. In the present research, each of these variables is viewed as a moderator of the relationship between the focal independent variable, ethical work climate, and the dependent variable, moral awareness.

A basic premise of the sociological perspective taken in this study is the primacy of society or groups over the individual (Durkheim, 1895/1962). Thus, even though most of the studies reviewed in the previous section suggest that these person variables do make a significant difference in moral judgment and behavior, the sociological perspective suggests, and it is my contention, that these individual characteristics do not moderate the relationship between EWC and moral awareness. The group influence, in the form of the ethical climate, is postulated to override the effects of the person variables.

Thus, the fourth through seventh hypotheses are listed below:

$\mathbf{H}_{4}$ : Sex will not exhibit a significant moderating effect on the relationship between ethical work climate and moral awareness.

H5: Age will not exhibit a significant moderating effect on the relationship between ethical work climate and moral awareness.

$\mathbf{H}_{6}$ : Level of formal education will not exhibit a significant moderating effect on the relationship between ethical work climate and moral awareness.

$\mathbf{H}_{7}$ : Exposure to formal ethics training will not exhibit a significant moderating effect on the relationship between ethical work climate and moral awareness.

Methods for testing these hypotheses will be discussed in the following chapter. 


\section{CHAPTER 3 - METHODOLOGY}

Chapters 1 and 2 have established a theoretical foundation for the hypothesized connections between ethical work climate and moral awareness. During that discussion, however, it also became obvious that both constructs have significant difficulties associated with measurement methodologies. Before describing the procedures that were used to perform the field work, I will briefly address the bases for the measurement techniques that were employed.

\section{BASES FOR METHODOLOGY}

\section{Ethical Work Climate}

Because the independent variable in this study is ethical work climate, a "climate approach" was used in this research as part of the conceptual base (Schneider, 1983). This research perspective has gained increased acceptance. It includes the following characteristics:

1. An emphasis on perception as a behaviorally integrative function,

2. Specification that organizational processes rather than structure are the bases for climate,

3. Distinction between psychological and organizational climate,

4. Agreement that climate is best described as a molar abstraction of specific sets of events, practices, and procedures, and

5. Recognition that different work groups or work setting within an organization will have different climates in each of those groups or settings (Schneider, 1983: 111).

The second conceptual basis for the EWC portion of this research is the distinction between the form and the content of ethical reasoning. Kohlberg (1984) conceptualized form and content as independent, because the same outcomes or values (content) can result from different styles of ethical deliberation (form). For example, two fathers could arrive at the same conclusion to steal the drug that will save their dying children's lives, but use very different decision criteria. One of the fathers might use a utilitarian form of reasoning, wherein he determines that stealing the drug would provide a net positive benefit when considering all parties affected by the action. On the other hand, the second father might use a deontological rationale that human life trumps property rights, and therefore the drug should be stolen. (This example is adapted-liberally - from the famous Heinz dilemma that Kohlberg regularly used in his research.) 
The ethical work climate construct refers to the form of moral reasoning, not to the content. The ethical climate questionnaire that was utilized in this research was specifically designed to elicit the form of ethical reasoning. Although organizational norms might be considered the outcome, or content, of ethical reasoning, each of the questions on the ECQ refers directly to one of the ethical criteria, thus providing a direct link back to the form of reasoning (Victor \& Cullen, 1988). In other words, while the organizational norm is a measure of what the influence is, the ECQ delves into how that norm was developed. The originators of the EWC conclude, "The criteria in use (e.g., the best for each person, the rules, the interest of the organization), then, are observable artifacts of the organizational ethical reasoning process" (Victor \& Cullen, 1988: 110). This is also why Victor and Cullen do not consider ethical work climate a normative construct.

The specific techniques that were used to measure ethical work climate rested on this conceptual base. As described in Chapter 2, there are three primary conceptual/measurement issues involved in climate research. The first of these, termed the "multi-dimensional issue" by Schneider \& Reichers (1983), is the failure to recognize that there is no such thing as a single type of work climate. This issue is not pertinent to this dissertation, since I have identified a specific type of work climate to investigate, the ethical work climate.

The second measurement issue is the aggregation problem (Schneider \& Reichers, 1983; Denison, 1996). Some of the studies of ethical work climate reviewed in Chapter 2 fell prey to this problem by surveying subjects from a wide variety of work organizations, thus negating the ability to aggregate individual perceptions (psychological climate) into a meaningful measure of shared perceptions (organizational climate). This issue was addressed in the present study by surveying sufficiently large representative samples of employees from multiple organizations. This, and the fact that seven different organizations from disparate sectors and industries were selected as research sites, allowed this research to conform to Joyce and Slocum's $(1979,1984)$ criteria for evidence of organizational climate.

The third, more conceptual issue is that of the supposed conflation of climate and attitudinal measures. As described in detail in both Chapters 2 and 3, the ECQ has been specifically designed to overcome this potential problem. Victor and Cullen (1987: 58, authors' emphasis) note that the ECQ emphasizes "the description of, rather than feelings about, the work setting. Thus, it must be noted that the measure of ethical climate in this study did not focus on whether the respondent believed he or she behaved ethically nor did it emphasize whether the respondent saw the ethical climate as good or bad. Rather, we asked only for descriptions regarding the bases of ethical decision making." Further tests employing the ECQ have validated its ability to identify distinct ethical work climates (Victor \& Cullen, 1988; Cullen, Victor, \& Bronson, 1993; Weber, 1995; Deshpande, 1996a, 1996b; DeConinck \& Lewis, 1997; Schwepker, Ferrell, \& Ingram, 1997; Sims \& Keon, 1997; Wimbush, Shepard, \& Markham, 1997a, 1997b; Treviño, Butterfield, \& McCabe, 1998; Agarwal \& Malloy, 1999).

\section{Moral Awareness}

As Rest (1986, 1994) and Bebeau (1994) note, measuring moral awareness is problematic. One source of potential aid is the academic field of decision theory, which is based 
on research that investigates how decisions are made and encompasses the notion of perception (Slovic, Fischhoff, \& Lichtenstein, 1977; Einhorn \& Hogarth, 1981).

Analogous to Kohlberg's (1984) distinction between the form and content of ethical reasoning, decision theorists have developed two models of decision making. Structural models of decision-making focus on the observable inputs to and outputs of decision behavior. Process models, on the other hand, focus on dynamic aspects of decision-making. "Structural models focus on the what of decision behavior, but process models focus on the how" (Abelson \& Levi, 1985: 255, authors' emphasis). Because process models provide information about the relative importance of cues and individuals' attentional processes during judgment or choice tasks (Abelson \& Levi, 1985), the research perspective in the present study paralleled this model of decision theory.

Abelson \& Levi (1985) also note that process models concentrate on the individual as the decision-making entity, rather than a group or organization. Although I have repeatedly emphasized the sociological perspective that was taken in this study, the focus on the individual here is not unwarranted. Moral awareness is an individual perceptual process, and I measured it as such. The sociological perspective is relevant in the ethical work climate's influence on moral awareness. Indeed, the research question in this dissertation is how EWC is related to "individuals' moral awareness."

\section{RESEARCH PROCEDURES}

A survey study was conducted at multiple sites to assess the relationship between ethical work climate and individual moral awareness. Subjects selected from various levels of the organizations were asked to identify and rate the importance of issues they observed in a video clip, and to complete questionnaires that provided certain demographic data and information related to their organizations' ethical climates. The dependent variable, moral awareness, was measured by evaluation of respondents' open-ended identification of issues from the video. There was no manipulation of the independent variable, ethical work climate - variation in this variable was generated by the measurement of respondents' perceptions of their organizations' EWCs.

\section{Research Sites}

The fieldwork for this study was conducted in seven different organizations. To control for organizational purpose, the sites represented distinct industries and sectors. In keeping with Joyce and Slocum's $(1979,1984)$ criteria for evidence of an organizational climate, research sites were selected partially based on a priori distinctions between their sectors (for-profit, government, and non-profit) and industries. In the initial study on ethical work climate, groups for the study were deliberately selected to "represent objectively distinct organizational environments and a priori distinct degrees of internal consistency" (Victor \& Cullen, 1987: 67). Agarwal and Malloy (1999) found evidence to suggest that individuals in the non-profit sector may perceive ethical climate differently than do their counterparts in the for-profit sector. By having research sites in different industries and sectors, this research extended our knowledge of 
the ethical work climate construct. Disparate sites also provided additional information regarding the effects the moderating variables have on the relationship between the independent and dependent variables. Brief descriptions of each of the organizations selected for inclusion in this study are shown below.

Group 1 (Regional bank) - This publicly traded commercial bank is a large familycontrolled bank in the United States, with corporate headquarters in a mid-Atlantic state. The site surveyed was the state headquarters of a different mid-Atlantic state than the one in which the corporate center is located. Approximately eighty full-time employees are located in the site city.

Group 2 (Engineering/surveying) - This organization is a privately held professional firm engaged in civil engineering and surveying services to a regional clientele. The firm has two offices, located in different cities in a mid-Atlantic state. Ownership is divided among three men, two of whom are related by marriage and work in the same office. The third owner is not related to the other two, and is located in the second office. The survey was administered in one of the offices, where approximately forty people are employed.

Group 3 (Manufacturing) - This firm is a single manufacturing plant, one of many owned and operated by a Japanese conglomerate. The local plant was purchased by its present owner about five years prior to time of the survey. It manufactures automotive parts for the original equipment and replacement markets. Workers here are unionized and have historically had, and continue to have, an adversarial relationship with management. All of the participants in the survey were members of the union, and represented approximately twenty-five percent of the total workforce in this facility.

Group 4 (Non-profit) - A quasi-governmental organization, this firm was founded more than fifty years ago to serve the housing and other needs of the poor in a mid-sized city in a midAtlantic state. The organization has grown to employ nearly one hundred people at the present time, all in the same location. The senior management team has been completely changed at least twice during the past ten years, with the current group beginning about four years prior to the survey. During its tenure the current management team has been attempting to change the focus of the organization from service to the poor to one geared more toward economic and real estate development.

Group 5 (Police department) - This department enforces the law in a relatively lowcrime mid-sized county in a mid-Atlantic state. All of those participating in the survey were police officers, either detectives or patrol personnel. The department has about 120 officers and a total payroll of nearly two hundred.

Group 6 (Utility company) - The employees surveyed from this large, publicly traded company represent about one-third of a self-contained repair and maintenance unit that is charged with keeping the company's generating machinery in working order. This department had been formed less than one year prior to the date of the survey. Members of this unit live in different locations, but work closely with each other because they travel to the different plant locations and work there for weeks at a time. 
Group 7 (Retail grocery) - All of the respondents from this company work in a regional administrative office of this national grocer. Roughly 150 people work in this office, supporting grocery operations in the five-state mid-Atlantic region. This company is one of the largest employers in the metropolitan area in which it is located, including its administrative office, warehouses, and retail stores.

\section{Samples}

Employee samples at each research site were drawn from representative groups within the organization. Subjects were recruited by a memorandum from me, with assistance from managers at each site (see Appendix A for an example of the memorandum). This process of selection is common in management research and is adequate to provide a representative sample (Victor \& Cullen, 1987, 1988). Corresponding with commonly accepted statistical sampling techniques, the samples included a minimum of thirty subjects at each site, where possible (Anderson, Sweeney, \& Williams, 1981). Because of the small size of two of the organizations, sample sizes there were smaller than thirty. Each sample was representative of the work group population, but these samples did present some concern during the data analyses (see Chapter 5 for further discussion of this issue).

\section{Level of Analysis}

It is very important to specify the level at which a climate is said to operate. By the design of the current study, all of the surveys provided data at the group or organizational level, not at the "psychological climate" level (Schneider, 1973; James \& Jones, 1974; Field \& Abelson, 1982). To further clarify the level of analysis for each of the groups surveyed, a brief summary is provided below.

Group 1 (Regional bank) - All respondents to the survey were employed as line personnel in the state headquarters of the bank, including lenders, tellers, and their managers. No staff personnel or part-time employees were included in the study. Those participating in the survey did work out of different offices within in the same city, although all were included in the same geographic group along which the bank was organized. Therefore, the climate being measured at the bank was at the geographic division level.

Group 2 (Engineering/surveying) - This survey took place solely within one of the two offices operated by the firm, and included engineers, surveyors, and administrative personnel. Consequently, this climate was tied to this particular office's operations.

Group 3 (Manufacturing) - Each of the participants from the manufacturer were workers from the local plant who belonged to the union; no management personnel were included in the survey. Therefore, the climate measured here inhered to the local manufacturing work group.

Group 4 (Non-profit) - Employees from nearly all departments and hierarchical levels within the non-profit participated in the survey, indicating that this climate should be applied at the organizational level. 
Group 5 (Police department) - Each respondent from the police department was either a detective or patrol officer. This indicates that the climate being measured was for active officers within the department.

Group 6 (Utility company) - As described above, these respondents all belonged to the repair and maintenance unit of the utility company, indicating that this climate was at the work group level.

Group 7 (Retail grocery) - These survey participants came from various departments within the regional administrative office. A few of the respondents had previously worked in retail stores or other regional offices within the company, but their common bond was clearly the regional administrative office at which they currently worked. Thus, this climate measurement was at the regional administration level.

\section{Data Collection}

Measurement data for all variables were collected from two separate questionnaires, both administered during one survey session. I was present at all survey sessions and supervised the group self-administered surveys.

\section{Research Procedures}

In order to avoid revealing the survey's focus on ethics, the procedures necessarily occurred in a specific order. After initially introducing myself and providing a very general statement of the intent of the research (such as "I am investigating the decision-making processes in business - or non-profit—organizations"), I showed scenes from the movie "Other People's Money." This movie is based on the play of the same name (Sterner, 1990). The movie depicts a corporate raider making a hostile takeover bid for a publicly traded corporation, while the existing managers and their attorney attempt to fight him off. The decision for which the subjects were asked to identify important issues was plainly evident-whether the takeover should occur or not. Of critical importance to the current study, the scenes did not provide overt cues to the viewer or state what the ethical dilemma might be. The subjects had to recognize the moral component(s) of the situation for themselves (if, in fact, they did recognize it), after viewing the video only once.

In order to avoid providing cues to the subjects, or framing the issues for them, no mention was made of the types of issues that the subjects should consider. This was considered essential to the present study, since the purpose was to measure the ethical work climate's effect on individual moral awareness, not the effect of framing. However, the dominant paradigm of the amoral theory of business may have overridden the respondent's moral perception if that individual worked in an environment in which the whole subject of ethics was considered irrelevant. In a previous study, Baucus and Rechner (1996) found that forty percent of the managers surveyed did not perceive the ethical component of a downsizing situation without being prompted to adopt an ethics frame. The individual responding to the question may have actually recognized the moral component inherent in the video clip, but rejected it as an important issue in a business setting. This "false negative" should not be considered a defect in 
the current study however-it was precisely this influence of ethical work climate on the individual's perception of the moral component in a business situation in which I was interested.

The use of videos in business ethics research is a relatively new phenomenon. Written vignettes, in contrast, have long been used in business ethics and decision theory research. More traditional paper and pencil surveys suffer from several shortcomings, including the inability to encompass complex issues in the survey questions and the tendency for a self-reporting bias on the part of the respondent. These two deficiencies are especially problematic in business ethics research. Use of vignettes allows the ethics researcher to more fully set the stage for the research, dramatize the issue, and portray a number of pertinent issues at one time (Cavanagh $\&$ Fritzsche, 1985). Using video clips extends the benefits of vignettes even further.

Studies of organizational communication have shown that different communication media vary in their capacities to convey information. These capacities can be arrayed along a "media richness" continuum, based on four criteria: 1) availability of timely feedback, 2) multiple cues, 3) language variety, and 4) personal focus. "Richer" media are capable of conveying significantly more information, and are typically characterized by personal interaction of some sort (e.g., face-to-face or telephone conversations), rather than written communication (Daft, Lengel, \& Treviño, 1987; Treviño, et. al., 1990). Although presentation of a video clip does not allow feedback (presentation of a scenario in any medium does not), the video is certainly a "richer" medium in the other three criteria than is a written vignette.

According to Weick (1979), ambiguity exists when there are multiple and conflicting interpretations of an issue. Arguably, ethical dilemmas are especially multi-faceted and ambiguous (Stephens \& Lewin, 1992). Using a video clip allowed me to present a complex scenario and to provide the subjects with substantially "richer" information about the situation than would a written vignette. Thus, the use of a video in the current study was supported by previous studies on media richness and should provide better information than other possible research techniques.

At the end of the video clip I distributed questionnaires to the subjects, asking them to identify the issues that they personally found important in coming to a decision about the situation portrayed in the scenario. The instructions stressed that the subjects should mentally place themselves within their organization when responding to the questions. The respondents were also asked to rate the relative importance of each of the issues that they considered on a scale of one to seven. See Appendix B for a copy of this questionnaire.

After completion and collection of the questionnaire regarding the video clip, I distributed a questionnaire to collect certain demographic data, responses to the ECQ, and recognition factors for the video clip (see Appendix C). Five different versions of this survey instrument were used, in which the ECQ descriptors were randomly mixed. This was done to avoid any order effects that may have occurred. 


\section{Pretests}

Because the ECQ has been used and validated in a number of prior studies, a pretest of this instrument was not required (Victor \& Cullen, 1987, 1988; Cullen, Victor, \& Bronson, 1993; Weber, 1995; Deshpande, 1996a, 1996b; DeConinck \& Lewis, 1997; Schwepker, Ferrell, \& Ingram, 1997; Sims \& Keon, 1997; Wimbush, Shepard, \& Markham, 1997a, 1997b; Treviño, Butterfield, \& McCabe, 1998; Agarwal \& Malloy, 1999).

The moral awareness portion of the survey was new, and so was pretested at a large research university. The purpose of the pretest was twofold: 1) to evaluate the clarity of the questions asked on the survey instrument, and 2) to determine if providing a cue to the respondents relating to potential ethical considerations in the video clip would make a statistically significant difference in the number of ethical issues identified by the respondents. Again, to avoid potential framing or cues to the subjects, the pretests were administered to undergraduate students not currently enrolled in a social issues course. Separate groups were given different instructions for identifying issues considered important in coming to a decision about the situation portrayed in the scenario. The control group was not given any suggestion about topics that might be considered, while the experimental group was provided with cues regarding possible issues to be considered. Both groups received identical instructions, but the experimental group's included an additional sentence (shown below in italics). The instructions stated, "Please identify all of the issues that you consider important in making a decision about the situation just shown in the video. These might include legal, financial, operational, ethical, marketing, or any other issue (or none of these) that you think is important. Please be as specific as possible in your description of the issues. Once you have identified the important issues, please rate the importance of each issue on a scale of 1 to 7 , with 7 being very important and 1 being of little importance. You are not ranking the issues by their importance-different issues can have the same relative importance."

The number and weight of ethical issues identified by the control and experimental groups were compared to see if there was a statistically significant difference. If there had been such a difference (assuming the experimental group was higher), the probable cause would have been the inclusion of the cue regarding ethical issues. If, on the other hand, the experimental group was significantly lower, the cause may have been the inclusion of cues regarding other business issues such as finance or marketing that are commonly viewed as having top priority in a business setting. No statistically significant difference between the two groups was noted.

\section{Data Analysis}

After completion of the field work, the data collected were analyzed using appropriate statistical techniques. Responses to the ECQ were factor analyzed, with the emergent factors used to construct scales for discriminant analysis. These analyses were used to determine the climate types that were most descriptive of the organizations in the study. Responses to the moral awareness survey were independently scored by three raters (two "blind" research assistants and me), with the unweighted average of the scores representing each respondent's moral awareness. Discussion of the analyses and results are included in Chapters 4 and 5. 
The measures collected during the field work are described below.

\section{MEASURES}

\section{Independent Variable—Ethical Work Climate}

The Ethical Climate Questionnaire is a series of thirty-six descriptors designed to elicit the form of ethical reasoning within the subject's work group or organization. The respondents' ratings of these descriptors, through subsequent factor and discriminant analyses, allowed me to identify ethical work climates within each of the research sites. As described earlier, the axes of the EWC construct represent distinct and relatively incompatible criteria and loci, thereby promoting the uniqueness of each of the climate types.

\section{Moderating Variables}

The moderating variables - age, gender, length of formal education, and ethics trainingwere measured by means of closed ended questions. One question each captured the data for these variables. Possible answers to these questions were specific integers, yes/no, or male/female, thereby causing no data problems or ambiguities.

\section{Dependent Variable-Moral Awareness}

The complexity of moral awareness was shown in Chapter 2 (Blum, 1991). Three essential aspects of moral awareness for the present study were described, including salience, sympathy, and construal of situations. The method of measuring moral awareness outlined below captures all three of these aspects. In asking subjects to identify issues important to making a decision about the scenario depicted in the video clip (without cues or framing), it is necessary for the respondents to first recognize the ethical components of the situation before they can report them. This recognition process necessarily entails 1) the salience of the moral components to the respondents, 2) feeling that the effect on other parties is sufficient to be considered (sympathy), and 3) construal of the situation in such a way that it is seen as having ethically relevant components. Thus, while the perception process is entirely internal to the subject, and therefore unobservable, the fact that the subject reports recognition of an issue indicates conclusively that he or she has indeed recognized it. Much as Victor \& Cullen (1988) see the ethical criteria in use as an observable artifact of the ethical reasoning process, the fact that an individual reports an issue as important is clear evidence of her awareness of the issue. Although the opposite (i.e., not reporting recognition of an issue) is not conclusive evidence that the subject failed to recognize it, it is reasonable to conclude that the subject did not find the issue an important consideration. As described below, importance of an issue is a key component in the measurement of moral awareness. Thus, if a respondent recognized an issue, but did not report it because he or she felt it was not sufficiently important, the measurement techniques will correctly account for this action.

Moral awareness was measured using a qualitative approach similar to those used in previous studies (Bebeau \& Brabeck, 1989; Shaub, Finn, \& Munter, 1993; Butterfield, Treviño, 
$\&$ Weaver, 1997, 2000). Responses to the open-ended questions on this survey instrument were generated by each participant, necessitating a manual scoring mechanism. First, I rated each of the issues identified by the subjects with either a zero (indicating that the issue did not deal with a moral component) or a one (indicating that it did have an ethical component). For each of the issues rated as a moral issue, the subject's rating of its importance (ranging from one to seven) were added together, producing a single numerical measure of the subject's moral awareness. The ratings were not a ranking of the issues - for example, two separate and totally different issues could each receive the same rating of importance from a respondent. Because such ratings are prone to rater bias, I had two "blind" assistants, who were not familiar with the study, also rate each of the issues in a similar manner.

Results of the field work and data analyses will be discussed in the following chapter. 


\section{CHAPTER 4 - RESULTS}

\section{INTRODUCTION}

Chapter 3 outlined the methodology and specific procedures to be used in this study. This chapter will provide details of the results of the data analyses and summarize the results in an overview of the research question. Each stage of the empirical research will be reported, including the pretest, data collection, factor analysis, discriminant analysis, interpretation of the results of the discriminant analysis, and tests of the hypotheses.

The review of the results of data analyses will proceed as follows. First, the test procedures and data collection will be reviewed. Second, the analytical procedures and results of the statistical tests will be reported. Third, the statistical results will be interpreted, with the aid of qualitative data about each of the organizations represented in the study. Finally, the results of the tests of hypotheses will be reported and summarized.

\section{TEST PROCEDURES}

\section{Pretest}

All portions of the survey instruments except the ECQ were administered to a group of fifty-five undergraduate students enrolled in a marketing class at a large state university. The ECQ was not included in the pretest because it has been used and validated in a number of prior studies (Victor \& Cullen, 1987, 1988; Cullen, Victor, \& Bronson, 1993; Weber, 1995; Deshpande, 1996a, 1996b; DeConinck \& Lewis, 1997; Schwepker, Ferrell, \& Ingram, 1997; Sims \& Keon, 1997; Wimbush, Shepard, \& Markham, 1997a, 1997b; Treviño, Butterfield, \& McCabe, 1998; Agarwal \& Malloy, 1999). Participation in this pretest represented partial fulfillment of a course requirement for these marketing students.

The purpose of the pretest was twofold: 1) to evaluate the clarity of the questions asked on the survey instrument, and 2) to determine if providing a cue to the respondents relating to potential ethical considerations in the video clip would make a statistically significant difference in the number of ethical issues identified by the respondents. The first purpose was achieved by soliciting written comments from the students regarding any items in the video clip or on the surveys that they did not understand or that they believed needed clarification. The students raised no substantive issues, so no modifications were made to the survey instruments for the actual tests.

The second purpose was accomplished by inserting an additional sentence in the instructions to one group of the students, while the control group received only the standard instructions (see Chapter 3 for the exact instructions provided). The experimental group had the 
following sentence included in its instructions. "These [considerations] might include legal, financial, operational, ethical, marketing, or any other consideration (or none of these) that you think is important." Twenty-seven of the students were randomly chosen for the control group and twenty-eight were randomly selected for the experimental group. An analysis of the average number of potential ethical considerations identified by each group showed no statistical difference in the numbers so identified. Therefore, because of the lack of a statistically significant difference between the control and experimental groups, and to avoid providing cues to the respondents in the actual tests, the sentence quoted above was not included in the instructions.

\section{Data Collection}

Data collection procedures went substantially as detailed in Chapter 3. Seven sites that represent a broad cross-section of industries, sectors, and size were selected. As the principal researcher, I personally supervised all group self-administered surveys. No instructions beyond those printed on the survey instrument were provided.

In each of the selected sites, subjects were recruited by a memorandum from me with the endorsement of a person in a position of authority within the firm (see Appendix A for an example of the memorandum). This process of selection is common in business ethics research and is deemed adequate to provide a representative sample of the employees in each site (Victor \& Cullen, 1987, 1988).

Except for the respondents' answers to the moral awareness survey, all data were collected in a format that could be compiled by computer. A total of 197 surveys was collected. With rare exceptions, each respondent answered all questions. Incomplete surveys were discarded from the data set. Because the surveys were completed at the times of each site visit, the response rate was one hundred percent. A summary of descriptive statistics is shown in Table 4.1.

Table 4.1: Descriptive Statistics of Sample

\begin{tabular}{|l|c|c|c|c|c|c|c|c|}
\hline ORGANIZATION & $\mathrm{N}$ & $\begin{array}{c}\# \\
\text { MEN }\end{array}$ & $\begin{array}{c}\# \\
\text { WOMEN }\end{array}$ & $\begin{array}{c}\text { AVG } \\
\text { AGE }\end{array}$ & $\begin{array}{c}\text { AVG } \\
\text { ED ** }\end{array}$ & $\begin{array}{c}\text { REC'D } \\
\text { TRAIN }\end{array}$ & $\begin{array}{c}\text { NO } \\
\text { TRAIN }\end{array}$ & $\begin{array}{c}\text { AVG } \\
\text { TENURE }\end{array}$ \\
\hline Regional bank & 31 & 8 & 23 & $30-39$ & 3 & 25 & 6 & 2.26 \\
\hline Engineer/survey & 17 & 9 & 8 & $30-39$ & 3 & 7 & 10 & 6.24 \\
\hline Manufacturing & 12 & 10 & 2 & $40-49$ & 2 & 3 & 9 & 16.75 \\
\hline Non-profit & 30 & 10 & 20 & $40-49$ & 3 & 19 & 11 & 6.97 \\
\hline Police department & 47 & $37 *$ & $8^{*}$ & $30-39$ & 3 & 37 & 10 & 10.62 \\
\hline Utility company & 29 & 28 & 1 & $40-49$ & 2 & 10 & 19 & 13.19 \\
\hline Retail grocery & 30 & 22 & 8 & $30-39$ & 4 & 22 & 8 & 15.7 \\
\hline Totals & 196 & 124 & 70 & & & 123 & 73 & \\
\hline Averages & & & & $30-39$ & 3 & & & 9.85 \\
\hline
\end{tabular}

* Two respondents in the police department did not report their sex.

** Code for Average Education:

$$
2 \text { - high school diploma or GED } 3 \text { - some college } 4 \text { - college degree }
$$


Based on the sample statistics noted above and the researcher's conversations with managers at each test site, this sample appears to be unbiased and representative of the selected segments of the workforce at each site. Therefore statistical analysis should provide valid and reliable results.

\section{RESULTS OF STATISITICAL ANALYSES}

\section{Factor Analysis}

The objective of any factor analysis is the orderly simplification of a relatively large number of potentially intercorrelated measures into a smaller number of constructs that serve as a satisfactory substitute for the original variables (Child, 1970; Comrey \& Lee, 1992). In this study factor analysis was used to identify emergent ethical climate types from the descriptors used in the Ethical Climate Questionnaire. In addition, the descriptors comprising the emergent factors, or climate types, were then used to construct a scale that would be used in a discriminant analysis. The results of the discriminant analysis, along with qualitative data collected from each of the organizations, would ultimately allow me to determine the climate type that was most descriptive of each of the organizations in the study.

The a priori decision rule adopted for inclusion of descriptors in the factor analysis and scale construction was a loading of at least 0.45 on one factor and loadings of less than 0.40 on all other factors. The initial criterion for inclusion (loading greater than 0.45) is substantially more stringent than the commonly employed benchmark of 0.30 (Child, 1970; Hair, et. al., 1984; Comrey \& Lee, 1992). I chose the stricter criterion to provide additional credence to the results of this study, and in recognition of the "greater than 0.50 " criterion employed in the initial EWC study (Victor \& Cullen, 1987) and the "greater than 0.45 " criterion used in their second study (Victor \& Cullen, 1988). The secondary criterion for inclusion (loadings of less than 0.40 on other factors) is actually less stringent than the commonly used criterion of 0.30 . This "looser" criterion was selected in recognition of the coexistence of multiple ethical climate types in theory and in practice (Victor \& Cullen, 1987, 1988; J. Weber, 1995).

SPSS was used for all data analysis in this research. The thirty-six descriptors of the ECQ were subjected to a factor analysis, using the principal component analysis extraction method and Varimax rotation with Kaiser Normalization. During the analytical process six of the thirty-six descriptors were eliminated from consideration in subsequent iterations of the factor analysis. The reasons for their elimination, in the order they were deleted, are shown below (all of the descriptors comprising the Ethical Climate Questionnaire are displayed in Appendix C).

Egoistic/Local3 - This item never loaded sufficiently on any factor. Its highest loading during the initial factor analysis was 0.356. Because it was "not like" any of the emergent factors this item was eliminated from the pool of descriptors and the factor analysis was run again (Child, 1970; Comrey \& Lee, 1992). 
Benevolence/Local3 and Egoistic/Cosmopolitan3 - Both of these items were highly intercorrelated (greater than 0.400 loadings) among multiple factors. Because this was outside the limits set for construction of the scales used in subsequent discriminant analysis, these descriptors were eliminated from the factor analysis.

Egoistic/Local1 and Egoistic/Local2 - These items actually loaded on a common item that would have been the eighth emergent factor in the analysis. However, this factor's reliability, as measured by Cronbach's alpha, was too low to use.

Benevolence/Cosmopolitan3 - During the penultimate iteration of the factor analysis this descriptor had loadings higher than 0.400 on two factors. Due to the high intercorrelation this item was discarded from the factor analysis.

Elimination of these six items from the factor analysis has several implications. First, the item with insufficient loadings (EL3) did not add to the descriptive power of the factor analysis. Its deletion made the analysis more parsimonious. Second, there were three items (BL3, EC3, and BC3) discarded because of their high intercorrelations among multiple factors. Deletions of these items increased independence of the factors, thus improving the ability to distinguish among emergent climate types. Third, an eighth factor comprised of EL1 and EL2 was eliminated because of its low reliability. Deletion of these two items added to the overall reliability of the scales constructed for subsequent discriminant analysis. An additional benefit of eliminating these descriptors from the factor analysis is that the resultant scales used in the discriminant analysis are identical to the emergent factors. This congruence obviates any concern over arbitrary exclusion of descriptors in the construction of the scales. ${ }^{6}$

The thirty items from the ECQ that remained in the factor analysis produced seven interpretable factors. All of the items comprising the factors met the a priori decision rules described above. Table 4.2 shows the emergent factors in graphic form. Table 4.3 shows the factor loadings for each of the thirty descriptors remaining in the analysis, and Table 4.4 provides the descriptors grouped by factor. The results of the factor analysis in this study substantially replicate findings of previous studies involving the EWC construct. In particular, the same seven factors are identified in this study as were found in Cullen, Victor, and Bronson (1993). A brief discussion of each factor identified in this study is provided below.

Factor 1 (Caring) - This factor is comprised of all four descriptors from the Benevolence/ Individual cell, three of the Benevolence/Local items, and two statements from the Principle/Individual cell. An examination of the descriptors in this factor (see Table 4.4) shows common themes of "each person," "each other," and "what is best" or "the good." Respondents to the ECQ did not appear to make a distinction between others as individuals (as described in the Benevolence/Individual cell) and others as members of that particular organization (Benevolence/Local cell). In addition, the two Principle/Individual statements share a focus on the individual, but the respondents did not distinguish between "the good" of the Benevolence descriptors and "right and wrong" of the Principle items. The descriptors comprising the caring

\footnotetext{
${ }^{6}$ In some prior studies employing the EWC construct, ECQ items have been used in the factor analysis, but have not been included in the scales used for the discriminant analysis. Proper statistical procedures dictate that items comprising the factors and those used for scale construction be identical.
} 
factor seem to share sufficient commonalities to provide an overall logic supporting this factor. The Caring factor has emerged in each of the prior studies, albeit with some differences in the number and source of the underlying descriptors.

Factor 2 (Law \& Code) - All four descriptors from the Principle/Cosmopolitan cell and one item from the Principle/Local intersection constitute the Law \& Code factor. All of these statements share a common emphasis on codified sets of rules and procedures, but there is some variance in the specific sources of those rules. The subjects' responses did not indicate recognition of the differences between sources at a detailed level, however. This factor has been identified in each of the studies reviewed in Chapter 2.

Factor 3 (Self Interest) - This factor is characterized by three descriptors from the Egoistic/ Individual cell and one statement from the Egoistic/Local cell. Each of these statements shares an element of self interest, but the respondents did not delineate among purely individual interest and the company's interest described in EL4. Victor \& Cullen $(1987,1988)$ identified a single factor that combined descriptors from both of these cells that they labeled "Instrumental." In this study, the predominance of the Egoistic/Individual descriptors comprising this factor appears to provide an underlying logic that supports the existence of an ethical climate type of Self Interest.

Factor 4 (Service) - Three items from the Benevolence/Cosmopolitan cell make up the Service factor in this study. The common refrain in these descriptors is a concern for the customer and the public. This factor has been identified as a separate ethical climate type in four of the previous studies reviewed in Chapter 2, although it has been referred to variously as "service," "social responsibility," and "social caring."

Factor 5 (Rules) - This factor is comprised of three descriptors from the Principle/Local cell, whose common theme is company rules, policies, and procedures. This same factor has been identified in three previous studies (Victor \& Cullen, 1987, 1988; Cullen, Victor, \& Bronson, 1993), while Wimbush, Shepard, \& Markham (1997a, 1997b) were unable to distinguish this factor from the law and code factor. There is ample support for the existence of the Rules factor as a separate ethical climate type in this study.

Factor 6 (Independence) - Two statements from the Principle/Individual cell and one item from the intersection of Egoistic/Individual constitute the Independence factor. The grouping of items from these two cells was initially puzzling, but upon examination (see Table 4.4) makes sense. All three statements deal with personal morals and beliefs, with the only difference being whether there is room for them in the organization. The Principle/Individual statements state this in the positive, while the Egoistic/Individual item says it in the negative. In fact, in the earlier factor analyses the loading of EI4 on the independence factor was negative 0.571 , so its respondent ratings were reversed, leading to a final loading of positive 0.537 . The Independence factor has been identified as a separate ethical climate type in all of the previous studies, and as described herein, there is a logic to its description in this study.

Factor 7 (Efficiency) - The efficiency factor is described by three statements from the Egoistic/ Cosmopolitan cell, each of which deals with efficient work and problem solving. This 
factor has appeared as a separate ethical climate type in only two of the previous studies. Victor and Cullen note that the Egoistic/Cosmopolitan items have been unstable, and postulate that "This instability may be due to the particular meaning the CE items have within each context (e.g. efficiency being more embedded in the rule of the plant than in the other contexts)" (Victor \& Cullen, 1988: 111). Indeed, it seems plausible that respondents to the ECQ view efficiency as a matter separate and distinct from work climates. "Efficiency" is so widely touted as a vital component of competitiveness that it may be viewed in many organizations as simply a sound business practice. In any event, the descriptors comprising the Efficiency factor in this study do hang together logically, and provide sufficient support for this ethical climate type.

Table 4.2: Emergent Ethical Climate Types

\begin{tabular}{|c|c|c|c|}
\hline$\overbrace{\text { CRITERION }}^{\text {LOCUS }}$ & INDIVIDUAL & LOCAL & COSMOPOLITAN \\
\hline EGOISM & $\begin{array}{c}\text { Factor } 3 \\
\text { Self Interest } \\
\text { EI } 1,2,3 \\
\text { EL } 4\end{array}$ & None & $\begin{array}{l}\text { Factor } 7 \\
\text { Efficiency } \\
\text { EC } 1,2,4\end{array}$ \\
\hline BENEVOLENCE & \multicolumn{2}{|c|}{$\begin{array}{c}\text { Factor } 1 \text { - Caring } \\
\text { BI } 1,2,3,4 \\
\text { BL } 1,2,4 \\
\text { PI } 1,4\end{array}$} & $\begin{array}{c}\text { Factor } 4 \\
\text { Service } \\
\text { BC } 1,2,4\end{array}$ \\
\hline PRINCIPLE & $\begin{array}{c}\text { Factor } 6 \\
\text { Independence } \\
\text { PI } 2,3 \\
\text { EI } 4\end{array}$ & $\begin{array}{c}\text { Factor } 5 \\
\text { Rules } \\
\text { PL } 1,3,4\end{array}$ & $\begin{array}{c}\text { Factor } 2 \\
\text { Law \& Code } \\
\text { PC } 1,2,3,4 \\
\text { PL } 2\end{array}$ \\
\hline
\end{tabular}


Table 4.3: Rotated Factors and Item Loadings

\begin{tabular}{|c|c|c|c|c|c|c|c|}
\hline \multirow[b]{2}{*}{ ECQ } & \multicolumn{7}{|c|}{ Factors } \\
\hline & 1 & 2 & 3 & 4 & 5 & 6 & 7 \\
\hline Items & Caring & Law/Code & Self Int. & Service & Rules & Indepen & Efficiency \\
\hline BL4 & 0.725 & 0.086 & -0.253 & 0.220 & 0.032 & 0.123 & 0.032 \\
\hline $\mathrm{BI} 3$ & $\overline{0.711}$ & 0.200 & -0.190 & 0.081 & 0.118 & 0.075 & 0.149 \\
\hline $\mathrm{Bl} 4$ & 0.684 & 0.068 & -0.137 & 0.148 & 0.097 & 0.138 & 0.157 \\
\hline $\mathrm{Bl1}$ & 0.670 & 0.149 & -0.166 & 0.049 & 0.017 & -0.047 & 0.325 \\
\hline BL1 & 0.664 & -0.045 & -0.193 & 0.168 & 0.332 & 0.045 & 0.010 \\
\hline $\mathrm{Pl} 4$ & 0.626 & 0.345 & 0.026 & -0.004 & 0.107 & 0.187 & 0.029 \\
\hline BL2 & 0.610 & 0.024 & -0.226 & 0.288 & 0.065 & 0.128 & 0.128 \\
\hline $\mathrm{Pl} 1$ & 0.522 & 0.179 & 0.214 & -0.035 & -0.130 & 0.274 & -0.018 \\
\hline $\mathrm{BI} 2$ & $\overline{0.469}$ & -0.007 & -0.337 & 0.129 & 0.263 & 0.244 & 0.325 \\
\hline PC1 & $\overline{0.020}$ & 0.739 & -0.114 & 0.209 & 0.172 & 0.069 & 0.196 \\
\hline PC4 & 0.197 & 0.724 & -0.010 & 0.003 & 0.064 & 0.069 & 0.040 \\
\hline PC3 & 0.244 & 0.702 & -0.057 & 0.127 & 0.074 & 0.049 & 0.040 \\
\hline PC2 & 0.182 & 0.630 & -0.116 & 0.262 & 0.288 & 0.163 & 0.001 \\
\hline PL2 & -0.059 & 0.624 & 0.084 & 0.155 & 0.166 & -0.365 & 0.146 \\
\hline EI3 & -0.234 & $-\overline{-0.015}$ & $\underline{0.810}$ & 0.001 & -0.118 & -0.093 & -0.099 \\
\hline EI2 & -0.102 & -0.042 & 0.797 & -0.097 & -0.041 & 0.130 & -0.015 \\
\hline El1 & -0.390 & -0.008 & 0.728 & -0.012 & -0.167 & -0.157 & -0.017 \\
\hline EL4 & -0.024 & -0.162 & $\overline{0.547}$ & -0.154 & 0.341 & -0.152 & -0.091 \\
\hline BC4 & 0.267 & 0.143 & $\overline{0.019}$ & 0.755 & 0.153 & 0.008 & 0.106 \\
\hline $\mathrm{BC} 1$ & 0.043 & 0.330 & -0.145 & $\overline{0.703}$ & 0.073 & 0.253 & 0.170 \\
\hline BC2 & 0.358 & 0.208 & -0.172 & 0.645 & 0.175 & -0.039 & 0.046 \\
\hline PL3 & 0.182 & 0.251 & -0.015 & $\overline{0.120}$ & 0.728 & 0.192 & 0.254 \\
\hline PL4 & 0.236 & 0.324 & -0.046 & 0.094 & 0.660 & -0.065 & 0.194 \\
\hline PL1 & 0.036 & 0.345 & -0.114 & 0.322 & 0.624 & -0.096 & -0.016 \\
\hline $\mathrm{Pl} 3$ & 0.167 & -0.012 & 0.076 & 0.040 & $\overline{0.206}$ & 0.755 & 0.082 \\
\hline PI2 & 0.350 & 0.104 & -0.084 & 0.042 & -0.176 & 0.616 & 0.058 \\
\hline $\mathrm{E} \mid 4$ & 0.176 & 0.109 & -0.347 & 0.233 & -0.029 & 0.537 & -0.071 \\
\hline EC4 & 0.123 & 0.053 & -0.109 & 0.054 & 0.102 & $\overline{0.043}$ & $\underline{0.847}$ \\
\hline EC1 & 0.311 & 0.148 & -0.125 & 0.103 & 0.153 & 0.143 & $\overline{0.674}$ \\
\hline EC2 & 0.127 & 0.244 & 0.170 & 0.182 & 0.050 & -0.392 & 0.546 \\
\hline
\end{tabular}




\section{Table 4.4: Descriptors for Emergent Factors/Ethical Climate Types}

\section{FACTOR 1 - CARING}

(BI1) In this company, our major concern is always what is best for the other person.

(BI2) In this company, people look out for each other's good.

(BI3) It is expected that each individual is cared for when making decisions here.

(BI4) What is best for each individual is a primary concern in this organization.

(BL1) Our major consideration is what is best for everyone in this company.

(BL2) People are very concerned about what is generally best for employees in the company.

(BL4) The most important concern is the good of all the people in the company.

(PI1) Each person in this company decides for himself what is right and wrong.

(PI4) The most important consideration in this company is each person's sense of right and wrong.

\section{FACTOR 2 - LAW \& CODE}

(PC1) In this company, people are expected to strictly follow legal or professional standards.

(PC2) In this company, the law or ethical code of their profession is the major consideration.

(PC3) People are expected to comply with the law and professional standards over and above other considerations.

(PC4) The first consideration is whether a decision violates any law.

(PL2) It is very important to follow strictly the company's rules and procedures here.

\section{FACTOR 3 - SELF INTEREST}

(EI1) In this company, people are mostly out for themselves.

(EI2) In this company, people protect their own interest above other considerations.

(EI3) People in this company are very concerned about what is best for themselves.

(EL4) Work is considered sub-standard only when it hurts the company's interests.

\section{FACTOR 4 - SERVICE}

(BC1) It is expected that you will always do what is right for the customer and public.

(BC2) People in this company are actively concerned about the customer's, and the public's interest.

(BC4) The effect of decisions on the customer and the public are a primary concern in this company.

\section{5 - RULES}

(PL1) Everyone is expected to stick by company rules and procedures.

(PL3) Successful people in this company go by the book.

(PL4) Successful people in this company strictly obey the company policies.

\section{FACTOR 6 - INDEPENDENCE}

(PI2) In this company, people are expected to follow their own personal and moral beliefs.

(PI3) In this company, people are guided by their own personal ethics.

(EI4) There is no room for one's own personal morals or ethics in this company.

\section{FACTOR 7 - EFFICIENCY}

(EC1) Efficient solutions to problems are always sought here.

(EC2) In this company, each person is expected, above all, to work efficiently.

(EC4) The most efficient way is always the right way, in this company. 


\section{Scale Construction}

In addition to providing additional support for Victor and Cullen's EWC construct, the foregoing factor analysis provides the data needed to construct scales for use in the discriminant analysis. Item selection for the scales was based on the criteria described previously for the factor analysis. Those descriptors loading greater than 0.45 on one factor and less than 0.40 on all other factors were used for the scales. All descriptors selected for use in the factor analysis were also used for the scales, thus making the factors and scales identical. The names given to the scales also mirror the factor names.

These scales were tested for internal consistency using Cronbach's alpha. According to Nunnally (1978), an alpha of 0.70 or higher is generally sufficient to show reliability. All of the alphas for the current scales except Independence and Efficiency exceeded the 0.70 benchmark. The alphas for Independence (0.6121) and Efficiency (0.6818) are also considered sufficient for use in the discriminant analysis, given their origin in the foregoing factor analysis.

The scales were also tested for independence using Pearson's Product-Moment Correlations. Although previous research has shown that the scales resulting from factor analysis of the ECQ are not generally completely independent, the intercorrelations have been considered low enough for use in subsequent discriminant analysis using the scales (Victor \& Cullen, 1987, 1988; Wimbush, Shepard, \& Markham, 1997a, 1997b). Support for this conclusion comes from two sources. First, the theoretical foundation for the EWC does not require strict independence, and in fact, recognizes the likelihood of the coexistence of multiple ethical work climates within one organization (Victor \& Cullen, 1987, 1988). Second, correlations less than 0.70 are not considered evidence of multicollinearity (Gunst \& Mason, 1980). Table 4.5 shows the inter-scale correlations and the scale reliabilities for the current study.

Table 4.5: Intercorrelation and Reliability of Scales

\begin{tabular}{|c|c|c|c|c|c|c|c|}
\hline Climate Scales & $\begin{array}{c}\text { Law } \\
\& \\
\text { Code }\end{array}$ & $\begin{array}{c}\text { Self } \\
\text { Interest }\end{array}$ & Service & Rules & $\begin{array}{c}\text { Indepen- } \\
\text { dence }\end{array}$ & Efficiency & $\begin{array}{c}\text { Cronbach's } \\
\text { Alpha }\end{array}$ \\
\hline Caring & $.395^{* *}$ & $-.450 * *$ & $.511 * *$ & $.421 * *$ & $.484 * *$ & $.422 * *$ & .8710 \\
\hline Law \& Code & & $-.159 *$ & $.527 * *$ & $.588 * *$ & $.192 * *$ & $.376 * *$ & .8014 \\
\hline Self Interest & & & $-.279 * *$ & $-.166^{*}$ & $-.322 * *$ & $-.152 *$ & .7682 \\
\hline Service & & & & $.492 * *$ & $.299 * *$ & $.394 * *$ & .7545 \\
\hline Rules & & & & & $.173 *$ & $.442 * *$ & .7763 \\
\hline Independence & & & & & & .113 & .6121 \\
\hline Efficiency & & & & & & & .6818 \\
\hline$* \mathrm{p}<.05$ & & & & & & & \\
\hline$* * p<.01$ & & & & & & & \\
\hline
\end{tabular}

Because the EWC construct anticipates the coexistence of multiple ethical work climates and none of the intercorrelations among the scales exceed 0.70 (Gunst \& Mason, 1980), the 
independence of these scales is considered adequate for the purposes of this study. In addition, as discussed above, the scales are deemed sufficiently reliable for use.

\section{Discriminant Analysis}

One description of discriminant analysis is "finding the linear combination that maximizes the variance between groups relative to the variance within groups" (Bernstein, 1988: 248). This definition is reminiscent of the criteria for evidence of an organizational climate set forth by Joyce and Slocum $(1979,1984)$ :

1. Differences in the mean perceptions between organizations,

2. Internal consistency in perceptions within organizations, and

3. Predictable relationships between mean perceptions and organizational characteristics.

If the purpose of discriminant analysis is to maximize the differences between groups and minimize the differences within groups, its method is to assign an observation of unknown origin to a distinct group on the basis of the value of the observation (Lachenbruch, 1975). In the current study, Lachenbruch's "observation" is the respondent, the "group" is one of the organizations surveyed, and "value" is the respondent's ratings of the ECQ descriptors used in the scales described previously. Thus, the role of discriminant analysis in this study was to "predict" which organization each respondent belonged to by using the scales constructed from the factor analysis and the respondent's answers to the ECQ items. By doing this, the functions that describe the effects of each scale could in turn be used to determine the ethical climate type that was most descriptive of each of the organizations in the study.

Of the six canonical discriminant functions identified in the analysis, two were significant at 0.01 or less, using Wilks' lambda. The first discriminant function had an eigenvalue of 0.614 , explaining 67.7 percent of the variance, with a canonical correlation of 0.617 . The second discriminant function accounted for an additional 15.1 percent of the variance (thus explaining a cumulative 82.9 percent of the variance-the difference of 0.1 percent is due to rounding). It had an eigenvalue of 0.137 and a canonical correlation of 0.347 . A summary of the discriminant analysis fit statistics is in Table 4.6.

Table 4.6: Discriminant Analysis Fit Statistics

\begin{tabular}{cccccccc}
\hline \hline & & $\begin{array}{c}\text { \% Of } \\
\text { Function }\end{array}$ & Eigenvalue & Cumulative & Canonical & Test of & Wilks' \\
Variance & Percent & Correlation & Function & Lambda & p-value \\
\hline 1 & 0.614 & 67.7 & 67.7 & 0.617 & 1 through 6 & 0.469 & $<0.001$ \\
2 & 0.137 & 15.1 & 82.9 & 0.347 & 2 through 6 & 0.756 & 0.01
\end{tabular}

The results of the discriminant analysis are shown in Table 4.7. The standardized discriminant function coefficients are listed on the left side of the table. These coefficients show which of the ethical climate scales contribute most to the differences among the seven organizations in this study. The largest coefficients (absolute values) are the most influential. On the right side of the table are the organizations' centroids, which represent (in multi- 
dimensional space) the groups' means on each of the ethical climate scales. Because there are a total of seven climate scales in this study, the centroids, in effect, pinpoint a spot in sevendimensional space where each of the organizations would be, based on the standardized discriminant functions. Data in Table 4.7, along with Table 4.9, will be used in the next section of this chapter to determine the ethical climate type that was most descriptive of each of the organizations in the study.

Table 4.7: Results of Discriminant Analysis

\begin{tabular}{|c|c|c|c|c|c|}
\hline \multirow{3}{*}{$\begin{array}{c}\text { Ethical } \\
\text { Climate } \\
\text { Scale }\end{array}$} & \multicolumn{2}{|c|}{ Standardized Discriminan } & \multicolumn{3}{|c|}{ Functions at } \\
\hline & \multicolumn{2}{|c|}{ Function Coefficients } & \multicolumn{3}{|c|}{ Group Centroids } \\
\hline & 1 & 2 & Organizations & 1 & 2 \\
\hline Caring & -0.039 & 0.431 & Regional bank & 0.788 & 0.551 \\
\hline Law \& Code & 1.077 & -0.290 & Engineer/survey & -0.119 & 0.461 \\
\hline Self Interest & 0.062 & -0.495 & Manufacturing & -1.822 & -0.316 \\
\hline Service & -0.073 & 0.002 & Non-profit & -0.240 & 0.111 \\
\hline Rules & -0.053 & 0.077 & Police department & 0.820 & -0.484 \\
\hline Independence & 0.196 & -0.168 & Utility company & -0.846 & 0.040 \\
\hline Efficiency & -0.123 & 0.580 & Retail grocer & -0.189 & -0.098 \\
\hline
\end{tabular}

The significant discriminant functions were used to predict group membership of each of the respondents to the surveys. The separate group option was used to classify respondents to their respective organizations, resulting in $54.1 \%$ being correctly classified. This classification method is considered more powerful than the method described in Victor and Cullen's 1987 study, and it also resulted in a higher percentage of correct classifications. Table 4.8 summarizes the results of this classification process.

Table 4.8: Discriminant Analysis Classification Results

\begin{tabular}{ccccccccc}
\hline Actual & & & \multicolumn{7}{c}{ Predicted Group } \\
Group & $(1)$ & $(2)$ & $(3)$ & $(4)$ & $(5)$ & $(6)$ & $(7)$ & Total \\
\hline 1 & 20 & 2 & 0 & 0 & 7 & 1 & 1 & 31 \\
2 & 3 & 10 & 1 & 0 & 2 & 0 & 1 & 17 \\
3 & 0 & 0 & 11 & 0 & 0 & 1 & 0 & 12 \\
4 & 3 & 2 & 0 & 8 & 8 & 5 & 4 & 30 \\
5 & 5 & 0 & 0 & 2 & 32 & 2 & 6 & 47 \\
6 & 2 & 1 & 1 & 2 & 6 & 12 & 5 & 29 \\
7 & 3 & 0 & 2 & 1 & 9 & 2 & 13 & 30 \\
\hline
\end{tabular}

Percent Correctly Classified $=54.1 \%$. 
Table 4.9: Results of One-Way ANOVA Scale Means and Standard Deviations by Organization

\begin{tabular}{|c|c|c|c|c|c|c|c|c|}
\hline \multirow[b]{2}{*}{ Climate Scales } & \multicolumn{8}{|c|}{ Group } \\
\hline & $\begin{array}{l}\text { Regional } \\
\text { bank }\end{array}$ & $\begin{array}{l}\text { Eng/ } \\
\text { Survey }\end{array}$ & $\begin{array}{l}\text { Manu- } \\
\text { facturing }\end{array}$ & $\begin{array}{l}\text { Non- } \\
\text { profit }\end{array}$ & $\begin{array}{c}\text { Police } \\
\text { dept }\end{array}$ & $\begin{array}{l}\text { Utility } \\
\text { co. }\end{array}$ & $\begin{array}{l}\text { Retail } \\
\text { grocery }\end{array}$ & $\mathrm{F}(6,189)$ \\
\hline $\begin{array}{lr}\text { Caring } \begin{array}{r}\text { mean } \\
\text { (std dev) }\end{array}\end{array}$ & $\begin{array}{r}3.867 \\
(.89)\end{array}$ & $\begin{array}{r}3.490 \\
(.74)\end{array}$ & $\begin{array}{r}2.509 \\
(.90)\end{array}$ & $\begin{array}{r}3.333 \\
(.92)\end{array}$ & $\begin{array}{r}3.222 \\
(.87)\end{array}$ & $\begin{array}{r}3.253 \\
(.83)\end{array}$ & $\begin{array}{r}3.067 \\
(.94)\end{array}$ & $4.344 * *$ \\
\hline Law \& Code & $\begin{array}{l}5.37 \\
(.43)\end{array}$ & $\begin{array}{r}4.720 \\
(.94)\end{array}$ & $\begin{array}{r}3.470 \\
(.73)\end{array}$ & $\begin{array}{r}4.450 \\
(.93)\end{array}$ & $\begin{array}{r}5.270 \\
(.62)\end{array}$ & $\begin{array}{r}4.130 \\
(.85)\end{array}$ & $\begin{array}{r}4.590 \\
(.69)\end{array}$ & $18.175 * *$ \\
\hline Self Interest & $\begin{array}{l}3.475 \\
(1.05)\end{array}$ & $\begin{array}{l}3.529 \\
(1.08)\end{array}$ & $\begin{array}{r}4.479 \\
(.63)\end{array}$ & $\begin{array}{l}3.767 \\
(1.11)\end{array}$ & $\begin{array}{r}4.038 \\
(.72)\end{array}$ & $\begin{array}{r}3.793 \\
(1.18)\end{array}$ & $\begin{array}{r}3.767 \\
.89)\end{array}$ & $2.230 *$ \\
\hline Service & $\begin{array}{r}5.09 \\
(1.02)\end{array}$ & $\begin{array}{r}4.800 \\
(.88)\end{array}$ & $\begin{array}{l}3.670 \\
(1.14)\end{array}$ & $\begin{array}{l}4.570 \\
(1.01)\end{array}$ & $\begin{array}{r}4.750 \\
(.82)\end{array}$ & $\begin{array}{r}4.450 \\
(.95)\end{array}$ & $\begin{array}{r}4.780 \\
(.67)\end{array}$ & $4.046 * *$ \\
\hline Rules & $\begin{array}{l}4.55 \\
(.81)\end{array}$ & $\begin{array}{r}4.310 \\
(.97)\end{array}$ & $\begin{array}{r}3.000 \\
(.96)\end{array}$ & $\begin{array}{l}3.700 \\
(1.06)\end{array}$ & $\begin{array}{l}4.300 \\
(1.02)\end{array}$ & $\begin{array}{r}4.030 \\
(.97)\end{array}$ & $\begin{array}{r}3.970 \\
(.94)\end{array}$ & $5.089 * *$ \\
\hline Independence & $\begin{array}{l}3.89 \\
(.80)\end{array}$ & $\begin{array}{r}3.730 \\
(.83)\end{array}$ & $\begin{array}{r}2.860 \\
(.86)\end{array}$ & $\begin{array}{l}4.030 \\
(1.15)\end{array}$ & $\begin{array}{r}3.840 \\
(.87)\end{array}$ & $\begin{array}{r}3.700 \\
(.93)\end{array}$ & $\begin{array}{l}3.770 \\
(1.04)\end{array}$ & $2.410^{*}$ \\
\hline Efficiency & $\begin{array}{l}4.46 \\
(.83)\end{array}$ & $\begin{array}{r}4.180 \\
(.92)\end{array}$ & $\begin{array}{r}3.610 \\
(.84)\end{array}$ & $\begin{array}{l}3.870 \\
(1.21)\end{array}$ & $\begin{array}{r}3.710 \\
(.88)\end{array}$ & $\begin{array}{r}3.560 \\
(.82)\end{array}$ & $\begin{array}{r}3.790 \\
(.97)\end{array}$ & $3.311 * *$ \\
\hline $\begin{array}{l}* p<.05 \\
* * p<.01\end{array}$ & & & & & & & & \\
\hline
\end{tabular}

The final step of the discriminant analysis was to perform ANOVAs to compare each of the seven organizations on the seven ethical climate scales. Table 4.9 compares the scale means and standard deviations for each of the organizations, and shows the F score for each group. Based on the results of the ANOVAs, each of the seven ethical climate types appears to vary significantly across all seven organizations. In fact, five of the seven $\mathrm{F}$ scores are highly significant, at $\mathrm{p}<0.01$. Therefore, it is logical to conclude that each of the organizations can be distinguished from the others.

\section{INTERPRETATION OF DISCRIMINANT ANALYSIS}

\section{General Issues}

The overarching goal of the factor and discriminant analysis in this study was to determine the ethical climate type that was most descriptive of each of the organizations in the study. The accuracy of this determination necessarily depends on several underlying issues. The first of these issues is the ability of the respondents to accurately report their perceptions of their organizations' work climate. This issue was covered in detail in Chapter 2, and it was recognized that "at least on average, respondents can act as objective organizational observers" (Victor \& Cullen, 1988: 110). In addition, careful wording of survey instruments can distinguish between respondents' beliefs concerning work climates and evaluation of those climates (Schneider, 1983; Schneider \& Reichers, 1983). The authors of the ECQ noted that the instrument did not "focus on whether the respondent believed he or she behaved ethically nor did 
it emphasize whether the respondent saw the ethical climate as good or bad" (Victor \& Cullen, 1987: 58).

The second issue is the "strength" of the climate, or how identifiable the climate is to the members of a specific organization (Schein, 1984). ${ }^{7}$ The ECQ does not purport to measure the strength of the ethical work climates directly, but through the results of the factor and discriminant analyses an organization's climate strength can be inferred. The results of this study's analyses show that the ethical climates in these seven organizations have sufficient strength and identifiability to allow statistically significant discrimination among the organizations.

A third issue is the need to use external data to substantiate and interpret the results of factor and discriminant analyses (Child, 1970; Comrey \& Lee, 1992). During the fieldwork for this research project I collected qualitative data about each of the organizations surveyed. This qualitative data will be incorporated into the interpretation of the analyses to assist in determining the ethical climate type that was most descriptive of each of the organizations in the study. The statistical data that was primarily used to make this determination is included in Tables 4.7 and 4.9. Selected data from these tables are reproduced and manipulated in Table 4.10 for ease of interpretation.

Before proceeding to the interpretation for each organization, it should first be noted that function 1 explains substantially more variance in the discriminant analysis (67.7 percent) than does function 2 (15.1 percent). Thus, more weight will be given to the Standardized Discriminant Function Coefficients from function 1 than from function 2.

Some general observations can also be made from the data in Table 4.10. From the data on Group Centroids for function 1, the bank and police department are the most distinct from the manufacturing firm, being separated by more than 2.5 standard deviations. The utility company is also distinct from the bank and police department, with a separation of over 1.5 standard deviations. It is also clear from the Function Coefficients for function 1 that the climate scale that carries the strongest impact is Law \& Code. The only other climate scales that have a nonnegligible influence for function 1 are Independence and Efficiency.

The Group Centroids for function 2 show that the bank and police are the most distinct from each other, separated by more than one standard deviation. The engineering firm is also quite distinct from the police department, with nearly one full standard deviation of separation. The Function Coefficients for function 2 show that the greatest impact is provided by the Efficiency, Self Interest, and Caring climate scales.

These general observations, along with data taken from the Scale Means section of Table 4.10, and qualitative data on each organizations will be used to determine the climate type most representative of each organization. Brief summaries of the logic employed in this interpretation will be shown below.

\footnotetext{
${ }^{7}$ Schein refers to "organizational culture" rather than climate, but the author's concept of strength is equally valid to both the culture and climate constructs.
} 
Table 4.10: Primary Results of Analyses Used in Interpretation

\begin{tabular}{|c|c|c|c|c|c|}
\hline \multirow{3}{*}{$\begin{array}{c}\text { Ethical } \\
\text { Climate } \\
\text { Scale }\end{array}$} & \multirow{2}{*}{\multicolumn{2}{|c|}{$\begin{array}{c}\text { Standardized Discriminant } \\
\text { Function Coefficients }\end{array}$}} & \multicolumn{3}{|c|}{ Functions at } \\
\hline & & & \multicolumn{3}{|c|}{ Group Centroids } \\
\hline & 1 & 2 & Organizations & 1 & 2 \\
\hline Caring & -0.039 & 0.431 & Regional bank & 0.788 & 0.551 \\
\hline Law \& Code & 1.077 & -0.290 & Engineer/survey & -0.119 & 0.461 \\
\hline Self Interest & 0.062 & -0.495 & Manufacturing & -1.822 & -0.316 \\
\hline Service & -0.073 & 0.002 & Non-profit & -0.240 & 0.111 \\
\hline Rules & -0.053 & 0.077 & Police department & $\mathbf{0 . 8 2 0}$ & -0.484 \\
\hline Independence & 0.196 & -0.168 & Utility company & -0.846 & 0.040 \\
\hline Efficiency & -0.123 & 0.580 & Retail grocer & -0.189 & -0.098 \\
\hline
\end{tabular}

Bold numbers hold special significance for interpretation of analyses.

\section{Scale Means by Group}

\begin{tabular}{|c|c|c|c|c|c|c|c|}
\hline ORGICLIMATES & caring & law/code & self interest & service & rules & indepen & efficiency \\
\hline$\overline{1-\text { bank }}$ & 3.867 & 5.370 & 3.475 & $\overline{5.090}$ & $\overline{4.550}$ & 3.890 & 4.460 \\
\hline 2 - engineer & 3.490 & 4.720 & 3.529 & $\underline{4.800}$ & 4.310 & 3.730 & 4.180 \\
\hline 3 - manufacturer & 2.509 & 3.470 & $\underline{4.479}$ & 3.670 & 3.000 & 2.860 & 3.610 \\
\hline 4 - nonprofit & 3.333 & 4.450 & 3.767 & $\underline{4.570}$ & 3.700 & 4.030 & 3.870 \\
\hline 5 - police & 3.222 & $\underline{5.270}$ & 4.038 & 4.750 & 4.300 & 3.840 & 3.710 \\
\hline 6 - utility & 3.253 & 4.130 & 3.793 & $\underline{4.450}$ & 4.030 & 3.700 & 3.560 \\
\hline 7 - grocery & 3.067 & 4.590 & 3.767 & $\underline{4.780}$ & 3.970 & 3.770 & 3.790 \\
\hline
\end{tabular}

Bold numbers indicate highest mean for that climate scale.

Underlined numbers indicate highest mean for that organization.

Italicized numbers indicate lowest mean for that climate scale.

\section{Interpretation of Organizations' Ethical Work Climates}

The underlying logic of the following interpretations made use of the data in Table 4.10 and qualitative data about each of the organizations collected during the fieldwork. Initial judgments regarding the predominant type of ethical climate in each organization were based on the Standardized Discriminant Function Coefficients, Functions at Group Centroids, and Scale Means by Group in the following manner. First, primary reliance was placed on Function 1 because it explains nearly sixty-eight percent of the variance in the discriminant analysis, and Function 2 explains fifteen percent. The Function Coefficients indicate which climate scales carry the most weight in classifying the organizations. Second, the Group Centroids for each organization were viewed in combination with the Function Coefficients. The absolute value of the Group Centroid indicates the relative "strength" of each of the scales in a specific function, for that organization. The sign of the Group Centroid indicates the "direction" of the effect each scale has. For example, if a group has a large negative centroid in Function 1, it indicates that 
the scales in Function 1 have a high degree of explanatory value in interpreting that group's ethical climate type, but in the opposite direction indicated by the Function Coefficients. Third, the Scale Means were used in conjunction with the Function Coefficients and Group Centroids to develop a pattern that indicated the ethical climate type that was most descriptive of each organization. The Scale Means indicated which of the scales the respondents rated as most true of their organization's ethical work climate (responses to the ECQ ranged from completely false to completely true, with higher numerical ratings meaning more true). Finally, the qualitative data collected during the fieldwork were compared to the conclusions drawn from the statistical data to provide further insight into each organization's climate type. Interpretations for each of the organizations are outlined below.

Group 1 (Regional bank) - The bank had the highest scale means for five out of the seven climate scales, including Caring, Law \& Code, Service, Rules, and Efficiency. This may be indicative of the relative strength of work climates in the bank, compared to the other organizations (this is a large family-controlled bank in the United States, and the family prides itself on a strong "positive atmosphere"). In addition, it had the second highest positive Group Centroid for function 1. When this fact is combined with the high Function Coefficient for Law \& Code in function 1, it indicates that the primary ethical climate at the bank is Law \& Code. The bank also has the highest positive Group Centroid in function 2, which indicate an emphasis on the Caring and Efficiency climate scales for function 2. All of this data is supported by the industry and ownership structure of this particular organization. As a commercial bank it is subject to a plethora of laws and regulations. It is also a relatively small bank, which means that it must depend, in large part, on meeting loan underwriting criteria set by other, larger institutions (three of the ten largest banks in the country compete directly with this bank in all of its geographic territories). Its size also is likely to play a part in its emphasis on Efficiency, knowing that acquisition by a larger bank is an ever-present threat. Finally, the fact that the bank is controlled by a single family that prides itself on providing a strong "positive atmosphere" would seem to support the existence of a Caring climate type. However, due to the combination of a high Group Centroid and Law \& Code Function Coefficient for function 1, it appears that the bank's primary ethical work climate is Law \& Code.

Group 2 (Engineering/surveying) - This small, privately-held company has two offices in small-to-medium-sized cities in a mid-Atlantic state. Its Group Centroids show a low negative number for function 1 and moderately high number for function 2. Combined with information from the Function Coefficients, these centroids indicate a positive emphasis on Caring and Service climate scales (both in the Benevolence ethical criterion) for function 1. There is also a positive relationship to the Service and Efficiency climate scales for function 1. Data for function 2 indicate a moderate concern with Caring and Efficiency on function 2 as well. The Scale Means for the engineering firm indicate that its highest mean is in the Service climate scale. The three owners of this firm are all heavily involved in civic organizations and emphasize service to the firm's clients and the community at large. This emphasis, along with the high Scale Mean in the Service climate scale, and positive emphasis in function 1 indicate that this company's primary ethical climate type is Service.

Group 3 (Manufacturing) - This organization had the largest negative Group Centroid in function 1 and a moderate negative in function 2. Combined with the Function Coefficients, 
this information indicates little concern is given to outside rules (Law \& Code), while there is a moderate to high emphasis on Self Interest. The Scale Means also support the emphasis on Self Interest, with a mean substantially higher in this climate scale than in any of the others. It is also interesting to note that the manufacturing firm has the lowest Scale Means in five out of the seven climate types, Caring, Law \& Code, Service, Rules, and Independence. In stark contrast to the bank's results, this firm does not appear to have any strong ethical climate types except Self Interest. This firm manufactures automobile parts for the original equipment and replacement markets, both extremely competitive industries. In addition, the company has a long history of labor/management disputes and has recently been bought out by a foreign company in the same industry. All of these factors seem to support the conclusion that the manufacturing firm's ethical work climate is predominantly one of Self Interest.

Group 4 (Non-profit) - This organization is characterized by moderate to negligible Group Centroids and Scale Means. The conclusion that I drew from this pattern is that this group has either no or many ethical climate types, or that there is little climate strength within the organization. This conclusion can be supported by a brief history of the firm. It was founded over fifty years ago as a quasi-governmental organization, whose mandate was to serve the poor in a small mid-Atlantic city. During the past ten years senior management has completely changed at least twice, and the current management team is trying to change the organization's focus from serving the poor to generating economic and real estate development for the city. Consequently there are several factions within the organization whose views on the proper focus (and likely the ethical work climates) are diametrically opposed. If this is indeed the case, it would follow that there is no clearly unified ethical work climate organization-wide. However, based on a moderate Scale Mean in the Caring climate scale, a positive emphasis on Caring in function 1, and its historical orientation as a social agency, it appears that the Caring ethical climate type is an adequate description for the non-profit organization.

Group 5 (Police department) - This police force operates in a relatively low-crime, medium sized county in a mid-Atlantic state. Its Group Centroids are the highest positive for function 1 and the largest negative for function 2. Considered in conjunction with the Function Coefficients, it appears that Law \& Code and Independence are important ethical climate scales on function 1. Function 2 indicates that Self Interest is an important consideration for the police officers and employees. The highest Scale Mean for the police department was, by far, for the Law \& Code climate scale. Given that the reason for this department's existence is to uphold the laws promulgated by other governmental officials, it seems entirely reasonable that the primary ethical work climate here is Law \& Code. More interesting is the secondary emphasis on Independence and Self Interest. Police officers are required to make many decisions on a daily basis whether to enforce specific laws or not ("Is five miles per hour over the speed limit speeding or not?" "Does the paperwork required for an arrest on a minor disturbance override the benefit of incarcerating the perpetrator?"), and they must often rely on their personal morals and beliefs to make many of those decisions (Ho, 1999). In a similar vein, putting their health and/or lives at risk on a daily basis would also likely make Self Interest a prime consideration (Helsen \& Starkes, 1999; Kane, 1999). But for purposes of this study, Law \& Code is clearly the primary ethical work climate of the police department. 
Group 6 (Utility company) - This group is from a maintenance department of a large electric provider in the eastern United States. Its members travel to generating plants in several states to perform scheduled maintenance on the heavy equipment, and to make emergency repairs. Like the non-profit organization, the utility department did not exhibit any clear ethical work climate. Because the department was newly formed less than a year before the study was conducted, it is possible that there had been insufficient time to develop a strong work climate within the group. This department did show a large negative centroid on function 1, which indicates little regard for Law \& Code. It also indicates a positive emphasis on Efficiency, Rules, and Service. The Scale Means for the utility department also showed the lack of clear emphasis on any one climate scale. Means for Law \& Code, Service, and Rules were the highest for this group, but were too close for any one to stand out. Law \& Code was eliminated from consideration because of its large negative score on function 1. With little else to go on, I chose Rules as the primary ethical climate type because of the strict time schedules and maintenance procedures imposed on the group by the company.

Group 7 (Retail grocery) - Respondents to this study were employed in a regional administrative office for this large grocery chain. A few of the subjects had experience working in the stores, but the primary identification with the work group was at the regional administrative level. The respondents in this organization exhibited a moderately low negative centroid on function 1, which translated to an emphasis on Efficiency, Service, and Rules on that function. Function 2 was of little help in deciphering an ethical work climate because the centroid was near zero. The grocery's Scale Means were highest in Service and Law \& Code. Combining this information with that from function 1 indicates that Service is the predominant ethical work climate at the grocery.

The following list summarizes the primary ethical work climates for each organization, based on the foregoing interpretation of factor and discriminant analyses and qualitative data.

Group 1 (Regional bank) - Law \& Code

Group 2 (Engineering/surveying) - Service

Group 3 (Manufacturing) - Self interest

Group 4 (Non-profit) - Caring

Group 5 (Police department) - Law \& Code

Group 6 (Utility company) - Rules

Group 7 (Retail grocery) - Service

In the next section of this chapter, these ethical climate types will be used to test the first three hypotheses, as stated in Chapter 2.

\section{TESTS OF HYPOTHESES}

Data for each of the independent and moderating variables were collected during the fieldwork, as described in Chapter 3. These data were collected in a computer-readable format and were summarized by the Test Scoring Services department at a large research university. Data for the dependent variable, moral awareness, was collected from the respondents' answers 
to an open-ended question asking the subjects to identify "all of the considerations that you deem important in making a decision about the situation just shown in the video." Respondents' answers to the moral awareness section of the survey were "scored" by two research assistants who were unfamiliar with the study and me. The research assistants viewed the video clip and were instructed to give each issue identified by the respondent that could reasonably involve an ethical concern (e.g. issues of fairness, concern for employees' welfare, the potential effect on the surrounding community, etc.) a score of 1 . Issues not involving ethical concerns were given a 0 . The respondents' rating of the importance of each consideration was multiplied by the rater's score. The numerical score for each consideration was then added to arrive at a single number representing the respondent's moral awareness regarding the scenario presented in the video clip. The dependent variable in each of the hypotheses is the average individual moral awareness score for each organization.

Because the scoring of the moral awareness variable is susceptible to rater bias, all three raters worked independently, and the final moral awareness score for each respondent is the unweighted average of the three raters' scores for that individual. The response sheets were also shuffled prior to being scored to prevent any individual rater's bias.

One concern that I had about using the video clip was the possibility that respondents had previously seen the movie or play, or had read the play Other People's Money. Previous exposure to the story line could give a respondent more information about the situation, or could have caused a bias that respondents seeing the video clip for the first time would not have. To control for this possibility each respondent was asked if he or she had ever seen the movie or play, or read the play prior to viewing the video clip during the survey. Forty-five of the respondents (out of a total sample of 196) reported previous exposure to the movie or play. The individual moral awareness scores for those who had seen or read the movie or play were compared to those who had not. Using ANOVA to analyze the variance between the groups showed no statistically significant difference in their moral awareness scores, thus obviating this concern.

The results of the factor and discriminant analyses have guided me to conclude that each of the organizations surveyed exhibited certain specific and distinct ethical work climates, as outlined in the previous section of this chapter. These climate types were then used as the independent variables in tests of hypotheses one, two, and three. The moderating variables for hypotheses four through seven were collected as separate data during the fieldwork. The dependent variable in all hypotheses, moral awareness, was represented by the average moral awareness scores for each organization, as described above. Results of the tests of hypotheses are reported below.

$\mathbf{H}_{1}$ : Organizations with ethical work climates that utilize benevolence or principle ethical criteria at all loci of analysis will be associated with higher levels of moral awareness among their members than will organizations with ethical work climates using the egoistic ethical criterion. In this test, the average moral awareness score for the manufacturing firm (whose ethical work climate was Self Interest, using the egoistic ethical criterion) was compared to all of the other firms' average moral awareness scores using ANOVA. The mean for the 
manufacturing firm was 4.47222, and the other firms' mean was 9.01842. F for this test was 4.737, significant at the 0.05 level of confidence. Thus, hypothesis one was supported.

$\mathbf{H}_{2}$ : Within a specific ethical criterion, organizations with ethical work climates employing broader loci of analysis will be associated with higher levels of moral awareness among their members than will organizations with ethical work climates utilizing narrower loci of analysis. This test involved comparing two separate groups of organizations. The average moral awareness score for the non-profit organization (with a Caring ethical work climate) was compared to the scores for the engineering/surveying and retail grocery firms (whose ethical work climates were Service). All three of these organizations employed the benevolence ethical criteria. The mean for the non-profit was 9.76667 and the mean for the engineering/surveying and grocery companies was 7.96454. Because the non-profit, using a narrower locus of analysis, had a higher mean than did the other two firms, this test did not support hypothesis two. In addition, the $\mathrm{F}$ score was 1.311 , not significant at 0.05 .

The second test of this hypothesis compared the mean moral awareness scores for the utility department, with a Rules ethical work climate, and the scores for the regional bank and police department, with a Law \& Code climate. Both of these climate types involve the principle ethical criterion. The mean moral awareness score for the utility was 5.36782, while the bank's and police department's mean was 10.72650. The mean for the ethical climate using the cosmopolitan locus of analysis, Law \& Code, was higher than the mean in the local locus of analysis, indicating support for the hypothesis. F for this test was 12.171 , highly significant at less than 0.01. This test did support hypothesis two.

Thus hypothesis two received partial support - firms using the cosmopolitan locus of analysis did show significantly higher levels of moral awareness in the principle ethical criterion, but did not in the benevolence criterion. Because of the mixed support for this hypothesis, I performed an additional test that was not part of the original hypotheses. This new hypothesis,

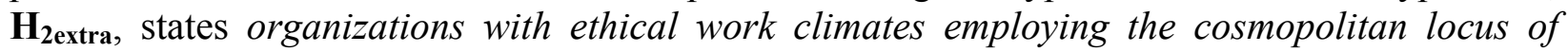
analysis will be associated with higher levels of moral awareness among their members than will organizations with ethical work climates utilizing the individual and local loci of analysis. Admittedly, this post hoc hypothesis is tailored to the existing data, as: 1) the non-profit organization has a Caring climate, which spans the individual and local loci, and 2) no organization in this study exhibited an Efficiency climate, thus avoiding the question raised in hypothesis one regarding heightened moral awareness in the benevolence and principle ethical criteria compared to the egoistic criterion. However, the results are interesting, so they are presented here.

In this test of $\mathbf{H}_{2 \text { extra }}$ the mean moral awareness score of the manufacturer (Self Interest), non-profit (Caring), and utility (Rules), referred to as Set 1, was compared to the mean for the engineers and grocer (Service) and bank and police department (Law \& Code), Set 2. The mean for Set 1 was 7.07512 and Set 2's was 9.68800. F for this test was 6.306, significant at the 0.05 level of confidence. Thus $\mathbf{H}_{2 \text { extra }}$ was supported by the data.

$\mathbf{H}_{3}$ : An organization with an ethical work climate associated with the egoistic ethical criterion and individual locus of analysis will be associated with the lowest degree of moral 
awareness among its members. Testing this hypothesis involved doing a series of two-tailed Ttests between the mean moral awareness score for the manufacturing firm (Self Interest climate) and each of the other firms. Mean and significance levels for each T-test are shown below in Table 4.11.

Table 4.11: Results of Two-Tailed T-tests for Hypothesis 3

\begin{tabular}{|l|c|c|l|}
\hline $\begin{array}{l}\text { COMPARISON } \\
\text { ORGANIZATION }\end{array}$ & $\begin{array}{c}\text { COMPARISON } \\
\text { MEAN }\end{array}$ & $\begin{array}{c}\text { MANUFACTURER } \\
\text { MEAN }\end{array}$ & $\begin{array}{c}\text { SIGNIFICANCE } \\
(2-T A I L E D)\end{array}$ \\
\hline Regional bank & 12.38710 & 4.47222 & $0.000 *$ \\
\hline Engineer/survey & 8.39216 & 4.47222 & $0.030 * *$ \\
\hline Non-profit & 9.76667 & 4.47222 & $0.044 * *$ \\
\hline Police department & 9.63121 & 4.47222 & $0.042 * *$ \\
\hline Utility department & 5.36782 & 4.47222 & 0.668 \\
\hline Retail grocery & 7.72222 & 4.47222 & $0.118 * * *$ \\
\hline
\end{tabular}

$\begin{array}{ll}* & \mathrm{p}<0.01 \\ * * & \mathrm{p}<0.05 \\ * * * & \mathrm{p}<0.10\end{array}$

Only one of the six T-tests (with the utility department) was not significant. All other tests showed significantly different mean moral awareness scores. Thus, on balance, the third hypothesis in this study was substantially supported.

The remaining tests examined the effects the moderating variables had on the relationship between the independent and dependent variables. Baron and Kenny (1986: 1174) state, "The moderator hypothesis is supported if the interaction... [between the independent and moderating variables] is significant." The authors' statement presumes that the hypothesis is stated in the positive, but because my moderator hypotheses are all stated in the negative, they will be supported if the interaction is not significant. In the present study, both the independent and moderating variables are categorical variables. The proper method for testing for an interaction between the independent and moderating variables in this case is a two-by-two ANOVA (Baron \& Kenny, 1986). This methodology was used in each of the tests reported below.

$\mathbf{H}_{4}$ : Sex will not exhibit a significant moderating effect on the relationship between ethical work climate and moral awareness. F for this two-by-two ANOVA test was 1.014, which was not significant at the 0.05 level. Thus, hypothesis four is supported.

$\mathbf{H}_{5}$ : Age will not exhibit a significant moderating effect on the relationship between ethical work climate and moral awareness. Respondents in this study reported their ages by range -20 to 29,30 to 39,40 to 49,50 to 59 , and 60 to 69 . The mean moral awareness scores for these groups are shown below in Table 4.12. 
Table 4.12: Mean Moral Awareness Scores by Age

\begin{tabular}{|c|c|c|}
\hline AGE GROUP & N (not all reported) & MEAN SCORE \\
\hline $20-29$ & 27 & 9.54321 \\
\hline $30-39$ & 60 & 9.01667 \\
\hline $40-49$ & 69 & 8.72464 \\
\hline $50-59$ & 35 & 7.28571 \\
\hline $60-69$ & 2 & 16.0000 \\
\hline
\end{tabular}

Testing age as a moderating variable produced an $\mathrm{F}$ of 0.612 , which was not significant at the 0.05 level. Thus hypothesis five was supported.

$\mathbf{H}_{6}$ : Level of formal education will not exhibit a significant moderating effect on the relationship between ethical work climate and moral awareness. Survey respondents reported their highest attained education level, from "no high school diploma or GED" to "graduate work or degree." Mean moral awareness scores are shown in Table 4.13.

Table 4.13: Mean Moral Awareness Scores by Education Level

\begin{tabular}{|l|l|l|}
\hline EDUCATION LEVEL & N (not all reported) & MEAN SCORE \\
\hline No diploma/GED & 3 & 2.33333 \\
\hline Diploma/GED & 29 & 7.26437 \\
\hline Some college & 55 & 8.75152 \\
\hline College degree & 86 & 9.17442 \\
\hline Graduate work or Degree & 22 & 9.60606 \\
\hline
\end{tabular}

As a moderating variable, education level was tested for interaction with the independent variable. The two-by-two ANOVA resulted in an F score of 1.928, which was significant at the 0.05 level. Thus, hypothesis six was not supported-education level did have a significant effect as a moderating variable.

$\mathbf{H}_{7}$ : Exposure to formal ethics training will not exhibit a significant moderating effect on the relationship between ethical work climate and moral awareness. One hundred twenty-three of the respondents reported attending a formal training course in diversity issues, sensitivity, or ethics. Seventy-three stated that they had never attended such a session. The mean for attendees was 8.86179 and the non-attendees mean was 8.53881 . In the test for training as a moderating variable, the F score was 0.372 , not significant at 0.05 . Thus hypothesis seven was supported.

\section{SUMMARY OF RESULTS}

Factor and discriminant analyses were performed on responses to the Ethical Climate Questionnaire in order to further validate the EWC construct and to determine the ethical climate type that was most descriptive of each of the organizations in the study. The ethical climate types so identified were then used as the independent variables in hypotheses one, two, and three. These hypotheses dealt with the expected relationship between an organization's ethical work 
climate type and its members' general level of moral awareness, the dependent variable. It was anticipated that organizations with ethical climates employing the benevolence or principle ethical criteria would have members whose level of moral awareness was higher than organizations utilizing the egoistic ethical criterion. It was also expected that organizations with a broader locus of analysis would have higher levels of moral awareness among their employees than would organizations with narrower loci of analysis. Finally, it was anticipated that organizations with an egoistic/individual climate type (Self Interest) would have the lowest levels of moral awareness among their members. All of these expectations were supported to a degree - there was a significant difference between moral awareness scores for the egoistic and benevolence/principle ethical criteria; the cosmopolitan locus of analysis was associated with heightened moral awareness scores in the principle ethical criterion, but not within the benevolence criterion; and the organization with a Self Interest climate had lower mean moral awareness scores than each of the other organizations, with all but one statistically significant. Therefore, hypothesis one was supported, hypothesis two was partially supported, and hypothesis three was substantially supported.

Hypotheses four, five, six, and seven dealt with the moderating variables' effects on the relationship between the independent variable, ethical work climate, and the dependent variable, moral awareness. The moderating variables were sex, age, attained educational level, and receipt of training in ethics, diversity, or sensitivity. It was expected that group influence, in the form of ethical work climate, would override the effects of the person variables. Therefore, I hypothesized that none of the moderating variables would have a significant moderating effect on the relationship between EWC and moral awareness. The expected results were obtained for hypotheses four, five, and seven. Only the level of formal education (hypothesis six) was shown to significantly moderate the relationship between the independent and dependent variables. Thus, hypotheses four, five, and seven were supported, and hypothesis six was not supported.

The results of these tests will be discussed and evaluated in further detail in Chapter 5. Limitations of the study will also be reviewed, and implications of the research will be explored. 


\section{CHAPTER 5 - DISCUSSION AND SUMMARY}

\section{INTRODUCTION}

The underlying assumption in this research has been that reducing unethical business practices is a desirable goal. In order to begin the process of improving ethical behavior, it is necessary to first understand the causes of the behavior. Multiple possible causes of individuals' ethical behavior were noted, including physical, cognitive, and environmental influences. The factors chosen to study in the present project, Ethical Work Climate (the independent variable) and moral awareness (the dependent variable), represent environmental and cognitive aspects of behavior. Selection of these two variables helped fill a lacuna in the literature; EWC, despite its introduction nearly fifteen years ago, is still being validated as a construct and its potential relationships with ethical behavior are just beginning to be tested. Similarly, moral awareness is a critical, albeit virtually overlooked, element in any ethical behavioral process (Blasi, 1980; Blum, 1991; Jones, 1991). Furthermore, the connection between organizational influences such as EWC and individual ethical choices has been presumed for years, but has rarely been tested empirically (Jones \& Ryan, 1997, 1998).

The previous chapters have outlined the theoretical foundation for the hypothesized relationships between ethical work climate and moral awareness, the methods employed to test those relationships, and the results of the tests and data analyses. This final chapter will evaluate and discuss the results of the study, delineate the limitations of the research, and explore its implications for future research and practice.

I will first review the overarching purposes and significance of the study, and then discuss the results of the data analyses, both in terms of the EWC research stream and the specifics of this project. Finally, the implications of the results and limitations of the present study for future research will be explored.

\section{Purpose of the Study}

This research project examined the relationship between an organization's ethical work climate and its members' moral awareness. The theoretical basis for the existence of such a connection was drawn from the fields of history, sociology, psychology, philosophy, and organization theory. Victor and Cullen's $(1987,1988)$ pioneering work on the Ethical Work Climate construct provided the framework for the independent variable. The authors posited that a typology of ethical climate types could be generated from two dimensions of moral reasoning - the ethical criteria used to make judgments about a moral situation and the locus of analysis considered. The bases of the ethical criteria dimension are rooted in moral philosophy (Williams, 1985) and cognitive moral development (Kohlberg, 1973, 1981, 1984; Rest, 1979, 1986, 1994). Victor and Cullen $(1987,1988)$ included three distinct and relatively incompatible ethical criteria: egoistic, benevolence, and principle. The rationale for locus of analysis comes 
from Kohlberg's work, as well as the sociological theories of Merton (1957) and Gouldner $(1957,1958)$. Philosophers have also addressed this concept (Deutsch, 1974, 1985; Staub, 1989; Opotow, 1990; Moberg \& Seabright, 2000). Similar to the ethical criteria, three separate and incompatible loci of analysis were presented: individual, local, and cosmopolitan. Blum's (1991, 1994) and Rest's $(1979,1994,1999)$ thoughts on moral awareness - the recognition that an ethical issue is at stake in a given situation — guided development of this concept.

The historical and theoretical bases for the link between social and work group influences and individuals' perceptions and actions came from a multitude of sources. In tracing the roots of the sociological tradition Nisbet (1993) noted two themes (individualization and the separation of the economy from other social institutions), that have contributed to the likelihood that individuals are influenced by the economic institutions they work for in a manner distinct from other social structures. Durkheim's (1895/1962) recognition of the existence of social facts and his emphasis on the primacy of society over the individual provide the conceptual support for the link between group influences and individual cognition and behavior. Finally, the idea of social embeddedness reiterates the influence that groups have on individuals (Granovetter, 1985).

Broadly speaking, I hypothesized that the use of the benevolence or principle ethical criteria in an organization's ethical climate would be associated with higher levels of individual moral awareness, when compared to members of organizations employing egoistic ethical criterion in their ethical work climates. I anticipated this result because the ethical criteria of benevolence and principle, by definition, involve consideration of multiple parties' interests, while the egoistic criterion emphasizes the moral agent's interests over the interests of others. Similarly, organizations with broader loci of analysis were expected to have members with higher levels of moral awareness than would groups with narrower loci of analysis. Broader loci of analysis should be associated with heightened moral sensitivity if only because the moral agent is "aware" of a wider population that may be affected by the situation in question.

In addition, prior research on various person variables provided a basis for predicting that moral awareness would vary with the existence of those characteristics. However, because of the overriding influence of group norms, the moderating variables, including sex, age, education level, and ethics training were hypothesized to not significantly affect the relationship between an organization's EWC and the moral awareness of its members. ${ }^{8}$

Secondarily, this study was designed to seek further support for the EWC construct by providing additional evidence of the existence of ethical work climates and of the validity of the different climate types.

\section{Significance of the Study}

I have previously stated that this research was designed to assist in filling a gap in the research literature by investigating that relationship between an environmental factor (Ethical Work Climate) and a cognitive antecedent to moral behavior (moral awareness). Shortcomings in the existing literature in this area include methodological issues, research perspectives, and

\footnotetext{
${ }^{8}$ See the "Moderating Variables" section of Chapter 2 for discussion and references.
} 
prescriptive elements of EWC, in addition to the basic investigation of the relationship between the two variables.

As noted in Chapter 2, the ability to meaningfully aggregate individuals' perceptions of their work environments remains the primary difficulty in measuring work climate (Joyce \& Slocum, 1979, 1984; Schneider \& Reichers, 1983). It was also observed that some of the prior studies involving EWC have suffered from methodological inadequacies in this area. From a theoretical standpoint, one of the contributions of the current research is evidence supporting the existence of ethical work climates through the aggregation of members' perceptions of their work environments. This study has, to my knowledge, the broadest range of organizations (in numbers, sectors, and industries) surveyed to date in EWC research, using methodologically valid techniques. In addition, the present study has continued the use of a prescriptive element in EWC research by showing that certain types of ethical climates are associated with higher levels of individual moral awareness. If, as a moral philosopher says, moral perception is a good in its own right (Blum, 1991, 1994), or if it is viewed more instrumentally, as a necessary precursor to moral judgment and behavior, the current study suggests that certain types of ethical climates may be connected with higher degrees of this moral good.

Chapter 2 also notes the measurement difficulties associated with moral awareness (Rest, 1986, 1994; Bebeau, 1994). Using techniques introduced by others in the psychology and business ethics fields (Bebeau \& Brabeck, 1989; Shaub, Finn, \& Munter, 1993; Butterfield, Treviño, \& Weaver, 1997, 2000), this study has provided further evidence that moral awareness can be measured effectively. Doing so helps operationalize concepts introduced by moral philosophy (Blum, 1991, 1994).

However, the most significant contribution provided by the current study is its evidence that a widely-recognized, but unobservable element of organizations, namely work climates, is in fact, associated with another important, and equally opaque factor, individual moral awareness. Business and organizational researchers often rely solely on structural functionalist approaches to their studies, relying exclusively on observable facets of their subjects, but the current project indicates the relevance and importance of the more nebulous elements of organizational operations. Many writers have described the profound effects culture (which would include the climate construct) has on organizations, but they also note the almost universal lack of attention given to it (Deal \& Kennedy, 1982, 2000; Goffee \& Jones, 1998; Collins \& Porras, 2000). The current study provides one more reason to recognize the impact of work climates and to view them as important as any other aspect of the organization.

\section{DISCUSSION OF RESULTS}

\section{Validation of the Ethical Work Climate Construct}

The originators of the EWC construct called for additional research to: 1) further develop the Ethical Climate Questionnaire, 2) validate the construct, and 3) extend the use of the EWC into related research questions (Victor \& Cullen, 1987, 1988). The current study aids in the fulfillment of the second and third of these mandates. 
Validation of the EWC construct requires evidence on two levels. First, a researcher must establish the existence of a climate in a general sense. This subsection of Chapter 5 will deal with this question using the widely recognized criteria promulgated by Joyce and Slocum (1979, 1984). The second level of evidence requires substantial replication of previously identified ethical climate types specific to the EWC construct. This will be done in the following subsection.

Evidence of the Existence of Climates The first step in validating Victor and Cullen's EWC construct is establishing that a climate does indeed exist within the organization or work group. Joyce and Slocum $(1979,1984)$ have outlined three criteria for evidence of an organizational climate:

1. Differences in the mean perceptions between organizations,

2. Internal consistency in perceptions within organizations, and

3. Predictable relationships between mean perceptions and organization characteristics.

Each of these criteria was used below to evaluate the results of the data analysis in the present study.

Tables 4.8 and 4.9 in Chapter 4, representing the results of the classification based on discriminant analysis and one-way ANOVA scale means and standard deviations, respectively, are the indicators used to determine the differences between organizations. Table 4.8 shows that discriminant analysis was able to correctly classify 54.1 percent of the respondents to their organizations, an acceptable level. Likewise, Table 4.9 indicates that each of the seven organizations surveyed in this study is distinguishable from the others. Thus, the first criterion is met in this research project.

The second criterion, internal consistency, is indicated by the standard deviations shown in Table 4.9. Compared to the means displayed in Table 4.9, it appears that the standard deviations for each group and climate scale indicate a reasonable degree of internal consistency. This measure also serves as a reasonably good proxy for the strength of the perceived climate in each organization (Schein, 1984). In the four organizations whose discriminant analysis results were most easily interpreted (the regional bank, manufacturing firm, police department, and retail grocer), the standard deviation for the predominant ethical climate was the lowest of all of the climate types in each organization. In each case the minimum standard deviation coincided with the highest scale mean. This confluence indicates a clearly held consensus about the prevailing ethical climate in each organization. Conversely, in the other three organizations, whose results were not as easily interpreted, the pattern of scale means and standard deviations was present, but not as well defined. Thus, on balance, Joyce and Slocum's second criterion, internal consistency, was also met.

Predictability of the relationships between mean climate perceptions and organizational characteristics (also known as "face validity") is the third criterion suggested by Joyce and Slocum. Again, this criterion for evidence of climate was met in this study. Specifics of these relationships for each organization were detailed in Chapter 4, and are summarized here. 
The two organizations exhibiting signs of the Law \& Code climate (the regional bank and police department) both operate in environments where reliance on laws and rules promulgated by parties outside the organization is essential. The police department's reason for existence is to enforce the laws of its jurisdiction. The bank also operates in a highly regulated industry, and because of the competition it faces from larger banks, many of its underwriting criteria and banking practices must be in line with those used by its competitors.

Two organizations, the engineering/surveying firm and the retail grocer, displayed characteristics of the Service climate type. Both companies operate in industries where care for and service to the customer/client is very important. In addition, the engineering firm is owned by three men who are active in community affairs and make service to the larger community a high priority. The grocer's mid-Atlantic regional headquarters are in the city where the survey was conducted; consequently its visibility as a large employer in the community necessitates its focus on the community.

The manufacturing company, with its Self Interest climate, has a long history of labor/management discord, and has recently been acquired by a foreign competitor. It is in a very competitive industry, with frequent lay-offs and plant closings, which adds to the "every man for himself" environment prevailing here.

The other two participating organizations, the non-profit and utility department, did not have climates as easily discernible as the others. However, the climates that were judged to be most descriptive of these groups did fit with their histories and characteristics. The non-profit, with a Caring climate, was formed to provide services to the poor in its local community. A new senior management team was attempting to change this focus more toward an economic development orientation, and the results of the ECQ reflected this flux. The utility department was a newly formed group (less than one year prior to the date of the survey) that had not yet coalesced into a cohesive unit. The results of the discriminant analysis for this organization were also mixed, with nearly equal weight placed on the Service, Rules, and Law \& Code climate types. This grouping makes sense, though, given the group's mandate to provide repair and maintenance services to power generating plants within the company (Service), closely follow service schedules and procedures (Rules), and ensure that the plants operate within Federal and state regulations (Law \& Code).

As detailed above, all three criteria to provide evidence of an organizational climate proposed by Joyce and Slocum $(1979,1984)$ were met in this study. Therefore, I conclude that this research provides additional support for the existence of ethical climates, as the EWC supposes.

Replication of EWC Factors The second stage of validating the EWC construct requires substantial replication of previously identified ethical climate types. If the Ethical Work Climate construct were a perfect representation of reality, and the Ethical Climate Questionnaire were worded to perfectly capture the essence of each of the nine potential climate types, then each study involving the EWC should produce identical results. Each of the nine climate types should be identifiable through a factor analysis, with each of the four descriptors loading on its respective factor and not loading on any other factor. Unfortunately, the EWC does not meet this 
standard of perfection. Therefore, in order to verify the validity of the construct, it is necessary to compare results from the present study to those from prior research efforts. Substantial replication of previously identified climate types lends credence to the construct and provides further evidence of its validity. This is presented in Table 5.1, by graphically representing the climate types identified in each of the studies reviewed in Chapter 2 that reported identifiable climate types. Each of these studies was examined in detail in Chapter 2; a summary is presented here for ease of comparison.

Because the various authors called the emergent climate types by different names, Table 5.1 employs the intersections of ethical criteria and loci of analysis to identify the climates. In the table headings, the first letter represents the ethical criterion (E-egoistic, B-benevolence, and $\mathrm{P}$ - principle) and the second letter stands for the locus of analysis (I-individual, L-local, and $\mathrm{C}$-cosmopolitan).

Table 5.1: Identified Ethical Climate Types of Studies Reviewed

\begin{tabular}{|l|c|c|c|c|c|c|c|c|c|}
\hline STUDY & EI & EL & EC & BI & BL & BC & PI & PL & PC \\
\hline VanSandt 2001 & $*$ & & $*$ & \multicolumn{2}{|c|}{$*$} & $*$ & $*$ & $*$ & $*$ \\
\hline Victor \& Cullen 1987 & \multicolumn{2}{|c|}{$*$} & $*$ & \multicolumn{2}{|c|}{$*$} & $*$ & $*$ & $*$ & $* *$ \\
\hline Victor \& Cullen 1988 & \multicolumn{2}{|c|}{$*$} & \multicolumn{2}{|c|}{$*$} & $*$ & $*$ & $*$ & $*$ \\
\hline Cullen, Victor \& Bronson 1993 & $*$ & & $*$ & \multicolumn{2}{|c|}{$*$} & $*$ & $*$ & $*$ & $*$ \\
\hline Wimbush, et. al. 1997a & $*$ & & & & & $*$ & $*$ & & $*$ \\
\hline Wimbush, et. al. 1997b & $*$ & & & $*$ & & $*$ & $*$ & & $*$ \\
\hline Agarwal \& Malloy 1999 & $*$ & & & $*$ & & $*$ & $*$ & & $*$ \\
\hline
\end{tabular}

* Climate type identified

** Climate type identified in conjunction with a non-adjacent cell

Examination of Table 5.1 reveals several interesting items. First, the climate types in the Egoistic/Individual, Benevolence/Individual, Principle/Individual, and Principle/ Cosmopolitan intersections have been identified in nearly every study. Second, of these four recurring climate types, the Principle/Individual cell always appeared as a separate factor, and the Egoistic/Individual and Principle/Cosmopolitan cells did so in nearly every case. The Benevolence/Individual factor combined with the Benevolence/Local cell in over half of the studies, indicating that the respondents often failed to make a distinction between loci of analysis when the benevolence ethical criterion was involved.

Second, the Egoistic/Local and Benevolence/Local cells never appeared as separately identified factors, and the Principle/Local intersection did only about half of the time. This pattern is especially interesting, given the emphasis that many senior management teams place on loyalty to the organization, competing against other firms, and "winning," however that might be defined. Four possible explanations for this pattern seem plausible. First, the ECQ items may not be descriptive of what respondents think of as firm specific. In the present study, one of the Egoistic/Local items never loaded on a factor and was eliminated from the factor analysis, two of the EL items loaded on an unreliable factor, and the fourth EL descriptor loaded on the Self 
Interest factor. One of the Benevolence/Local items was discarded from the factor analysis because it loaded on more than one factor, and the other three BL descriptors combined with the Benevolence/Individual items to form a single factor. However, three of the Principle/Local descriptors did load on the expected Rules factor and the fourth loaded on the adjacent Law \& Code climate type. There does appear to be sufficient "noise" among the local locus of analysis descriptors to warrant review and possible revision of some of these items.

The second possible explanation for the lack of identification with the local locus of analysis is the composition of the organizations surveyed in the studies. Cullen, Victor, and Bronson (1993) surveyed four accounting firms, none of which identified an Egoistic/Local ethical climate type. Given CPAs' emphasis on professional rules and standards, it is hardly surprising that they would not emphasize the local level of analysis. In addition, because the partnership form of organization is predominant in the accounting profession, profits inure directly to the partners, rather than to the organization, effectively shifting the focus from the local level to the individual. The Wimbush, Shepard, and Markham (1997a, 1997b) studies utilized the same data pool for both papers. The organization surveyed was a single national retail chain, which the authors argued may have had a cosmopolitan locus of analysis because of its industry. Agarwal and Malloy (1999) surveyed one non-profit group in their study. They argued that non-profits typically do not have sub-climates that emphasize organizational rules and procedures. The six previous studies that reported emergent ethical climate types surveyed only thirteen existing entities (Victor \& Cullen, 1987 purposefully included a group of MBA students employed by a variety of companies), and four of those were from the same industry. Therefore, it is possible that the organizations studied prior to this project represent a skewed sample that is unrepresentative of the firms using the local locus of analysis.

The third possible explanation for the lack of emphasis on the local locus of analysis is employees' lack of loyalty to, or identity with the organization. Because of recent widespread layoffs and declining job security, employees may feel less committed to the organization, and as a result the locus of analysis could shift to the individual or the community at large. Hofstede (1998) notes that organizational members must follow the practices of the organization in order to remain a participant, but they do not have to embrace its values.

Fourth, as noted in Chapter 2, the locus of analysis axis is best viewed as a continuum, rather than as a discrete variable. Because of the infinite variation possible in "who" or "what" is considered in ethical deliberations, it may be inherently difficult for respondents to make the distinctions required to classify ethical climates along the locus of analysis axis. Victor and Cullen (1988) also noted that ethical climates within organizations are defined primarily by the ethical criteria, rather than the locus of analysis, although the authors did not speculate on possible explanations.

The third pattern that can be discerned from Table 5.1 is the erratic appearance of the Egoistic/Cosmopolitan climate type. The developers of the EWC state, "at the cosmopolitan locus of analysis, it [the particular entity in whose interests one is expected to act] is defined as considerations of the larger social or economic 'system's' interest (e.g., efficiency)" (Victor \& Cullen, 1988: 106). Because of the current emphasis on "efficiency" in most organizations (i.e., "lean"), many respondents may view these descriptors as tautologies. It is also possible that 
many respondents are unable to make the distinction between the "larger social or economic 'system's' interest" as intended by the ECQ's authors, and the efficiency that benefits the organization itself.

Finally, earlier studies appeared to show that ethical climates within organizations were defined mainly by the ethical criteria described. This can be seen graphically in Table 5.1 by the number of horizontal combinations within each study. However, the present study indicates a higher degree of distinction based on the locus of analysis than did the previous studies. The reason for this is not immediately apparent, but may be related to the design of the study, with seven widely disparate organizations included.

In summary, four of the theoretically possible climate types have been identified in virtually every study reviewed, and one other, the Benevolence/Cosmopolitan factor, has been a part of a factor in each study. In addition, the present study, which identified seven factors, reproduced the findings of the Cullen, Victor, and Bronson (1993) study. Thus it is fair to say that, at a minimum, five, and as many as seven of the ethical climate types have been replicated, and should be considered valid. This finding lends credence to the EWC construct and provides further evidence of its validity.

\section{Results of Tests of Hypotheses}

Seven hypotheses related to the relationship between an organization's Ethical Work Climate and the moral awareness of its members were presented in this study. The first three of these concerned the direct relationship between the two variables, unmoderated by any other variables. The expectation was that organizations with ethical climates described by the benevolence or principle ethical criteria would have higher levels of moral awareness among their members than would organizations with egoistic ethical climate types (hypothesis one). The second hypothesis anticipated that organizations with ethical climates characterized by broader loci of analysis within a given ethical criterion would have higher levels of moral awareness from its participants than would organizations with ethical climates using narrower loci of analysis, within the same ethical criterion. The third hypothesis was a logical outgrowth of the first two hypotheses, that organizations characterized by the Self Interest climate type (Egoistic/ Local intersection) would have lower levels of moral awareness among their members than would organizations described by any of the other climate types.

Each of these hypotheses was supported by the results of the data analyses. Hypothesis one was fully supported, while the second hypothesis received partial support. Organizations described by ethical climates in the principle criterion did exhibit higher levels of moral awareness among members when associated with a broader locus of analysis than those employing a narrower locus. The hypothesized relationship did not hold for organizations employing the benevolence criterion, however. Only one organization was identified as having an egoistic climate type, so it was not possible to test hypothesis two within that ethical criterion. Hypothesis three received substantial support from the data analyses. One firm was described by the Self Interest ethical climate, and the mean moral awareness score of its members was lower than each of the other six organizations. The differences between the focal organization's mean and five of the other six groups' means were statistically significant. Thus, the preponderance of 
evidence indicated that the hypothesized relationships between Ethical Work Climate and moral awareness were supported by the results of the data analyses.

Hypotheses four through seven dealt with the effects of moderating variables on the relationship between Ethical Work Climate and moral awareness. The moderating variables were sex, age, level of formal education, and training in ethics. The sociological perspective taken in this study recognized that group influences are often stronger predictors of individual behavior and cognition than are individual characteristics. Thus, although I was aware that certain person variables have been identified in previous studies as significant predictors of moral judgment and behavior, I hypothesized that none of the moderators would have a significant moderating effect on the relationship between ethical work climate and moral awareness. By hypothesizing non-significant moderating effects, I was anticipating that the effects of ethical work climate would outweigh the influence of the person variables. Of the four potential moderators tested, only education level was indicated to be a significant moderating variable. This exception is not wholly surprising. Both Kohlberg (1984) and Rest $(1986,1994)$ have found that length of formal education is the single most important factor in the development of moral judgment. Education is also a more sociologically based variable than are the other moderating variables. Given this finding, and the connections between moral judgment and moral awareness that were discussed in Chapter 1, it is reasonable to conclude that education level may also have a strong role in developing moral awareness.

The support for six of the seven hypotheses indicates that Ethical Work Climate is a primary predictor of members' degree of moral awareness. The moderating variables that were predicted not to alter the relationship between EWC and moral awareness were indeed shown to be insignificant, with the sole exception of education level. From this positive and primary relationship between EWC and moral awareness, it is clear that an organization's ethical climate is strongly related to individual's moral awareness.

The influence of corporate culture on organizational performance has been expounded by many authors (Deal \& Kennedy, 1982, 2000; Goffee \& Jones, 1998; Collins \& Porras, 2000), and the results of this study provide evidence that extends that line of reasoning. The demonstrated relationship between Ethical Work Climate and individual moral awareness provides evidence that employees' perceptions and cognitive processes are also associated with their working environments.

\section{LIMITATIONS OF THE STUDY}

In this section I will present limitations of the present study, both those that are common to all research of this type, and those that may be unique to this particular project. I will also discuss how those limitations were mitigated and how they may be questions for future research.

\section{Some Standard Disclaimers}

As noted below in the discussion of circularity of effects, this study does not, and cannot show cause-and-effect relationships. The results of the data analyses have, however, indicated 
the existence of a direct, positive relationship between the independent variable, Ethical Work Climate, and the dependent variable, moral awareness. Still, the existence of a causal relationship cannot be directly concluded from this connection.

Although the results of statistical analyses do not, by themselves, allow conclusions of causality, the sociological perspective employed in this study supports an inference of a causeand-effect relationship between group influences and individual cognition (Shepard, 1999). In a discussion of moderating and mediating variables, causality is virtually assumed, "Within this framework, moderation implies that the causal relation between two variables changes as a function of the moderator variable" (Baron \& Kenny, 1986: 1174, emphasis added). Durkheim's $(1895 / 1962)$ emphasis on the primacy of society and Granovetter's (1985) work on social embeddedness also lend additional credence to such an inference.

Extensive use of researcher judgment and interpretation necessarily influenced the conclusions drawn from this study. The need for judgment and interpretation exists in virtually every study, but this fact is often overlooked or under-emphasized (Child, 1970; Comrey \& Lee, 1992). The judgment in this study occurred primarily in the interpretation of the results of the discriminant analysis, used to determine which ethical climate type was most descriptive of each organization. The logic of this interpretive process is detailed in Chapter 4, and the reader may judge its reasonableness.

\section{Limitations Unique to this Study}

Two of the research sites provided small sample sizes (seventeen for the engineering/surveying firm and twelve at the manufacturer). These sample sizes did not affect the factor analysis through which the emergent climate types and climate scales were developed, because the results were drawn from the entire sample of 196. The sample sizes of the engineering and manufacturing firms may have affected the results of the discriminant analysis and average moral awareness scores, since these were performed at the firm level. However, for reasons stated below, these samples were considered acceptable for the present study.

To avoid problems of abnormality, statistical sampling techniques generally call for a minimum sample size of thirty (Anderson, Sweeney, \& Williams, 1981). Sample sizes of this magnitude were not possible at either site. Each firm had fewer than fifty employees at the local site, and managers were unwilling to provide access to more than sixty percent of their workforce at one time. The obvious solution to this problem would have been to hold multiple survey sessions at each site. However, to do so would have run the risk of providing cues to participants in the latter sessions (from potential conversations with co-workers who participated in earlier sessions). Because this potential for cuing some respondents and not others would have introduced an unquantifiable bias into the sample, I made the decision to use the smaller sample size. Finally, the goal of the sampling techniques used was to obtain a representative sample, not a random sample. From conversations I had with managers at both sites, I was satisfied that the samples drawn were representative of the work groups selected for the study.

The second limitation peculiar to this study is the possibility of circularity of effects. It has been noted that organizational climates are enhanced and made more homogeneous by the 
effects of socialization and individual attraction, selection, and attrition (Schneider, 1983; Schneider \& Reichers, 1983). Other authors note that the similarity in reported levels of worker satisfaction across the companies they surveyed suggests that "most workers develop at least a palliative level of satisfaction with their organization's climates. Those who fail to fit in an organization's climate probably turn over..." (Victor \& Cullen, 1988: 119). In the current context, these observations raise the possibility that the direction of the relationship between ethical work climate and moral awareness may be the reverse of that suggested by their designations as independent and dependent variables. That is, individuals with higher levels of moral awareness may help alter an organization's ethical climate to a broader locus of analysis and/or a benevolence or principle ethical criterion. Conversely, persons with lower levels of moral awareness may influence a change toward narrower loci of analysis and/or egoistic ethical criterion. Reciprocal influences between ethical work climate and individual moral awareness are also likely. This question could be investigated through future inquiries, employing the "person-organization fit" stream of research. Person-organization fit is defined as the congruence between individuals' and organizations' value systems, practices, and cultures (Vandenberghe, 1999; Valentine, 2000). Its basis is in the attraction, selection, and attrition framework provided by Schneider $(1983,1987)$.

Having reviewed the results and limitations of this research, the focus shifts to opportunities for further investigations into related topics.

\section{IMPLICATIONS FOR FUTURE RESEARCH}

As noted earlier in this chapter, the primary purpose of this study was to examine the relationship between an organization's ethical work climate and individuals' moral awareness. The results of the data analyses suggest a direct, positive relationship between the two variables. This further implies that changing an organization's ethical work climate may be associated with changes in the average degree of its employees' moral awareness. However, no prescriptions are offered here telling how to alter the ethical work climate. This lack of prescriptive information was not a defect in research design or implementation. First, describing methods of altering work climates was outside the purposes of this study. In addition, some climate researchers have noted that organizational elites can manipulate climates, but the precise means for doing so remain unclear. Other authors have called for future research in this area, noting, "A possible fruitful investigation might specify those aspects of organizational design and managerial practices that produce certain types of climates and in turn associated ethical behaviors" (Victor \& Cullen, 1987: 68).

Research into methods of manipulating work climates could be extremely beneficial both to academicians and practitioners. The current study is only one of many indications that an organization's climate ${ }^{9}$ has a tremendous influence on its outcomes. As one book describes it, "Whether weak or strong, culture has a powerful influence throughout an organization; it affects practically everything-from who gets promoted and what decisions are made, to how employees dress and what sports they play" (Deal \& Kennedy, 1982: 4). Although the effects of

\footnotetext{
${ }^{9}$ Most of the literature refers to "culture" rather than "climate," but the general meaning is the same in this context (irrespective of the academic culture-climate debate described in Chapter 2).
} 
organizational climate are widely acknowledged, very little is known about effective and efficient means of creating (or changing) a certain type of work environment. "There is a paucity of research about actual organizational attempts to implement cultural change. Most publications to date have attempted only to ascertain the important elements in cultures of successful organizations (Kanter, 1983; Peters \& Waterman, 1982, [also Deal \& Kennedy, 1982, 2000; Goffee \& Jones, 1998; Collins \& Porras, 2000]), to define culture (Bartunek, 1988; Fisher, 1993; Miller, 1995, Morgan, 1986; Schein, 1985), or to suggest methods of studying organizational culture (Barnett \& Goldhaber, 1993)" (Ross \& Benson, 1995). Admittedly this type of research would be extremely difficult, because of the length of time required to form or change climates, difficulty in tracing the exact origins of a given climate, and the lack of directly observable facets of climates. However, given the profound effects of organizational climate, every attempt should be made to study it systematically.

Related to the investigation of methods of manipulating climates would be a study of organizational variables that affect the types of ethical climates organizations have. The originators of the EWC construct referred to these factors as antecedents of climates. One such variable noted was that internal consistency improved with decreasing size of the organization (Victor \& Cullen, 1987). (More will be said about this factor later in this section.) Another factor apparently affecting ethical climates was average length of tenure of a group's employees. Victor \& Cullen (1988) observed that perceptions of a caring climate tended to increase with length of tenure. Neither of these factors was observed during the current study, but further study is certainly warranted.

Two patterns associated with different climate types that were noted in this study relate to coherence of organizational goals and age of the work group. Both of these variables seem to relate to Durkheim's theories of socialization (1937/1996). The clarity of organizational goals would seemingly affect members' ability to accurately perceive the prevailing work climate. In a similar manner, the maturity of a work group should be positively associated with the extent of socialization among its members.

The non-profit group surveyed in this study was in the midst of an effort by senior management to re-focus the organization away from services to the poor toward economic and real estate development. Scale means and standard deviations derived from the discriminant analyses both indicated lack of clarity in the employees' minds regarding the organization's ethical climate types. Other surveyed firms that had more clearly defined purposes and goals (based on qualitative data) also had more consistent responses to the ECQ from their employees.

The age of the organization was also related to internal consistency. The utility company's service department was less than one year old at the time of the survey, and this group displayed an internal consistency near the bottom of the organizations in this study. More mature firms tended to have greater internal consistency among their members. One exception to this trend was the regional bank, which had existed in this location for less than five years. Contrary to what would be expected from the trend being described, this organization displayed relatively high internal consistency. This anomaly can be attributed to two factors. First, the organization prides itself on having a strong "positive atmosphere," that the employees are indoctrinated into soon after being hired. Second, the core management team and several lower- 
level employees migrated to this bank from another en masse precisely because of the change in work climates it offered. Thus, many of the key employees in this organization were "presocialized" into this climate. These four antecedents of ethical climate, and others, could be fruitfully investigated in future research.

Another implication for future research derived from the present study is the need for further development of the ECQ instrument. It was noted earlier in this section that the intersection of the Egoistic ethical criterion and Cosmopolitan locus of analysis has been unstable in the studies done to date. It is also becoming increasingly clear that respondents to the survey do not make the fine distinctions between loci of analysis that the EWC construct envisions. In addition, the Egoistic/Local cell has never been identified as a separate climate type, and several of the other descriptors in the local locus of analysis load on other, sometimes dissimilar factors. The lack of an Egoistic/Local climate type is particularly puzzling because of the confluence it appears to have with the stereotypical profit driven corporation. Compounding the conundrum of the counterintuitive results is the fact that relatively few studies have been conducted that employ the ECQ in a statistically valid manner. This lack of experience, combined with the questions noted above and the originators' call for further instrument development (Victor \& Cullen, 1987; Cullen, Victor, \& Bronson, 1993) suggest the need for further work in this area.

In this study the organization's Ethical Work Climate was proposed as an independent variable that would be associated with individuals' moral awareness and test results indicate that EWC is a primary predictor. However, ethical climates are surely not the only factors influencing moral awareness. Future research could extend this study by using EWC as a mediating variable between characteristics of an ethical situation ("situational variables") and moral awareness. A mediating variable is one through which the focal independent variable influences the dependent variable (Baron \& Kenny, 1986). A logical place to start this investigation would be to use the moral intensity construct developed by Jones (1991). This construct postulates that six characteristics of a moral issue would be positively related to moral decision making and behavior. These six characteristics are magnitude of consequences, social consensus, probability of effect, temporal immediacy, proximity, and concentration of effect. Tests combining the moral intensity elements, ethical work climate, and moral awareness could provide significant new insights into reasons why some issues are recognized and addressed while others never appear on organizations' radar screens.

The final suggestion for future research that I will offer relates to the observation by others that the internal consistency of responses improves with decreased organization size (Victor \& Cullen, 1987). Although this finding was not replicated in the current study, its implications are so far-reaching that they should be investigated. The concept of "bounded rationality," the inability of humans to be fully rational in their decision-making efforts, has long been recognized (Simon, 1957; March \& Simon, 1958). Contributing to humans' limited capacity to process information and make completely rational decisions are time constraints, conflicting or illdefined decision criteria, and excessive amounts of information, among other factors. Each of these factors is likely to be exacerbated with increased organization size. 
Evidence from other fields of study provides additional support for March and Simon's observations. For example, anthropologists have discovered a biologically based limitation on primates' abilities to maintain relations with others of their species (referred to as "channel capacity"). British anthropologist Robin Dunbar has studied the relationship between brain size in primates (specifically the neocortex, which deals with complex thought and reasoning) and a variety of social and survival factors. The one thing that Dunbar has found that correlates with brain size is group size. The larger the neocortex, the larger the group size that the primate lives with tends to be. Dunbar argues that as brain sizes have evolved, they have gotten bigger in order to handle the complexities of larger social groups. He has developed a formula that predicts an expected maximum group size based on the "neocortex ratio" (the size of the neocortex relative to the size of the brain) for a specific species. The predicted group size for humans based on Dunbar's formula is 147.8. Thus, Dunbar predicts that a human will have a limit of about 150 people with whom she can develop and maintain close ties (Gladwell, 2000). Any number of relations above 150 is likely to result in the non-rational behaviors that March and Simon (1958) observed in other facets of managers' behaviors.

Based on Dunbar's findings, it appears that humans have an innate limitation on their ability to interact effectively with others, in addition to the information processing limitations noted by Simon (1957) and March and Simon (1958). If this is so, no advance in technology is going to increase this channel capacity, regardless of the claims of computer, communications, or organizational design experts. The ability humans have to work effectively in groups may depend as much on the bonds that individuals can develop among themselves as on organizational structure or the technology available to them. The bonds that can be formed in small groups are "essentially a kind of peer pressure: it's knowing people well enough that what they think of you matters....Above that point, there begin to be structural impediments to the ability of the group to agree and act with one voice" (Gladwell, 2000: 182, 186).

The implications of bounded rationality, channel capacity, and Victor and Cullen's (1987) finding of the inverse relationship between internal consistency and organizational size should give researchers pause for reflection. As organizations continue to get larger and more widely dispersed, managers' ability to develop a strong climate and cohesive work groups will decrease. Research into this relationship, along with studies on methods of manipulating climates, may provide valuable insights.

\section{SUMMARY}

The current research indicates that an organization's EWC is related to its members' moral awareness, which raises the possibility that managers can have some influence over their workers' moral awareness by manipulating the group's ethical work climate. Of course, the results of this study do not indicate that the employee is a blank slate upon entering the work group, or that the group's ethical climate is the sole, or even dominant influence on the person. But if a manager is interested in raising the level of moral awareness among her employees, the present study's results indicate that manipulating the ethical work climate may be an effective means to do so. Certainly, producing a certain type of ethical climate would have all of the difficulties associated with managing organizational culture - time, effort, senior management 
commitment, enforcement of violations, effective communication, gaining employee buy-in, and so on. Unfortunately, no blueprint is provided here to guide the manager in designing and implementing such a climate, and to my knowledge, no such guide exists. But then, doing the improbable with no guidelines may just be what the art of management is all about. In a very real way, understanding and managing an organization's ethical work climate may go a long way toward defining the difference between how a company does and what kind of organization it is. 


\section{REFERENCES}

Abelson, R. P. (1976) Script Processing in Attitude Formation and Decision-Making. In J. S. Carroll and J. W. Payne (Eds.), Cognition and Social Behavior. Hillsdale, NJ: Lawrence Erlbaum Associates.

Abelson, R. P. (1981) Psychological Status of the Script Concept. American Psychologist, 36, 715-729.

Abelson, R. P., \& Levi, A. (1985) Decision Making and Decision Theory. In G. Lindzey and E. Aronson (Eds.), Handbook of Social Psychology Volume 1 Theory and Method 3d ed. New York: Random House.

Agarwal, J., \& Malloy, D. C. (1999) Ethical Work Climate Dimensions in a Not-For-Profit Organization: An Empirical Study. Journal of Business Ethics, 20, 1-14.

Anderson, D. R., Sweeney, D. J., \& Williams, T. A. (1981) Introduction to Statistics: An Applications Approach. St. Paul, MN: West Publishing Co.

Arlow, P. (1991) Characteristics in College Students' Evaluations of Business Ethics and Corporate Responsibility. Journal of Business Ethics, 10, 63-69.

Babin, B. J., Boles, J. S., \& Robin, D. P. (2000) Representing the Perceived Ethical Work Climate Among Marketing Employees. Journal of the Academy of Marketing Science, 28, 345-358.

Barnett, G., \& Goldhaber, G. (1993) Organization Communication $6^{\text {th }}$ ed. Madison, WI: W. C. Brown.

Barnett, J. H., \& Karson, M. J. (1989) Managers, Values, Executive Decisions: An Exploration of the Role of Gender, Career Stage, Organizational Level, Function, and the Importance of Ethics, Relationships and Results in Managerial Decision-Making. Journal of Business Ethics, 8, 35-44.

Baron, R. M., \& Kenny, D. A. (1986) The Moderator-Mediator Variable Distinction in Social Psychological Research: Conceptual, Strategic, and Statistical Considerations. Journal of Personality and Social Psychology, 51, 1173-1182.

Bartunek, J. (1988) The Dynamics of Personal and Organizational Reframing. In R. Quinn and K. Cameron (Eds.), Paradox and Transformation: Toward a Theory of Change in Organization and Management. Cambridge, MA: Ballinger. 
Baucus, M. S., \& Rechner, P. L. (1995) Framing and Reframing: A Process Model of Ethical Decision Making. International Association for Business and Society Proceedings.

Baucus, M. S., \& Rechner, P. L. (1996) Choosing and Constructing Frames in Ethical Decision Making. Presentation at the national Academy of Management meeting, Cincinnati, Ohio.

Bebeau, M. J. (1994) Influencing the Moral Dimensions of Dental Practice. In J. R. Rest and D. Narváez (Eds.), Moral Development in the Professions. Hillsdale, NJ: Lawrence Erlbaum Associates, Publishers.

Bebeau, M., \& Brabeck, M. (1989) Ethical Sensitivity and Moral Reasoning Among Men and Women in the Professions. In M. Brabeck (Ed.), Who Cares? Theory, Research and Educational Implications of the Ethic of Care. New York: Praeger.

Bellah, R. N. (1973) Émile Durkheim on Morality and Society, Selected Writings. Chicago: University of Chicago Press.

Bernstein, I. H. (1988) Applied Multivariate Analysis. New York: Springer-Verlag.

Blasi, A. (1980) Bridging Moral Cognition and Moral Action: A Critical Review of the Literature. Psychological Bulletin, 88, 1-45.

Blum, L. (1991) Moral Perception and Particularity. Ethics, 101, 701-725

Blum, L. A. (1994) Moral Perception and Particularity. Cambridge: Cambridge University Press.

Bok, D. (1976) Can Ethics be Taught? Change, October, 26-30.

Brandt, R. B. (1995) Morality, Utilitarianism, and Rights. Cambridge: Cambridge University Press.

Brower, H. H., \& Shrader, C. B. (2000) Moral Reasoning and Ethical Climate: Not-for-Profit vs. For-Profit Boards of Directors. Journal of Business Ethics, 26, 147-167.

Butterfield, K. D., Treviño, L. K., \& Weaver, G. R. (1996) Moral Awareness in Organizations: A Socialization Perspective. Academy of Management Proceedings.

Butterfield, K. D., Treviño, L. K., \& Weaver, G. R. (1997) Moral Awareness in Organizations: Influences of Societal and Organizational Socialization. Unpublished paper presented at the Academy of Management, Boston, MA.

Butterfield, K. D., Treviño, L. K., \& Weaver, G. R. (2000) Moral Awareness in Business Organizations: Influences of Issue-Related and Social Context Factors. Human Relations, 53, 981-1018. 
Campbell, J. P., Dunnette, M. D., Lawler, E. E., III, \& Weick, K. E., Jr. (1970) Managerial Behavior, Performance, and Effectiveness. New York: McGraw-Hill.

Cavanagh, G. F., \& Fritzsche, D. J. (1985) Using Vignettes in Business Ethics Research. In L. E. Preston (Ed.), Research in Corporate Social Performance and Policy (Vol 7). Greenwich, CT: JAI Press.

Child, D. (1970) The Essentials of Factor Analysis. London: Holt, Rinehart and Winston.

Cohen, D. V. (1995) Creating Ethical Work Climates: A Socioeconomic Perspective. The Journal of Socio-Economics, 24, 317-343.

Collins, J. C., \& Porras, J. I. (2000) Built to Last: Successful Habits of Visionary Companies. $3^{\text {rd }}$ ed. London: Random House Business.

Comrey, A. L., \& Lee, H. B. (1992) A First Course in Factor Analysis $2^{\text {nd }}$ ed. Hillsdale, NJ: Lawrence Erlbaum Associates.

Cullen, J. B., Victor, B., \& Bronson, J. W. (1993) The Ethical Climate Questionnaire: An Assessment of its Development and Validity. Psychological Reports, 73, 667-674.

Cullen, J. B., Victor, B., \& Stephens, C. U. (1989) An Ethical Weather Report: Assessing the Organization's Ethical Climate. Organizational Dynamics, 18, 50-62.

Daft, R. L., Lengel, R. H., \& Trevino, L. K. (1987) Message Equivocality, Media Selection, and Manager Performance: Implications for Information Systems. MIS Quarterly, September, 355-366.

Davy, G. (1996) Introduction. In E. Durkheim (Author), Professional Ethics and Civic Morals. London: Routledge.

Deal, T. E., \& Kennedy, A. A. (1982) Corporate Cultures: The Rites and Rituals of Corporate Life. Cambridge, MA: Perseus Books.

Deal, T. E., \& Kennedy, A. A. (2000) The New Corporate Cultures: Revitalizing the Workplace After Downsizing, Mergers, and Reengineering. Cambridge, MA: Perseus Books.

DeConinck, J. B., \& Lewis, W. F. (1997) The Influence of Deontological and Teleological Considerations and Ethical Climate on Sales Managers' Intentions to Reward or Punish Sales Force Behavior. Journal of Business Ethics, 16, 497-506.

Denison, D. R. (1996) What $I s$ the Difference Between Organizational Culture and Organizational Climate? A Native's Point of View on a Decade of Paradigm Wars. Academy of Management Review, 21, 619-654. 
Derry, R. (1989) An Empirical Study of Moral Reasoning. Journal of Business Ethics, 8, 855862.

Deshpande, S. P. (1996a) Ethical Climate and the Link between Success and Ethical Behavior: An Empirical Investigation of a Non-profit Organization. Journal of Business Ethics, 15, $315-320$.

Deshpande, S. P. (1996b) The Impact of Ethical Climate Types on Facets of Job Satisfaction: An Empirical Investigation. Journal of Business Ethics, 15, 655-660.

Dessler, G. (1998) Management: Leading People and Organizations in the $21^{\text {st }}$ Century. Upper Saddle River, NJ: Prentice Hall.

Deutsch, M. (1974) Awakening the Sense of Injustice. In M. Lerner and M. Ross (Eds.), The Quest for Justice: Myth, Reality, Ideal. Montreal: Holt, Rinehart and Winston.

Deutsch, M. (1985) Distributive Justice: A Social Psychological Perspective. New Haven: Yale University Press.

Durkheim, E. (1895/1962) The Rules of Sociological Method. New York: The Free Press of Glencoe.

Durkheim, E. (1937/1996) Professional Ethics and Civic Morals. London: Routledge.

Einhorn, H. J., \& Hogarth, R. M. (1981) Behavioral Decision Theory: Processes of Judgment and Choice. In M. R. Rosenzweig and L. W. Porter (Eds.), Annual Review of Psychology (Vol 32). Palo Alto, CA: Annual Reviews, Inc.

England, G. W. (1978) Managers and Their Value Systems: A Five-Country Comparative Study. Columbia Journal of World Business, 13, 35-44.

Field, R. H. G., \& Abelson, M. A. (1982) Climate: A Reconceptualization and Proposed Model. Human Relations, 35, 181-201.

Fisher, D. (1993) Communication in Organizations $2^{\text {nd }}$ ed. St. Paul, MN: West.

Forehand, G. A., \& Gilmer, B. (1964) Environmental Variations in Studies of Organizational Behavior. Psychological Bulletin, 62, 361-382.

Frederick, W. C. (1995) Values, Nature, and Culture in the American Corporation. New York: Oxford University Press.

Fritzsche, D. (1988) An Examination of Marketing Ethics: Role of the Decision Maker, Consequences of the Decision, Management Position, and Sex of the Respondent. Journal of Macromarketing, Fall, 29-39. 
Fritzsche, D. J. (2000) Ethical Climates and the Ethical Dimension of Decision Making. Journal of Business Ethics, 24, 125-140.

Fukuyama, F. (1999) The Great Disruption. The Atlantic Monthly, 283, 55-80.

Gautschi, F. H., III, \& Jones, T. M. (1998) Enhancing the Ability of Business Students to Recognize Ethical Issues: An Empirical Assessment of the Effectiveness of a Course in Business Ethics. Journal of Business Ethics, 17, 205-216.

Gerde, V.W. (1998) The Design Dimension of the Just Organization: An Empirical Test of the Relation between Organization Design and Corporate Social Performance. Blacksburg, VA: University Libraries, Virginia Polytechnic Institute and State University.

Gilligan, C. (1982) In a Different Voice. Cambridge, MA: Harvard University Press.

Gioia, D. A. (1992) Pinto Fires and Personal Ethics: A Script Analysis of Missed Opportunities. Journal of Business Ethics, 11, 379-389.

Gioia, D. A., \& Poole, P. P. (1984) Scripts in Organizational Behavior. Academy of Management Review, 9, 449-459.

Gladwell, M. (2000) The Tipping Point. Boston: Little, Brown and Company.

Glaser, B. G., \& Strauss, A. L. (1967) The Discovery of Grounded Theory: Strategies for Qualitative Research. Hawthorne, NY: Aldine de Gruyter.

Goffee, R., \& Jones, G. (1998) The Character of a Corporation: How Your Company's Culture Can Make or Break Your Business. London: HarperCollinsBusiness.

Gouldner, A. W. (1957) Cosmopolitans and Locals: Toward an Analysis of Latent Social Roles-I. Administrative Science Quarterly, 2, 281-306.

Gouldner, A. W. (1958) Cosmopolitans and Locals: Toward an Analysis of Latent Social Roles-II. Administrative Science Quarterly, 3, 444-480.

Granovetter, M. (1985) Economic Action and Social Structure: The Problem of Embeddedness. American Journal of Sociology, 91, 481-510.

Guion, R. M. (1973) A Note on Organizational Climate. Organizational Behavior and Human Performance, 9, 120-125.

Gunst, R. F., \& Mason, R. L. (1980) Regression Analysis and Its Applications. New York: Marce Dekker, Inc.

Haan, N., Aerts, E., \& Cooper, B. A. (1985) On Moral Grounds. New York: University Press. 
Hair, J. F., Anderson, R. E., Tatham, R. L., \& Grablowsky, B. J. (1984) Multivariate Data Analysis. New York: Macmillan Publishing Co.

Harris, B. (1999) Steal This Book and Get Life Without Parole. Monroe, ME: Common Courage Press.

Hellriegel, D., \& Slocum, J. W., Jr. (1974) Organizational Climate: Measures, Research and Contingencies. Academy of Management Journal, 19, 255-280.

Helsen, W. E., \& Starkes, J. L. (1999) A New Training Approach to Complex Decision Making for Police Officers in Potentially Dangerous Interventions. Journal of Criminal Justice, 27, 395-410.

Herman, B. (1985) The Practice of Moral Judgment. Journal of Philosophy, 87, 414-436.

Ho, T. (1999) Section A: Selecting and Assessing Police Officers. Journal of Offender Rehabilitation, 29, 1-24.

Hofstede, G. (1998) Attitudes, Values and Organizational Culture: Disentangling the Concepts. Organization Studies, 19, 477-492.

Hume, D. (1751) An Enquiry Concerning the Principles of Morals. London: A. Millar.

James, L. R., \& Jones, A. P. (1974) Organizational Climate: A Review of Theory and Research. Psychological Bulletin, 81, 1096-1112.

Johannesson, R. E. (1973) Some Problems in the Measurement of Organizational Climate. Organizational Behavior and Human Performance, 10, 118-144.

Johnson, R. A., Neelankavil, J. P., \& Jadhav, A. (1986) Developing the Executive Resource. Business Horizons, 29, 33.

Jones, A. P., \& James, L. R. (1979) Psychological Climate: Dimensions and Relationships of Individual and Aggregated Work Environment Perceptions. Organizational Behavior and Human Performance, 23, 201-250.

Jones, T. M. (1991) Ethical Decision Making by Individuals in Organizations: An IssueContingent Model. Academy of Management Review, 16, 366-395.

Jones, T. M., \& Ryan, L. V. (1997) The Link Between Ethical Judgment and Action in Organizations: A Moral Approbation Approach. Organization Science, 8, 663-680.

Jones, T. M., \& Ryan, L. V. (1998) The Effect of Organizational Forces on Individual Morality. Business Ethics Quarterly, 8, 431-445. 
Joyce, W. F., \& Slocum, J. W., Jr. (1979) Climates in Organizations. In S. Kerr (Ed.), Organizational Behavior. Columbus, OH: Grid.

Joyce, W. F., \& Slocum, J. W., Jr. (1984) Collective Climate: Agreement as a Basis for Defining Aggregate Climates in Organizations. Academy of Management Journal, 27, 721-742.

Kane, R. J. (1999) Patterns of Arrest in Domestic Violence Encounters: Identifying a Police Decision-Making Model. Journal of Criminal Justice, 27, 65-80.

Kant, I. (1785/1959) Foundations of the Metaphysics of Morals. New York: Liberal Arts Press.

Kanter, R. (1983) The Change Masters. New York: Simon \& Schuster.

Key, S. (1999) Organizational Ethical Culture: Real or Imagined? Journal of Business Ethics, 20, 217-225.

Kohlberg, L. (1973) Continuities in Childhood and Adult Moral Development Revisited. In P. B. Baltes and K. Schaie (Eds.), Life-Span Development Psychology: Personality and Socialization. New York: Academic Press.

Kohlberg, L. (1981) The Philosophy of Moral Development (Vol. 1) San Francisco: Harper \& Row.

Kohlberg, L. (1984) The Psychology of Moral Development (Vol. 2) San Francisco: Harper \& Row.

Korsgaard, C. M. (1996) Creating the Kingdom of Ends. Cambridge: Cambridge University Press.

Kuhn, A. (1963) The Study of Society: A Unified Approach. Homewood, IL: Irwin.

Kuhn, A. (1974) The Logic of Social Systems: A Unified, Deductive, System-Based Approach to Social Science. San Francisco: Jossey-Bass.

Lachenbruch, P. A. (1975) Discriminant Analysis. New York: Hafner Press.

Lafollette, W. R., \& Sims, H. P. (1975) Is Satisfaction Redundant with Organizational Climate? Organizational Behavior and Human Performance, 13, 257-278.

Langdale, C. H. (1983) Moral Orientations and Moral Development: The Analysis of Care and Justice Reasoning Across Different Dilemmas in Females and Males from Childhood through Adulthood. Doctoral Dissertation, Harvard University (University Microfilms, Ann Arbor, Michigan). 
Lewin, A. Y., \& Stephens, C. U. (1993) Designing Postindustrial Organizations: Combining Theory and Practice. In G. Huber and W. Glick (Eds.), Organizational Change and Redesign. London: Oxford University Press.

Litwin, G. H., \& Stringer, R. A. (1968) Motivation and Organizational Climate. Boston: Harvard Business School, Division of Research.

Logsdon, J. M., \& Yuthas, K. (1997) Corporate Social Performance, Stakeholder Orientation, and Organizational Moral Development. Journal of Business Ethics, 16, 1213-1226.

Luthar, H. K., DiBattista, R. A., \& Gautschi, T. (1997) Perceptions of What the Ethical Climate is and What it Should be: The Role of Gender, Academic Status, and Ethical Education. Journal of Business Ethics, 16, 215-217.

Lyons, N. P. (1983) The Perspectives: On Self, Relationships, and Morality. Harvard Educational Review, 53, 125-145.

March, J. G., \& Simon, H. A. (1958) Organizations. New York: Wiley.

Mathews, M. C. (1988) Strategic Intervention in Organizations: Resolving Ethical Dilemmas. Newbury Park, CA: Sage Publications.

Mayer, J. (1988) Themes of Social Responsibility: A Survey of Three Professional Schools. Journal of Business Ethics, 7, 313-320.

McDonald, R. A., \& Victor, B. (1988) Towards the Integration of Individual and Moral Agencies. Business \& Professional Ethics Journal, 7, 103-118.

McNichols, C. W., \& Zimmer, T. W. (1985) Situational Ethics: An Empirical Study of Differentiators of Student Attitudes. Journal of Business Ethics, 4, 175-180.

Merton, R. K. (1957) Social Theory and Social Structure. New York: Free Press.

Miles, M. B., \& Huberman, A. M. (1984) Qualitative Data Analysis: A Sourcebook of New Methods. Beverly Hills, CA: Sage Publications.

Miller, K. (1995) Organizational Communication: Approaches and Processes. Belmont, CA: Wadsworth.

Miller, W. W. (1996) Durkheim, Morals and Modernity. London: UCL Press.

Moberg, D. J., \& Seabright, M. A. (2000) The Development of Moral Imagination. Business Ethics Quarterly, 10, 845-884.

Morgan, G. (1986) Images of Organization. Newbury Park, CA: Sage. 
Murdoch, I. (1970) The Sovereignty of Good. London: Routledge \& Kegan Paul.

Naylor, J. D., Pritchard, R. D., \& Ilgen, D. R. (1980) A Theory of Behavior in Organizations. New York: Academic Press.

Newman, J. E. (1977) Development of a Measure of Perceived Work Environment (PWE). Academy of Management Journal, 20, 520-534.

Nisbet, R. A. (1965) Émile Durkheim. Englewood Cliffs, NJ: Prentice-Hall.

Nisbet, R. A. (1993) The Sociological Tradition. New Brunswick, NJ: Transaction Publishers.

Nunnally, J. C. (1978) Psychometric Theory. New York: McGraw-Hill.

Nussbaum, M. (1985) The Discernment of Perception. In J. Cleary (Ed.), Proceedings of the Boston Area Colloquium on Ancient Philosophy. Washington, D.C.: University Press of America.

Nussbaum, M. (1986) The Fragility of Goodness. Cambridge: Cambridge University Press.

Opotow, S. (1990) Moral Exclusion and Injustice: An Introduction. Journal of Social Issues, 46, $1-20$.

Payne, R. L., \& Pugh, S. S. (1976) Organizational Structure and Organizational Climate. In M. D. Dunnette (Ed.), Handbook of Industrial and Organizational Psychology. Chicago: Rand McNally.

Peters, T. J., \& Waterman, R. H. (1982) In Search of Excellence. New York: Harper \& Row.

Pettigrew, A. (1990) Organizational Climate and Culture: Two Constructs in Search of a Role. In B. Schneider (Ed.), Organizational Climate and Culture. San Francisco: Jossey-Bass.

Powell, G. N., \& Butterfield, D. A. (1978) The Case for Subsystem Climates in Organizations. Academy of Management Review, 3, 151-157.

Rachels, J. (1989) The Right Thing To Do. New York: McGraw-Hill.

Rachels, J. (1999) The Elements of Moral Philosophy. Boston: McGraw-Hill College.

Randall, D. M., \& Gibson, A. M. (1990) Methodology in Business Ethics Research: A Review and Critical Assessment. Journal of Business Ethics, 9, 457-471.

Ravlin, E. C., \& Meglino, B. M. (1987) Issues in Work Values Measurement. In W. C. Frederick (Ed.), Research in Corporate Social Performance and Policy: Empirical Studies of Business Ethics and Values. Greenwich, CT: JAI Press. 
Rechner, P. L., \& Baucus, M. S. (1997) Business Ethics as a Lifelong Journey: Developing Reflective Judgment, Self-Awareness, and Empathy. In S. A. Waddock (Ed.), Research in Corporate Social Performance and Policy (Supplement 2). Greenwich, CT: JAI Press.

Reichers, A., \& Schneider, B. (1990) Climate and Culture: An Evolution of Constructs. In B. Schneider (Ed.), Organizational Climate and Culture. San Francisco, Jossey-Bass.

Rest, J. R. (1979) Development in Judging Moral Issues. Minneapolis: University of Minnesota Press.

Rest, J. R. (1986) Manual for the Defining Issues Test. Minneapolis: Center for the Study of Ethical Development, University of Minnesota.

Rest, J. R. (1994) Background: Theory and Research. In J. R. Rest and D. Narváez (Eds.), Moral Development in the Professions. Hillsdale, NJ: Lawrence Erlbaum Associates, Publishers.

Rest, J., Narvaez, D., Bebeau, M. J., \& Thoma, S. J. (1999) Postconventional Moral Thinking. Mahwah, NJ: Lawrence Erlbaum Associates, Publishers.

Robbins, S. P., \& Coulter, M.K. (1999) Management $6^{\text {th }}$ ed. Upper Saddle River, NJ: Prentice Hall.

Robbins, S. P., \& De Cenzo, D. A. (1998) Fundamentals of Management $2^{\text {nd }}$ ed. Upper Saddle River, NJ: Prentice Hall.

Ross, D. L., \& Benson, J. A. (1995) Cultural Change in Ethical Redemption: A Corporate Case Study. Journal of Business Communication, 32, 345-362.

Ruegger, E., \& King, E. W. (1992) A Study of the Effect of Age and Gender upon Student Business Ethics. Journal of Business Ethics, 11, 179-186.

Salmans, S. (1987) Suddenly Business Schools Tackle Ethics. New York Times Education Life, August 2, 64-69.

Schein, E. H. (1984) Coming to a New Awareness of Organizational Culture. Sloan Management Review, 25, 3-16.

Schein, E. H. (1985) Organizational Culture and Leadership. San Francisco: Jossey-Bass.

Schneider, B. (1973) The Perception of Organizational Climate: The Customer's View. Journal of Applied Psychology, 57, 248-256.

Schneider, B. (1975) Organizational Climates: An Essay. Personnel Psychology, 28, 447-479.

Schneider, B. (1983) An Interactionist Perspective. In N. W. Feimer and E. S. Geller (Eds.), Environmental Psychology: Directions and Perspectives. New York: Praeger. 
Schneider, B. (1985) Organizational Behavior. Annual Review of Psychology, 36, 573-611.

Schneider, B. (1987) The People Make the Place. Personnel Psychology, 40, 437-453.

Schneider, B., \& Reichers, A. E. (1983) On the Etiology of Climates. Personnel Psychology, 36, 19-39.

Schneider, B., \& Snyder, R. A. (1975) Some Relationships Between Job Satisfaction and Organizational Climate. Journal of Applied Psychology, 60, 318-328.

Schwepker, C. H., Jr., Ferrell, O. C., \& Ingram, T. N. (1997) The Influence of Ethical Climate and Ethical Conflict on Role Stress in the Sales Force. Journal of the Academy of Marketing Science, 25, 99-108.

Shain, B. A. (1994) The Myth of American Individualism: The Protestant Origins of American Political Thought. Princeton, NJ: Princeton University Press.

Shaub, M. K., Finn, D. W., \& Munter, P. (1993) The Effects of Auditors' Ethical Orientation on Commitment and Ethical Sensitivity. Behavioral Research in Accounting, 5, 145-169.

Shepard, J. M. (1999) Sociology $7^{\text {th }}$ ed. Belmont, CA: Wadsworth.

Shepard, J. M., Shepard, J., Wimbush, J. C., \& Stephens, C. U. (1995) The Place of Ethics in Business: Shifting Paradigms? Business Ethics Quarterly, 5, 577-601.

Sherman, N. (1989) The Fabric of Character. Oxford: Clarendon.

Silk, L., \& Vogel, D. (1976) Ethics and Profits: The Crisis of Confidence in America. New York: Simon \& Schuster.

Simon, H. A. (1957) Administrative Behavior $2^{\text {nd }}$ ed. New York: Free Press.

Sims, R. R. (1992) The Challenge of Ethical Behavior in Organizations. Journal of Business Ethics, 11, 505-513.

Sims, R., \& Keon, T. L. (1997) Ethical Work Climate as a Factor in the Development of PersonOrganization Fit. Journal of Business Ethics, 16, 1095-1105.

Slovic, P., Fischhoff, B., \& Lichtenstein, S. (1977) Behavioral Decision Theory. In M. R. Rosenzweig and L. W. Porter (Eds.), Annual Review of Psychology (Vol 28). Palo Alto, CA: Annual Reviews, Inc.

Smelser, N. J., \& Swedberg, R. (1994) The Sociological Perspective on the Economy. In N. J. Smelser and R. Swedberg (Eds.), The Handbook of Economic Sociology. New York: Princeton University Press. 
Smith, A. (1759/1986) The Theory of Moral Sentiments. In R. L. Heilbroner (Ed.), The Essential Adam Smith. New York: W. W. Norton \& Company.

Social Investment Forum. (1999) Socially Responsible Investing in U. S. Tops Two Trillion Dollar Mark. http://www.socialinvest.org/areas/news/1999-trends.htm. (November 4).

Solomon, R. C. (1992) Ethics and Excellence. New York: Oxford University Press.

Staub, E. (1989) The Roots of Evil: The Psychological and Cultural Origins of Genocide. New York: Cambridge University Press.

Stead, W. E., \& Stead, J. G. (1992) Management for a Small Planet: Strategic Decision Making for the Environment. Newbury Park, CA: Sage Publications.

Stephens, C. U., \& Lewin, A. Y. (1992) Bounded Morality: A Cross-Level Model of the Determinants of Ethical Choice in Organizations. In D. Ludwig and K. Paul (Eds.), Contemporary Issues in the Business Environment. Lewiston/Queenston/Lampeter: The Edwin Mellen Press.

Sterner, J. (1990) Other People's Money: The Ultimate Seduction. New York: Applause Theatre Book.

Stevens, G. (1984) Business Ethics and Social Responsibility: The Responses of Present and Future Managers. Akron Business and Economics Review, 15, 6-11.

Swedberg, R. (1999) Essays in Economic Sociology. Princeton, NJ: Princeton University Press.

Tagiuri, R. (1968) The Concept of Organizational Climate. In R. Tagiuri and G. H. Litwin (Eds.), Organizational Climate: Explorations of a Concept. Boston: Harvard University Press.

Tagiuri, R., \& Litwin, G. (Eds.) (1968) Organizational Climate: Explorations of a Concept. Boston: Harvard Business School.

Taylor, S. E., \& Crocker, J. (1981) Schematic Bases of Social Information Processing. In E. T. Higgins, C. P. Herman, \& M. P. Zanna (Eds.), Social Cognition (Vol. 1). Hillsdale, NJ: Lawrence Erlbaum Associates, Publishers.

The New York Times (1996) The Downsizing of America. New York: Times Books.

Thompson, J. D. (1967) Organizations in Action. New York: McGraw-Hill Book Company.

Treviño, L. K. (1990) A Cultural Perspective on Changing and Developing Organizational Ethics. In W. A. Pasmore and R. W. Woodman (Eds.), Research in Organizational Change and Development (Vol. 4). Greenwich, CT: JAI Press. 
Treviño, L. K. (1999) Personal correspondence, August 29.

Treviño, L. K., \& Weaver, G. R. (1996) Barriers to and Facilitators of Moral Perception: The Case of Competitive Intelligence Practitioners. Paper presented at Academy of Management. Cincinnati.

Treviño, L. K., Butterfield, K. D., \& McCabe, D. L. (1998) The Ethical Context in Organizations; Influences on Employee Attitudes and Behaviors. Business Ethics Quarterly, $8,447-476$.

Trevino, L. K., Lengel, R. H., Bodensteiner, W., Gerloff, E. A., \& Muir, N. K. (1990) The Richness Imperative and Cognitive Style: The Role of Individual Differences in Media Choice Behavior. Management Communications Quarterly, 4, 176-197.

Turner, B. S. (1996) Preface to the Second Edition. In E. Durkheim (Author), Professional Ethics and Civic Morals. London: Routledge.

Valentine, S. (2000) International Person-Organization Fit: The Role of National Culture. International Journal of Management, 17, 295-302.

Vandenberghe, C. (1999) Organizational Culture, Person-Culture Fit, and Turnover: A Replication in the Health Care Industry. Journal of Organizational Behavior, 20, 175-184.

VanSandt, C. V., \& Neck, C. P. (forthcoming) Bridging Ethics and Self Leadership: Overcoming Ethical Discrepancies Between Employee and Organizational Standards.

Verbeke, W., Volgering, M., \& Hessels, M. (1998) Exploring the Conceptual Expansion within the Field of Organizational Behavior: Organizational Climate and Organizational Culture. Journal of Management Studies, 35, 303-329.

Victor, B., \& Cullen, J. B. (1987) A Theory and Measure of Ethical Climate in Organizations. In W. C. Frederick (Ed.), Research in Corporate Social Performance and Policy (Vol. 9). Greenwich, CT: JAI Press.

Victor, B., \& Cullen, J. B. (1988) The Organizational Bases of Ethical Work Climates. Administrative Science Quarterly, 33, 101-125.

Victor, B., \& Stephens, C. U. (1994) The Dark Side of the New Organizational Forms: An Editorial Essay. Organizational Science, 5, 479-482.

Vroom, V. H., \& Jago, A. G. (1988) Managing Participation: A Critical Dimension of Leadership. Journal of Management Development, 7, 32-42.

Wallwork, E. (1972) Durkheim, Morality, and Milieu. Cambridge, MA: Harvard University Press. 
Waters, J. A. (1978) Catch 20.5: Corporate Morality as an Organizational Phenomenon. Organizational Dynamics, 6, 2-19.

Weber, J. (1995) Influences Upon Organizational Ethical Subclimates: A Multi-departmental Analysis of a Single Firm. Organization Science, 6, 509-523.

Weber, M. (1904-05/1958) The Protestant Ethic and The Spirit of Capitalism. New York: Charles Scribner's Sons.

Weber, M. (1910/1978) Economy and Society. Berkeley: University of California Press.

Weick. K. (1979) The Social Psychology of Organizing. Reading, MA: Addison-Wesley.

Werhane, P. H. (1998) Moral Imagination and the Search for Ethical Decision-Making in Management. Business Ethics Quarterly, The Ruffin Series Special Issue No. 1, 75-98.

Williams, B. (1985) Ethics and the Limits of Philosophy. Cambridge: Harvard University Press.

Wilson, J. (1983) Social Theory. Englewood Cliffs, NJ: Prentice-Hall.

Wimbush, J. C., \& Shepard, J. M. (1994) Toward an Understanding of Ethical Climate: Its Relationship to Ethical Behavior and Supervisory Influence. Journal of Business Ethics, 13, 637-647.

Wimbush, J. C., Shepard, J. M., \& Markham, S. E. (1997a) An Empirical Examination of the Multi-dimensionality of Ethical Climate in Organizations. Journal of Business Ethics, 16, $67-77$.

Wimbush, J. C., Shepard, J. M., \& Markham, S. E. (1997b) An Empirical Examination of the Relationship Between Ethical Climate and Ethical Behavior from Multiple Levels of Analysis. Journal of Business Ethics, 16, 1705-1716.

Woodman, R. W., \& King, D. C. (1978) Organizational Climate: Science or Folklore? Academy of Management Review, 3, 816-826.

Wyld, D. C., \& Jones, C. A. (1997) The Importance of Context: The Ethical Work Climate Construct and Models of Ethical Decision Making-An Agenda for Research. Journal of Business Ethics, 16, 465-472. 


\section{APPENDIX A MEMORANDUM FOR PARTICIPATION IN SURVEY}

Craig VanSandt, a Ph.D. candidate at Virginia Tech's R. B. Pamplin School of Business, will be conducting an information session this day and date, on how work climate affects decision making in organizations. There will be a short video presentation and survey following. Data from the session will be used to provide information to the organization about its decision making processes and to assist Mr. VanSandt in his research for a doctoral degree in management.

Mr. VanSandt invites everyone to attend and participate in this entertaining and informative session. Please plan to attend.

Date:

Time:

Place:

Coffee and donuts will be available. 


\section{APPENDIX B \\ MORAL AWARENESS SURVEY}

You have just watched scenes from the movie "Other People's Money." At the end of the video shareholders of New England Wire \& Cable are being asked to decide whether controlling interest in the company should be sold or not. Please consider the directions below as if you are representing your employer when answering these questions.

Please identify all of the considerations that you deem important in making a decision about the situation just shown in the video. Please be as specific as possible in your description of the considerations. Once you have identified the important considerations, please rate the importance of each on a scale of 1 to 7 , with 7 being very important and 1 being of little importance. You are not ranking the considerations by their importancedifferent considerations can have the same relative importance.

1.

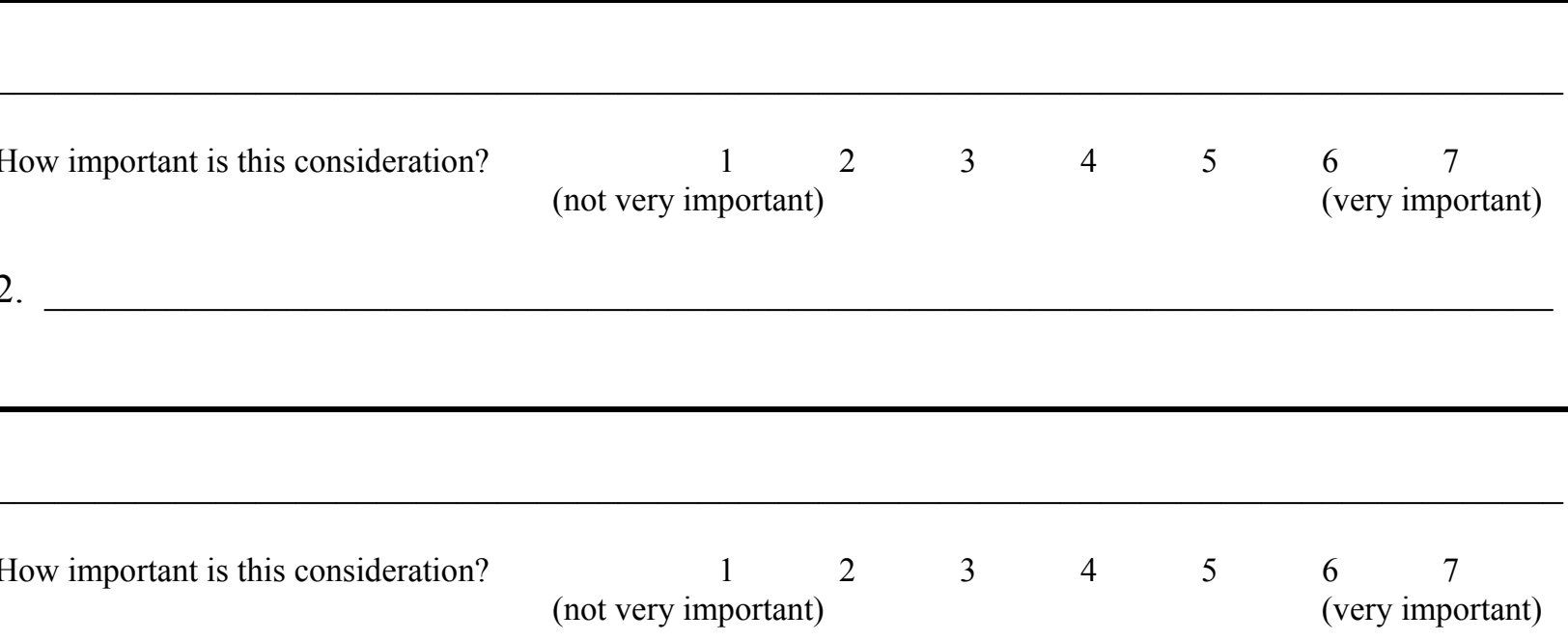

3.

How important is this consideration?

12

3

4

5

$6 \quad 7$

(not very important)

(very important)

(FOR ADDITIONAL SPACE, SEE REVERSE) 
4.

How important is this consideration?

$\begin{array}{clllll}1 & 2 & 3 & 4 & 5 & 6 \\ \text { (not very important) } & & & & & \begin{array}{l}7 \\ \text { (very important) }\end{array}\end{array}$

5.

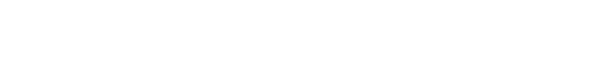

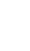

How important is this consideration?

${ }_{(\text {not very important) }}^{1}$

3

4

4

5

$\begin{array}{ll}6 & 7\end{array}$

(very important)

6.

$\bar{P}$

\begin{tabular}{lrllllll}
\hline How important is this consideration? & 1 & 2 & 3 & 4 & 5 & $\begin{array}{l}6 \\
\text { (very important) }\end{array}$
\end{tabular}

7.

How important is this consideration?

$\begin{array}{cccccl}1 & 2 & 3 & 4 & 5 & 6 \quad \begin{array}{l}7 \\ \text { (not very important) }\end{array} \\ & & & & \text { (very important) }\end{array}$

8.

西

How important is this consideration?

\begin{tabular}{|c|c|c|c|c|}
\hline $\begin{array}{c}1 \\
\text { (not very important) }\end{array}$ & 2 & 4 & 5 & $\begin{array}{lc}6 & 7 \\
\text { (very important) }\end{array}$ \\
\hline
\end{tabular}




\section{APPENDIX C \\ DEMOGRAPHIC, ECQ, AND RECOGNITION FACTOR SURVEY}

FORM

Random Number

\section{SECTION 1}

\section{PLEASE ANSWER THE FOLLOWING DEMOGRAPHIC QUESTIONS. THESE ANSWERS WILL BE USED STRICTLY FOR TEST PURPOSES. YOUR RESPONSES WILL BE KEPT CONFIDENTIAL AND YOUR IDENTITY ANONYMOUS.}

1. What is your sex?

2. How old were you on your last birthday?

$$
\text { Male }=1 \quad \text { Female }=2
$$

$\begin{array}{ll}\text { Under } 20 \text { years old } & 1 \\ 20-29 \text { years old } & 2 \\ 30-39 \text { years old } & 3 \\ 40-49 \text { years old } & 4 \\ 50-59 \text { years old } & 5 \\ 60-69 \text { years old } & 6 \\ 70-79 \text { years old } & 7 \\ 80-89 \text { years old } & 8 \\ 90-99 \text { years old } & 9 \\ \text { Over 99 years old } & 10\end{array}$

3. What is the highest level of formal education you have completed?

$\begin{array}{ll}\text { No high school diploma or GED } & 1 \\ \text { High school diploma or GED } & 2 \\ \text { Some college } & 3 \\ \text { College degree } & 4 \\ \text { Graduate work or degree } & 5\end{array}$

4. Have you ever attended a formal training course in diversity issues, sensitivity, or ethics?

$$
\text { Yes }=1 \quad \text { No }=2
$$

5. How many years have you been employed with your present organization?

(Please indicate the number of complete years you have been employed by darkening the corresponding circle on the answer sheet. If you have been employed for less than two full years, mark the circle labeled "1." If you have worked here for two years or more, but less than three full years, mark the circle labeled " 2 " and so on. If you have worked here for eleven years or more please leave all of the circles blank and write in the number of years to the left of the answer number " 5 " on the answer sheet.) 


\section{SECTION 2}

PLEASE ANSWER THE FOLLOWING QUESTIONS ABOUT THE GENERAL CLIMATE IN YOUR COMPANY IN TERMS OF HOW IT REALLY IS IN YOUR COMPANY, NOT HOW YOU WOULD PREFER IT TO BE. PLEASE BE AS CANDID AS POSSIBLE; REMEMBER, ALL YOUR RESPONSES WILL REMAIN STRICTLY ANONYMOUS AND CONFIDENTIAL.

PLEASE INDICATE THE EXTENT TO WHICH YOU AGREE WITH EACH OF THE FOLLOWING STATEMENTS ABOUT YOUR COMPANY. USE THE SCALE BELOW AND INDICATE ON THE ANSWER SHEET NEXT TO THE NUMBER OF THE CORRESPONDING STATEMENT THE NUMBER WHICH BEST REPRESENTS YOUR ANSWER.

TO WHAT EXTENT ARE THE FOLLOWING STATEMENTS TRUE ABOUT YOUR COMPANY?

$\begin{array}{cccccc}\text { COMPLETELY } & \text { MOSTLY } & \text { SOMEWHAT } & \text { SOMEWHAT } & \text { MOSTLY } & \text { COMPLETELY } \\ \text { FALSE } & \text { FALSE } & \text { FALSE } & \text { TRUE } & \text { TRUE } & \text { TRUE } \\ 1 & \mathbf{2} & \mathbf{3} & \mathbf{4} & \mathbf{5} & \mathbf{6}\end{array}$

6. (EI) In this company, people are mostly out for themselves.

7. (EI) In this company, people protect their own interest above other considerations.

8. (EI) People in this company are very concerned about what is best for themselves.

9. (EI) There is no room for one's own personal morals or ethics in this company.

10. (EL) Decisions here are primarily viewed in terms of contributions to profit.

11. (EL) People are concerned with the company's interests - to the exclusion of all else.

12. (EL) People are expected to do anything to further the company's interests.

13. (EL) Work is considered sub-standard only when it hurts the company's interests.

14. (EC) Efficient solutions to problems are always sought here.

15. (EC) In this company, each person is expected, above all, to work efficiently.

16. (EC) The major responsibility for people in the company is to consider efficiency first.

17. (EC) The most efficient way is always the right way, in this company.

18. (BI) In this company, our major concern is always what is best for the other person. 
19. (BI) In this company, people look out for each other's good.

20. (BI) It is expected that each individual is cared for when making decisions here.

21. (BI) What is best for each individual is a primary concern in this organization.

22. (BL) Our major consideration is what is best for everyone in this company.

23. (BL) People are very concerned about what is generally best for employees in the company.

24. (BL) People in this company view team spirit as important.

25. (BL) The most important concern is the good of all the people in the company.

26. (BC) It is expected that you will always do what is right for the customer and public.

27. (BC) People in this company are actively concerned about the customer's, and the public's interest.

28. (BC) People in this company have a strong sense of responsibility to the outside community.

29. (BC) The effect of decisions on the customer and the public are a primary concern in this company.

30. (PI) Each person in this company decides for himself what is right and wrong.

31. (PI) In this company, people are expected to follow their own personal and moral beliefs.

32. (PI) In this company, people are guided by their own personal ethics.

33. (PI) The most important consideration in this company is each person's sense of right and wrong.

34. (PL) Everyone is expected to stick by company rules and procedures.

35. (PL) It is very important to follow strictly the company's rules and procedures here.

36. (PL) Successful people in this company go by the book.

37. (PL) Successful people in this company strictly obey the company policies.

38. (PC) In this company, people are expected to strictly follow legal or professional standards.

39. (PC) In this company, the law or ethical code of their profession is the major consideration.

40. (PC) People are expected to comply with the law and professional standards over and above other considerations.

41. (PC) The first consideration is whether a decision violates any law. 


\section{SECTION 3}

PLEASE ANSWER THE FOLLOWING QUESTIONS ABOUT THE ACTORS IN THE MOVIE SCENES. THESE QUESTIONS PERTAIN TO THE ACTORS THEMSELVES, NOT THE ROLES THEY PLAYED IN THIS MOVIE.

\section{USE THE FOLLOWING SCALE TO RATE EACH OF THE ACTORS. not at all likeable

$\begin{array}{lllllll}1 & 2 & 3 & 4 & 5 & 6 & 7\end{array}$

42. How generally likeable is the actor who portrayed Lawrence Garfield (the investor who wanted to buy New England Wire \& Cable)?

43. How generally likeable is the actor who portrayed Andrew Jorgenson (the owner of New England Wire \& Cable)?

44. How generally likeable is the actor who portrayed William Coles (the president of New England Wire \& Cable)?

45. How generally likeable is the actor who portrayed Bea Sullivan (the woman who worked for New England Wire \& Cable)?

46. How generally likeable is the actor who portrayed Kate Sullivan (the young attorney)? 


\section{SECTION 4}

LOOKING BACK AT THE MOVIE SCENES YOU WATCHED TODAY, PLEASE ANSWER THE FOLLOWING QUESTIONS AS AN EMPLOYEE OF YOUR ORGANIZATION.

USE THE FOLLOWING SCALE TO RATE THE IMPORTANCE OF EACH OF THE ISSUES FOR QUESTIONS 47 - 53. not important at all

$\begin{array}{lllllll}1 & 2 & 3 & 4 & 5 & 6 & 7\end{array}$

47. In your role as an employee of your organization, how important to you was the issue of financial gain for the stockholders of New England Wire \& Cable?

48. In your role as an employee of your organization, how important to you was the issue of elimination of jobs at New England Wire \& Cable?

49. In your role as an employee of your organization, how important to you was the issue of paying money to Garfield so he would quit trying to take over New England Wire \& Cable?

50. In your role as an employee of your organization, how important to you was the issue of New England Wire \& Cable's company history and traditions?

51. In your role as an employee of your organization, how important to you was the issue of "fairness" as it relates the ownership and control of New England Wire \& Cable?

52. In your role as an employee of your organization, how important to you was the issue of the operation of the free market system in a capitalistic economy?

53. In your role as an employee of your organization, how important to you was the issue of how Lawrence Garfield treated his employees and others?

54. In your role as an employee of your organization, did you think there were any moral or ethical issues involved in the scenes?

$$
\text { Yes }=1 \quad \text { No }=2
$$




\section{SECTION 5}

\section{TO HELP US INTERPRET THE ANSWERS THAT YOU HAVE PROVIDED IN PREVIOUS SECTIONS, PLEASE ANSWER THE FOLLOWING QUESTIONS.}

55. Have you ever seen the movie "Other People's Money"?

Yes $=1 \quad$ No $=2$

56. Have you ever read the play “Other People's Money”?

$$
\text { Yes }=1 \quad \text { No }=2
$$

57. Have you ever seen “Other People's Money” performed as a play? Yes $=1 \quad$ No $=2$

IF YOU ANSWERED "NO" TO ALL THREE OF THESE QUESTIONS, PLEASE SKIP THE REMAINDER OF THIS QUESTIONNAIRE. IF YOU ANSWERED "YES" TO AT LEAST ONE OF THE PRECEDING QUESTIONS (55 - 57), PLEASE ANSWER QUESTIONS 58 - 65.

58. Did you enjoy the movie or play?

$$
\text { Yes }=1 \quad \text { No }=2
$$

59. How realistic did the portrayal of the hostile takeover bid seem to you?

$\begin{array}{crllllr}1 & 2 & 3 & 4 & 5 & 6 & 7 \\ \text { not very realistic } & & & & & \text { very realistic }\end{array}$

60. How strongly did your familiarity with the plot affect your interpretations of the scenes you just watched?

$\begin{array}{ccccccc}1 & 2 & 3 & 4 & 5 & 6 & 7 \\ \text { not at all } & & & & & & \text { very much }\end{array}$

Please indicate the extent to which you believe that the following scenes occurred in "Other People's Money" using the following scale. sure it did not occur

$\begin{array}{lllllll}1 & 2 & 3 & 4 & 5 & 6 & 7\end{array}$

61. William Coles, the president of New England Wire \& Cable, tries to sell his shares of stock in the company to Lawrence Garfield.

62. The shareholders vote to allow the takeover

63. Andrew Jorgenson's father founded New England Wire \& Cable.

64. Andrew Jorgenson gives a speech at the shareholders' meeting, accusing Lawrence Garfield of trying to destroy New England Wire \& Cable.

65. Lawrence Garfield wants to marry Kate Sullivan.

66. Indicator for the organization $(1-7)$. 


\author{
Craig V. VanSandt, Ph.D. \\ Augustana College \\ Department of Business Administration \\ $63938^{\text {th }}$ Street \\ Rock Island, Illinois 61201-2296 \\ Telephone: 309-794-7334 \\ Fax: 309-794-7605 \\ Email: bavansandt@augustana.edu
}

\title{
EDUCATION:
}

Virginia Polytechnic Institute and State University (August 1996 - August 2001)

Ph.D. in Management

Dissertation: An Examination of the Relationship Between Ethical Work Climate and Individual Moral Awareness

University of North Carolina at Chapel Hill (August 1982 - May 1984)

Masters of Business Administration (May 1984)

Texas Christian University (August 1972 - May 1976)

Bachelor of Business Administration, Magna Cum Laude (May 1976)

Major: Accounting

\section{RESEARCH INTERESTS:}

Corporate climate's effect on employee behavior

Ethical issues of corporate governance

Interaction of corporate strategy and ethics

Business's role in society

\section{TEACHING INTERESTS:}

Business Ethics

Social Issues in Management

Organization Theory

Strategy 


\section{PUBLICATIONS:}

\section{Articles:}

Neck, Christopher P., Ashcraft, Robert F. and VanSandt, Craig V. 1998. "Employee Self-Leadership: Enhancing The Effectiveness of Nonprofits." International Journal of Organization Theory and Behavior, 1 (4), 521-551.

Wokutch, Richard E., and VanSandt, Craig V. 2000. "National Styles of Worker Protection in the United States and Japan: The Case of the Automotive Industry." Law in Japan, forthcoming.

\section{Book Chapter:}

Wokutch, Richard E., and VanSandt, Craig V. 2000. "Occupational Safety and Health Management in the United States and Japan: The DuPont Model and the Toyota Model." In Kaj Frick, Per Langaa-Jensen, Michael Quinlan, and Ton Wilthagen (eds.) Systematic Occupational Health and Safety Management: Perspectives on an International Development, forthcoming.

\section{Proceedings:}

VanSandt, Craig V. 1998. "Three on Three: A Fable for Business Ethics Classes." International Association for Business and Society 1998 Proceedings. 565-567.

\section{Presentations:}

Wokutch, Richard E., Stephens, Carroll U., and VanSandt, Craig V. 2001. "Ideology and Evaluations of Behavioral-Based Occupational Safety and Health Management Systems: The DuPont Model." Presented by Mr. VanSandt at the 61st Annual Conference of the Academy of Management, Washington, D.C., August.

VanSandt, Craig V. 2001. "The End (and Beginning) of CSR." Presented at the twelfth Annual Conference of the International Association for Business and Society, Sedona, Arizona, March.

VanSandt, Craig V. 1999. “An Intellectual History and Marxian Critique of Rawls's Difference Principle." Poster presentation at the Academy of Management Critical Management Studies Workshop, August.

VanSandt, Craig V. 1998. "Three on Three: A Fable for Business Ethics Classes." Presented at the ninth Annual Conference of the International Association for Business and Society, Kailua-Hilo, Hawaii, June.

VanSandt, Craig V., and Neck, Christopher P. 1998. "Bridging Ethics and SelfLeadership: Overcoming Ethical Discrepancies Between Employee and Organizational Standards." Presented by Mr. VanSandt at the ninth Annual Conference of the International Association for Business and Society, KailuaHilo, Hawaii, June. 
Wokutch, Richard E., Stephens, Carroll U., and VanSandt, Craig V. 1999. "Ideology and Evaluations of Behavioral-Based Occupational Safety and Health Management Systems: The DuPont Model." Presented by Dr. Wokutch at the tenth Annual Conference of the International Association for Business and Society, Paris, France, June.

Wokutch, Richard E., and VanSandt, Craig V. 1998. "Occupational Safety and Health Management in the United States and Japan: The DuPont Model and the Toyota Model." Presented by Dr. Wokutch at the Policies for Occupational Health and Safety Management Systems and Workplace Change Conference, Amsterdam, Holland, September.

Wokutch, Richard E., and VanSandt, Craig V. 1997. "National Styles of Worker Protection in the United States and Japan: The Case of the Automotive Industry." Presented by Dr. Wokutch at the Sho Shato Conference at the University of California at Berkeley, May.

\section{Papers in Progress:}

VanSandt, Craig V. "Three on Three: A Fable for Business Ethics Classes."

VanSandt, Craig V., and Neck, Christopher P. "Bridging Ethics and Self-Leadership: Overcoming Ethical Discrepancies Between Employee and Organizational Standards."

Wokutch, Richard E., Stephens, Carroll U., and VanSandt, Craig V. "Ideology and Evaluations of Behavioral-based Occupational Safety and Health Management Systems: The DuPont Model."

\section{TEACHING EXPERIENCE:}

\section{$\underline{\text { Augustana College }}$}

The Department of Business Administration collects information from students on a voluntary basis to assess teaching performance. My average student ratings for classes in Social Issues in Management, Business Policy, Management Concepts, Organizational Behavior, and Diversity in the Workplace averaged 4.78 on a five-point scale.

\section{Virginia Polytechnic Institute and State University:}

The R. B. Pamplin College of Business uses a twelve-item questionnaire for students to assess teaching performance. The scale ranges from 5 (excellent) to 1 (unsatisfactory). Student ratings for each course taught are shown below. My student ratings consistently placed me well above the average of student ratings in the management department. 


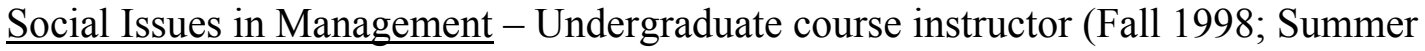
1999). Complete responsibility for course preparation and delivery. Classes had 35, 29, and 13 students respectively. Average student rating of teaching performance: 4.58, 4.65 , and $4.77 / 5.00$.

Business Policy and Strategy - Undergraduate course instructor (Spring 1999). Complete responsibility for course preparation and delivery. Two sections of 43 students each. Average student rating of teaching performance: 4.53 and 4.56/5.00.

Management Theory - Undergraduate course instructor (Fall 1997; Summer 1998; Fall 1999). Complete responsibility for course preparation and delivery. One section each term with 57, 42, and 63 students respectively. Average student rating of teaching performance: $4.49,4.36$, and $4.45 / 5.00$.

\section{PROFESSIONAL EXPERIENCE:}

Eighteen years professional experience in public and private accounting, real estate finance and development, and banking. CPA certificate earned 1977. Work experience includes:

1976-1978 Peat, Marwick, Mitchell \& Co., Jacksonville, FL

1978-1982 The Bos Group, Jacksonville, FL (real estate developers)

1982-1984 Obtaining MBA at UNC, Chapel Hill, NC

1984-1987 The Citizens \& Southern National Bank (now Bank of America), Atlanta

1987-1989 CrossLand Savings, FSB, Atlanta, GA

1989-1990 The Vortex Group (independent mortgage broker), Atlanta, GA

1990-1995 Dominion Bank/First Union National Bank, Roanoke, VA

1995-1996 Hockey Roanoke, Inc. (owner of Roanoke Express minor league team)

1996-2001 Obtaining Ph.D. at Virginia Tech

2000-2001 Instructor in Department of Business Administration, Augustana College

2001-present Assistant Professor in Department of Business Administration, Augustana College

\section{HONORS:}

Phi Kappa Phi (April 1998) - honor society for high scholastic achievement Beta Gamma Sigma (April 1976) - honorary business fraternity Beta Alpha Psi (October 1974) - honorary accounting fraternity Elijah Watt Sells Certificate of Honorable Mention for performance on the November 1976 CPA Exam

Senior Scholar in Accounting, Texas Christian University, April 1976 


\section{PROFESSIONAL MEMBERSHIPS:}

Academy of Management

International Association for Business and Society

Society for Business Ethics

\section{SERVICE:}

Member, Athletics Committee, Augustana College, 2001-present.

Member, Faculty Research Committee, Augustana College, 2001-present.

Panelist, Academy of Management, Social Issues in Management Division Doctoral Consortium, 2001.

Member of Nominating Committee, Academy of Management, Social Issues in Management Division, 2000-2001.

Member of the Coordinating Committee, Critical Management Studies interest group, Academy of Management, 1999-present. Responsible for organizing the doctoral workshop for the August 2000 meeting in Toronto.

Co-chairman of the Virginia Tech Management Ph.D. students' association, 1998-1999.

Virginia Tech Management Graduate Curriculum Committee, 1998-1999.

Panelist for the Virginia Tech Graduate Honors Court, 1996-present.

Presented talks to various business students' organizations at Virginia Tech.

Problem Captain - Roanoke Region Odyssey of the Mind Competition, 1993-1999.

Volunteer for Old Dominion Athletic Conference sports events, 1995-present.

Coach of various youth recreation league sports teams. 